\title{
WestVirginiaUniversity
}

THE RESEARCH REPOSITORY @ WVU

Graduate Theses, Dissertations, and Problem Reports

2003

\section{Evaluation of binder grades on rutting performance}

Sri Harsha Nallamothu

West Virginia University

Follow this and additional works at: https://researchrepository.wvu.edu/etd

\section{Recommended Citation}

Nallamothu, Sri Harsha, "Evaluation of binder grades on rutting performance" (2003). Graduate Theses, Dissertations, and Problem Reports. 1354.

https://researchrepository.wvu.edu/etd/1354

This Thesis is protected by copyright and/or related rights. It has been brought to you by the The Research Repository @ WVU with permission from the rights-holder(s). You are free to use this Thesis in any way that is permitted by the copyright and related rights legislation that applies to your use. For other uses you must obtain permission from the rights-holder(s) directly, unless additional rights are indicated by a Creative Commons license in the record and/ or on the work itself. This Thesis has been accepted for inclusion in WVU Graduate Theses, Dissertations, and Problem Reports collection by an authorized administrator of The Research Repository @ WVU. For more information, please contact researchrepository@mail.wvu.edu. 
EVALUATION OF BINDER GRADES ON RUTTING PERFORMANCE

\title{
SRI HARSHA NALLAMOTHU
}

Thesis submitted to the College of Engineering and Mineral Resources at West Virginia University in partial fulfillment of the requirements for

the degree of

Master of Science

In

Civil Engineering

Dr. John P. Zaniewski, Chair

Dr. Ronald W. Eck,

Dr. Indrajit N. Ray

Department of Civil and Environmental Engineering

\author{
Morgantown, West Virginia \\ 2003
}

Keywords: Asphalt Binders, Polymer-modified binders, Rutting, Large Stone Mixes 


\section{ABSTRACT \\ EVALUATION OF BINDER GRADES ON RUTTING PERFORMANCE}

\section{SRI HARSHA NALLAMOTHU}

Asphalt mixes that have a good history of resisting rutting in posted speed applications may not perform well in intersections, climbing lanes, truck weigh stations, and other slow speed areas. The West Virginia Division of Highways, WVDOH, has implemented the Performance Grade binder specifications for all paving projects and Superpave for high volume road projects. The standard binder specified in the state is a PG 64-22; for high volume roads a PG 70-22 is specified. These binders appear to be working well for most projects in the state. The Superpave guidelines have provision for increasing the binder grade by one level to accommodate slow moving traffic. Prior to 2002, the WVDOH had not implemented this option. In 2002, the WVDOH elected to use a Superpave mix with a PG 76-22 binder to resolve maintenance issues at an intersection near Fort Gay, WV.

The objective of this research was to evaluate the rutting potential of the asphalt concrete mixes prepared with three binder grades. The research included mix designs for the base course and the wearing course of the pavement. The base course was a $37.5 \mathrm{~mm}$ mix with limestone aggregates and the wearing course was a $12.5 \mathrm{~mm}$ mix with predominantly blast furnace slag aggregates.

The three different binders were compared by making specimens with each of the two mix designs. The Asphalt Pavement Analyzer, APA, was used to evaluate rutting performance of the gyratory compacted samples. The statistical analysis of the rut depths provides evidence that the PG 76-22 polymer-modified binder performs better than PG 70-22 and PG 64-22 binder. 


\section{ACKNOWLEDGEMENTS}

I would like to express my sincere gratitude to Dr. John Zaniewski for his guidance and encouragement throughout the research and thesis writing process. Without his support, guidance and time this research would not have been possible.

I would also like to thank Dr. Ronald Eck and Dr. Indrajit Ray, members of my thesis committee, for their precious time and guidance.

Special thanks to Keith Bishop, Mountain Enterprise Inc. and Larry Barker, Stewart Groves and Dave Mattox of the West Virginia Department of Highways for their assistance.

Thanks to Andy Kincell and my Lab mates in WVU Asphalt Technology Laboratory, for their assistance.

Finally my sincere thanks to my entire family for their love and support have been a source of strength and motivation. I also thank all my friends for their support and friendship. 


\section{TABLE OF CONTENTS}

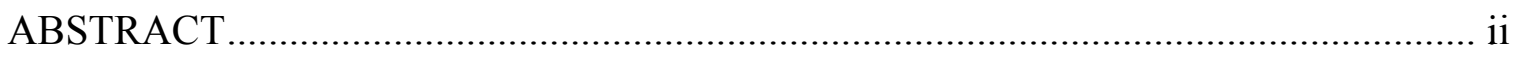

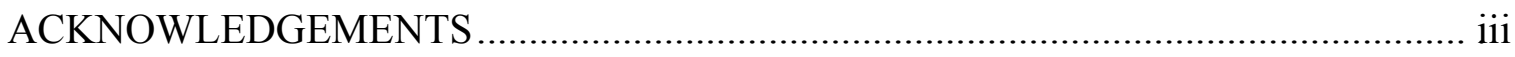

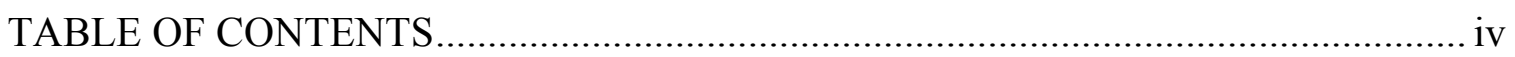

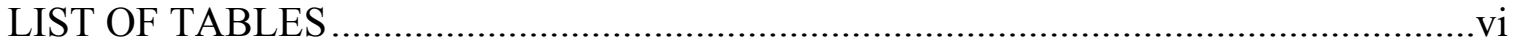

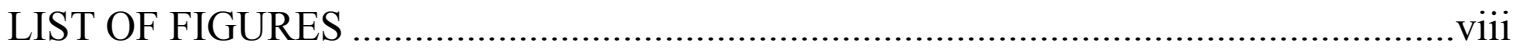

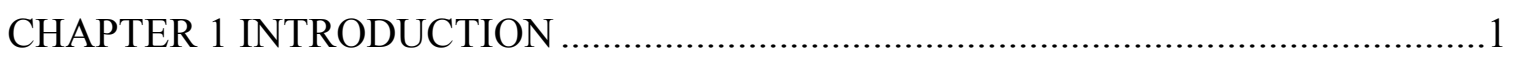

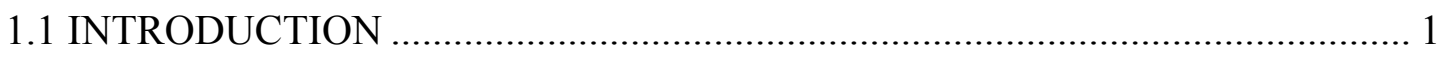

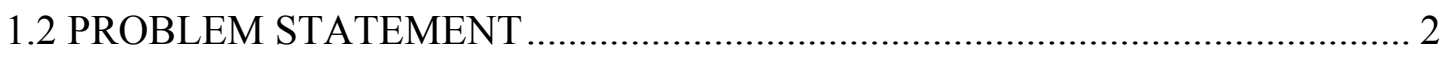

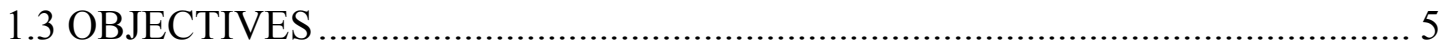

1.4 SCOPE OF WORK AND LIMITATIONS …................................................ 5

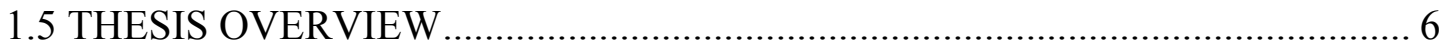

CHAPTER 2 LITERATURE REVIEW …...........................................................

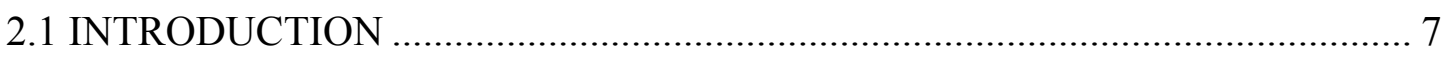

2.2 PERFORMANCE GRADE BINDER TESTS.................................................... 7

2.2.1 ROTATIONAL VISCOMETER ........................................................

2.2.2 ROLLING THIN FILM OVEN .......................................................... 10

2.2.3 DYNAMIC SHEAR RHEOMETER .....................................................10

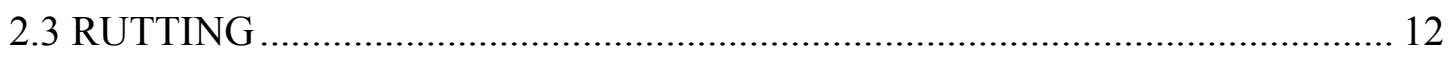

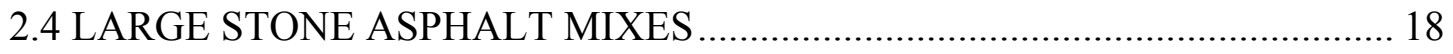

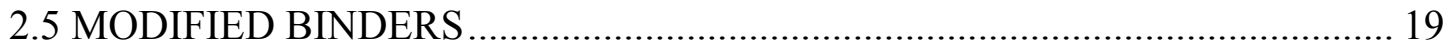

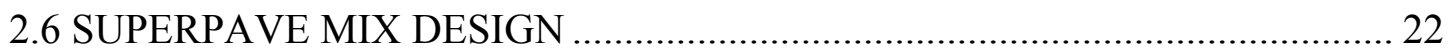

2.6.1 AGGREGATE SPECIFICATIONS .....................................................22

2.6.2 SUPERPAVE GYRATORY COMPACTION .....................................23

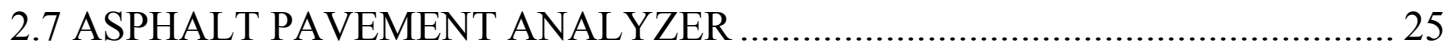

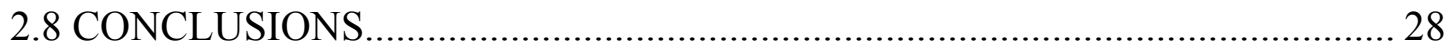

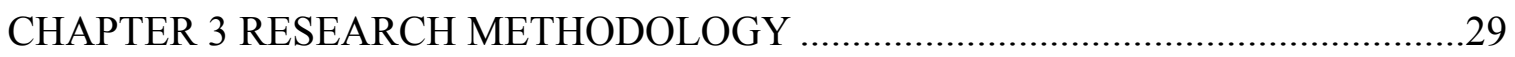

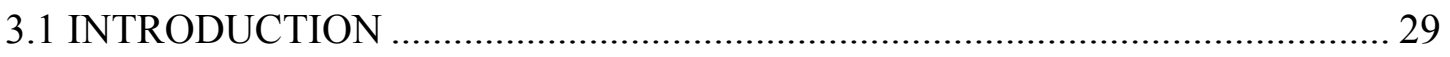

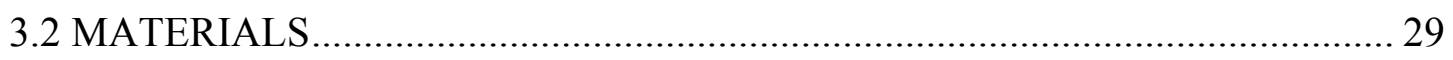




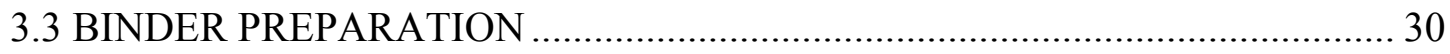

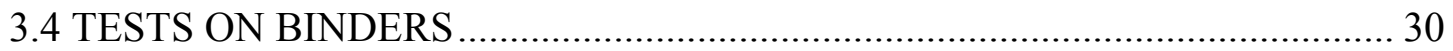

3.4.1 ROLLING THIN FILM OVEN...........................................................

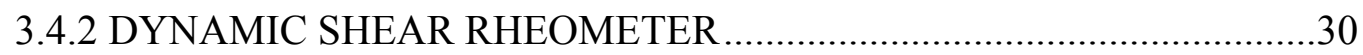

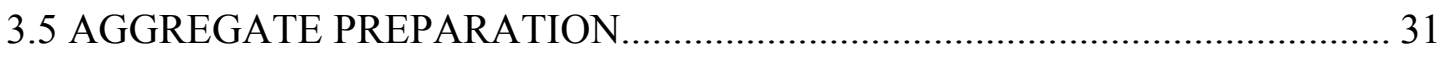

3.5.1 SPECIFIC GRAVITY OF AGGREGATES ……………………….........31

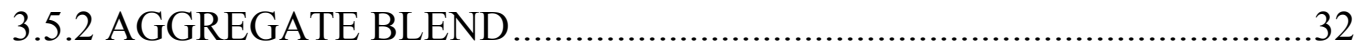

3.6 THEORETICAL MAXIMUM SPECIFIC GRAVITY …………………........... 37

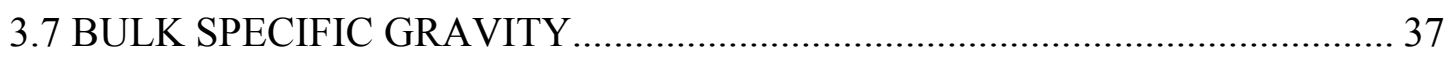

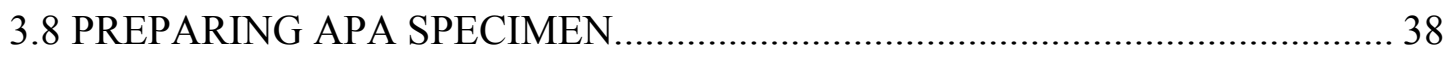

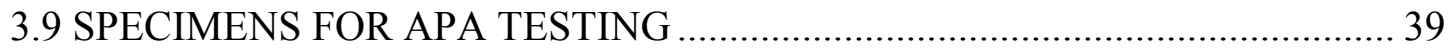

3.10 ASPHALT PAVEMENT ANALYZER RUNS.................................................. 40

CHAPTER 4 RESULTS AND DATA ANALYSIS .......................................................

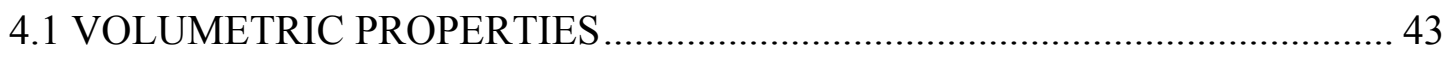

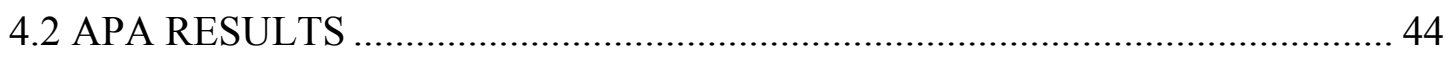

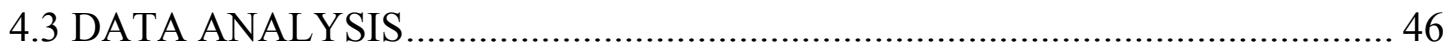

4.4 COMPARISON TO PREVIOUS WV SUPERPAVE MIXES ............................ 48

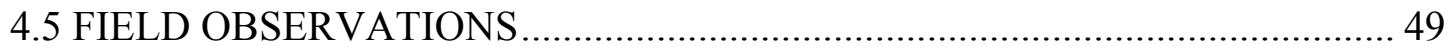

CHAPTER 5 CONCLUSIONS AND RECOMMENDATIONS .....................................51

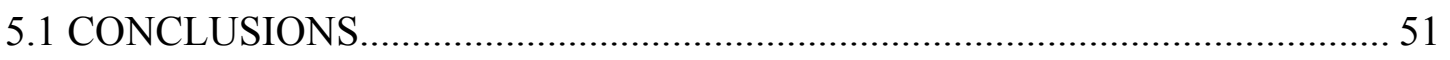

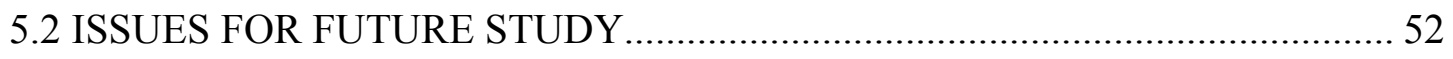

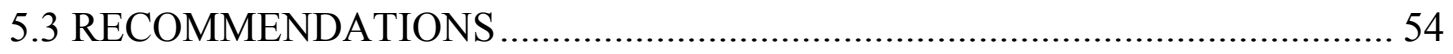

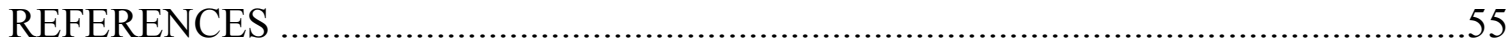

APPENDIX A. AGGREGATES SPECIFIC GRAVITIES …………………….............59

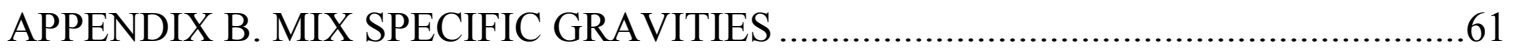

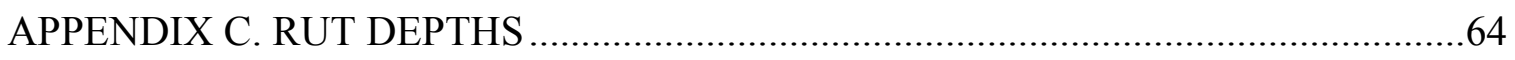

APPENDIX D. PHOTOGRAPHS OF RUT DEPTH SPECIMENS ………………….......67 


\section{LIST OF TABLES}

Table 2.1 Performance grade asphalt binder testing equipment and purpose................... 9

Table 2.2 Design aggregate gradation requirements.............................................. 23

Table 2.3 Selection of number of gyrations for Superpave Gyratory Compactor ............ 25

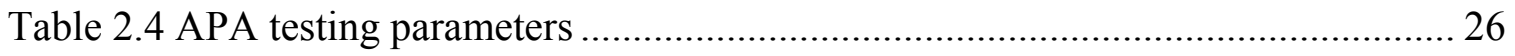

Table 3.1 Viscosity of binders at $135^{\circ} \mathrm{C}$ and the mixing and compaction temperatures .30

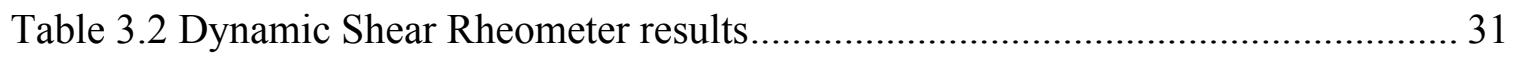

Table 3.3 Specific gravities of limestone aggregates for $37.5 \mathrm{~mm}$ mix ........................ 32

Table 3.4 Specific gravities of blast furnace slag aggregates for $12.5 \mathrm{~mm}$ mix .............. 32

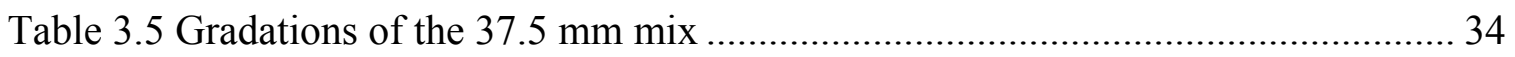

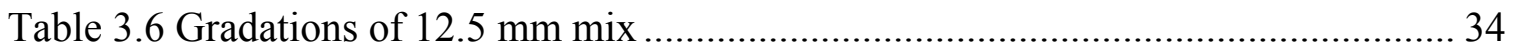

Table 3.7 Average $G_{m m}$ of HMA for the two mixes using three asphalt binders ............ 37

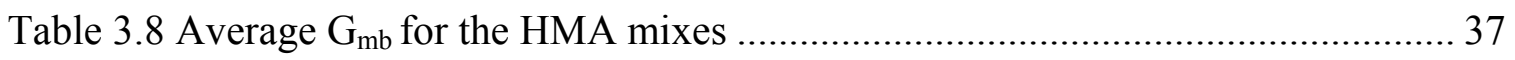

Table 3.9 Laboratory testing pattern for APA samples ........................................... 41

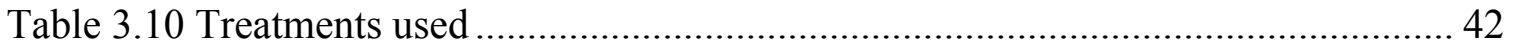

Table 3.11 Testing sequence for laboratory mixes ................................................ 42

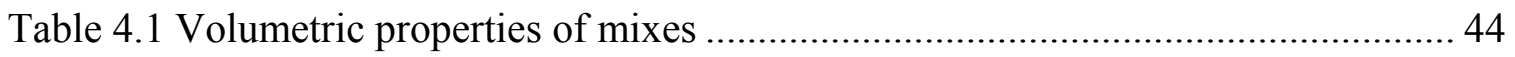

Table 4.2 Average rut values with percent air for the field specimens with position....... 45

Table 4.3 Average rut values with percent air for the lab specimens with position........ 45

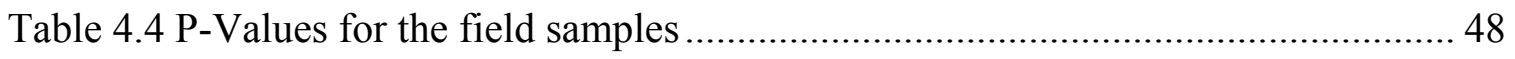

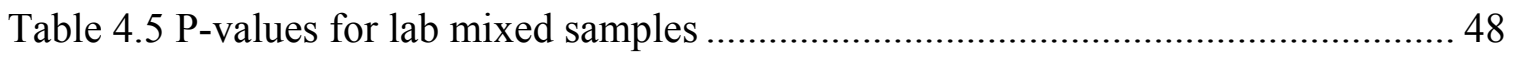

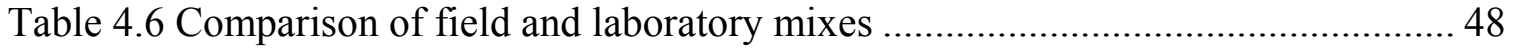

Table A.1 Specific gravities of $37.5 \mathrm{~mm}$ mix aggregates........................................ 59 
Table A.2 Specific gravities of $12.5 \mathrm{~mm}$ mix aggregates......................................... 59

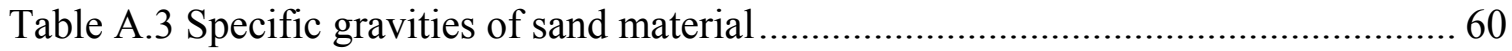

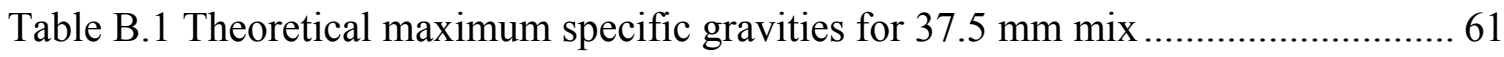

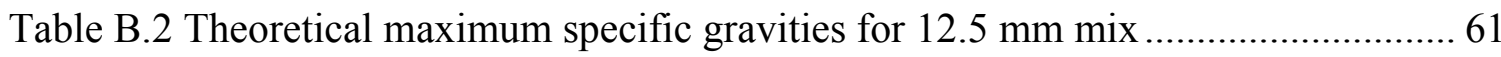

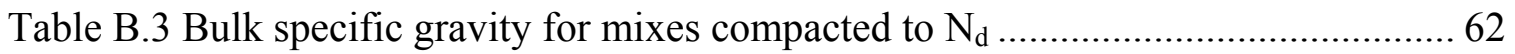

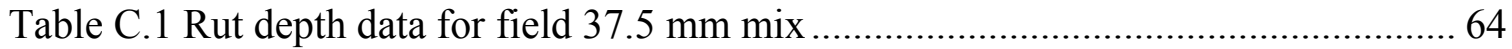

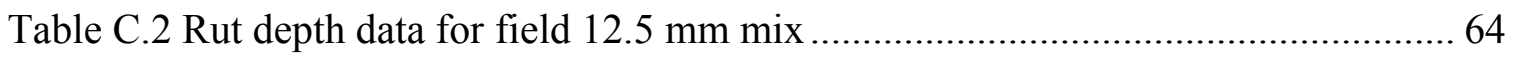

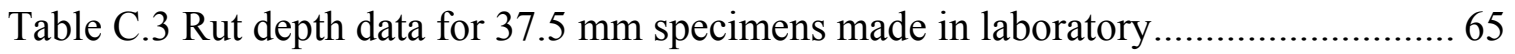

Table C.4 Rut depth data for $12.5 \mathrm{~mm}$ mix specimens made in laboratory .................... 66 


\section{LIST OF FIGURES}

Figure 1.1 Location of Fort Gay intersection............................................................ 3

Figure 1.2 Condition of north bound approach on intersection .................................... 3

Figure 1.3 Trench of Fort Gay intersection pavement .............................................. 4

Figure 1.4 Construction plan for Fort Gay intersection .......................................... 4

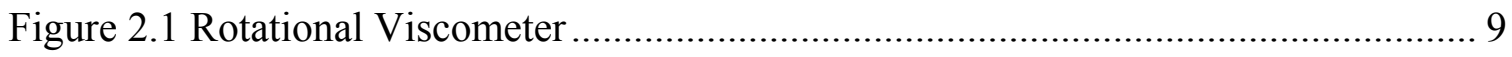

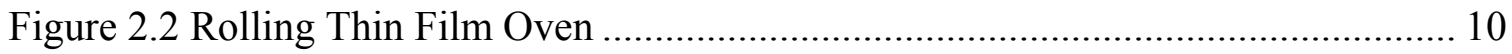

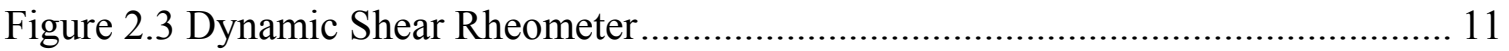

Figure 2.4 Superpave Gyratory Compactor ............................................................ 24

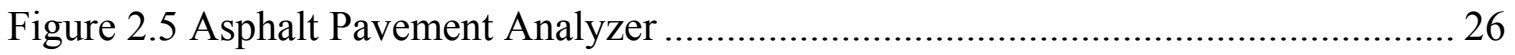

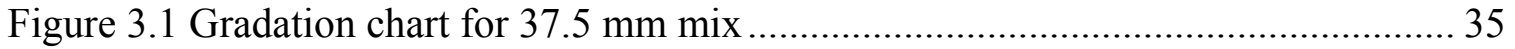

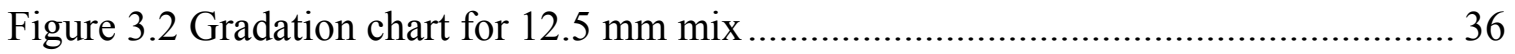

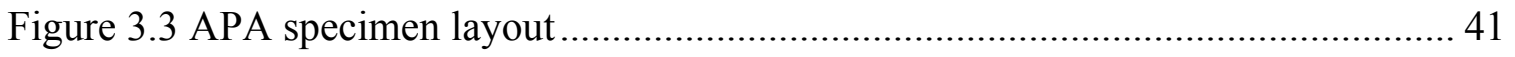

Figure 4.1 Sample after APA testing, $12.5 \mathrm{~mm}$ specimen, field gradation and PG 64-22

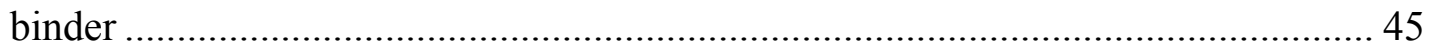

Figure 4.2 Comparison of Fort Gay mixes to other WVDOH Superpave mixes ............ 49

Figure 4.3 Fort Gay Intersection in Mid-January .................................................. 50

Figure D.1 37.5 mm specimen, design gradation and PG 76-22 binder ....................... 67

Figure D.2 12.5 mm specimen, field gradation and PG 76-22 binder ......................... 67

Figure D.3 37.5 mm specimen, design gradation and PG 70-22 binder ........................ 68

Figure D.4 12.5 mm specimen, field gradation and PG 70-22 binder .......................... 68

Figure D.5 37.5 mm specimen, design gradation and PG 64-22 binder ........................ 69 


\section{CHAPTER 1 INTRODUCTION}

\subsection{INTRODUCTION}

During the past several years, many states experienced problems with amount and severity of permanent deformation in hot mix asphalt pavements. This problem with permanent deformation, or rutting, was attributed to an increase in truck tire pressures, axle loads, and volume of traffic (Brown and Cross, 1992).

In West Virginia, coal carrying trucks have created problems with permanent deformation of the pavements. The rutting problem is more severe at intersections. The weight of the trucks and their tire pressures subject the hot mix asphalt, HMA, nearest the pavement surface to high stresses which promote rutting. The rutting problem is also associated with high pavement temperatures during the summer months. The high temperatures reduce the asphalt cement viscosity, which can make the mix susceptible to rutting.

In response to highway performance issues of the 1980's, Congress funded the Strategic Highway Research Program, SHRP. Two products of this research have been widely implemented by the highway community, Performance Grading, PG, of the asphalt binder and the Superior Performing Asphalt Pavements, Superpave ${ }^{\mathrm{TM}}$, mix design method. The PG specification for binders is much more robust than previous methods for specifying asphalt cements. The PG specifications consider three condition states of the binder: tank, following construction, and long term aging. The PG specification also incorporates the entire temperature range the binders experience both during the construction and while in service. Finally, the binder specifications were specifically designed to address the binder's role with request to three types of pavement distress: rutting, fatigue, and low temperature cracking. The Superpave mix design method uses volumetric principles to determine the optimum binder content for a given blend of aggregates. It also specifies a stringent set of aggregate requirements.

The West Virginia Division of Highways, WVDOH, has implemented the Performance Grade binder specifications for all paving projects and Superpave for high 
volume road projects. The standard binder specified in the state is a PG 64-22; for high volume roads a PG 70-22 is specified. These binders appear to be working well for most projects in the state. The Superpave guidelines have provision for increasing the binder grade by one level to accommodate slow moving traffic. Prior to 2002, the WVDOH had not implemented this option. In 2002, the WVDOH elected to use a Superpave mix with a PG 76-22 binder to resolve maintenance issues at an intersection near Fort Gay, WV. The objective of this research was to evaluate the performance of the mix used at the Fort Gay intersection and compare it to the expected performance of mixes with PG 64-22 and PG 70-22 binders.

\subsection{PROBLEM STATEMENT}

In recent decades, pavement engineers have been challenged to use conventional methods to design cost-effective pavements that are to withstand unconventional wheel loads and tire pressures. Large stone mixes are becoming a popular means for reducing rutting in flexible pavements. Heavy concentration of aggregate interlock in large stone mixes allows for efficient dissipation of compressive and shear stresses that are otherwise known to be responsible for rutting and shoving in flexible pavements (Mahboub and Allen, 1990). Some polymer-modified asphalt cements are being used in asphalt concrete pavements because of their role in reducing several types of pavement distress and enhancing pavement performance (Khattak and Baladi, 1998).

The Fort Gay, West Virginia intersection developed excessive rutting annually due to heavy traffic from the coal carrying trucks. The intersection is located in southwest West Virginia as shown in Figure 1.1. Figure 1.2 shows condition of the north bound approach on the intersection before reconstruction. The surface shown in the photograph was only six months old. The WVDOH sought an alternative rehabilitation method that would improve pavement life. A trench study showed that the rutting deformation of the pavement was primarily in the top five inches of the pavement, Figure 1.3. Recently, the intersection was rehabilitated using a $37.5 \mathrm{~mm}$ base course and $12.5 \mathrm{~mm}$ wearing course and PG 76-22 binder. The areas with the heaviest rutting were milled down to 5 inches to remove the top two layers and this material was replaced with the $37.5 \mathrm{~mm}$ base course. 


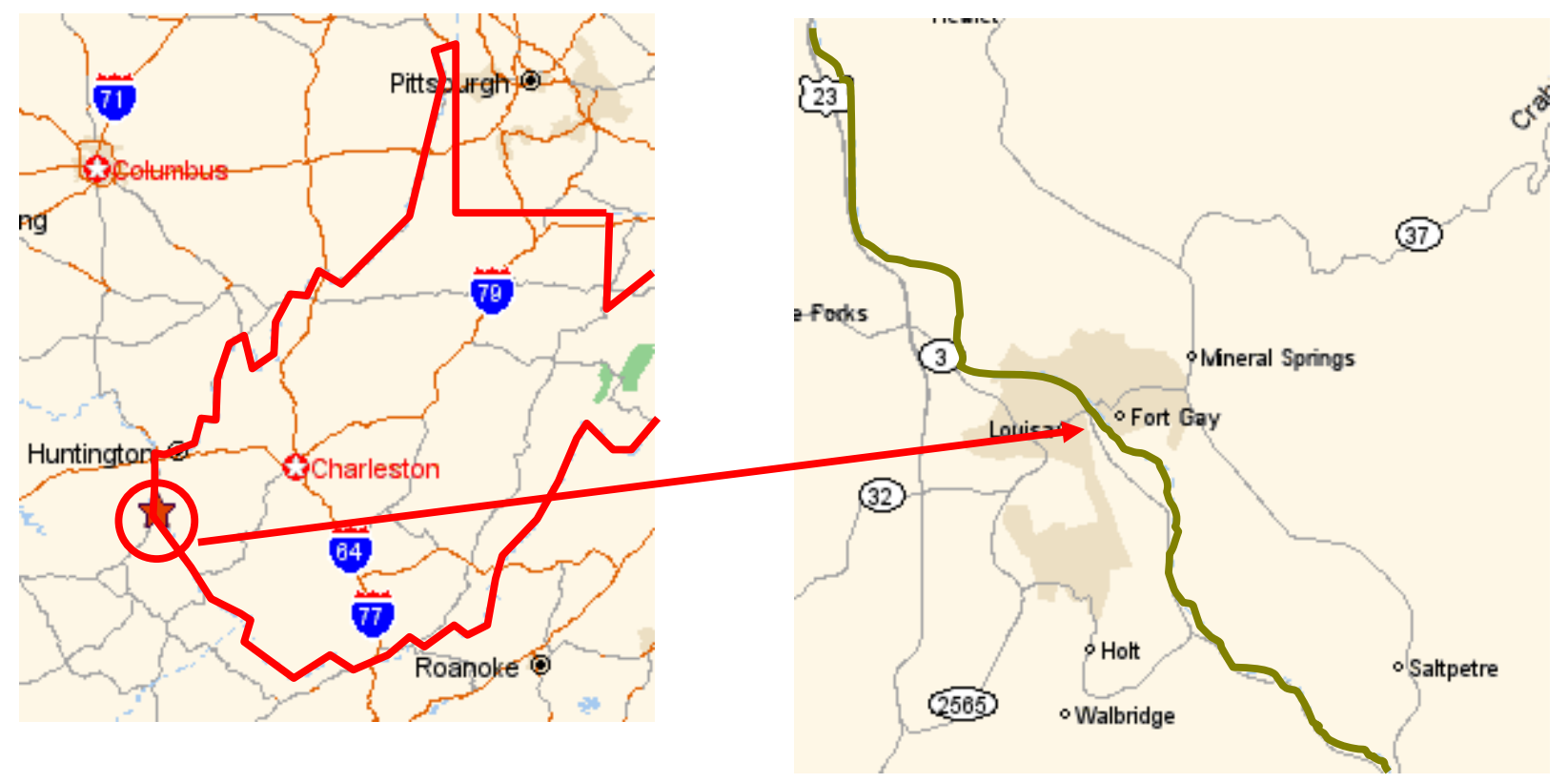

Figure 1.1 Location of Fort Gay intersection

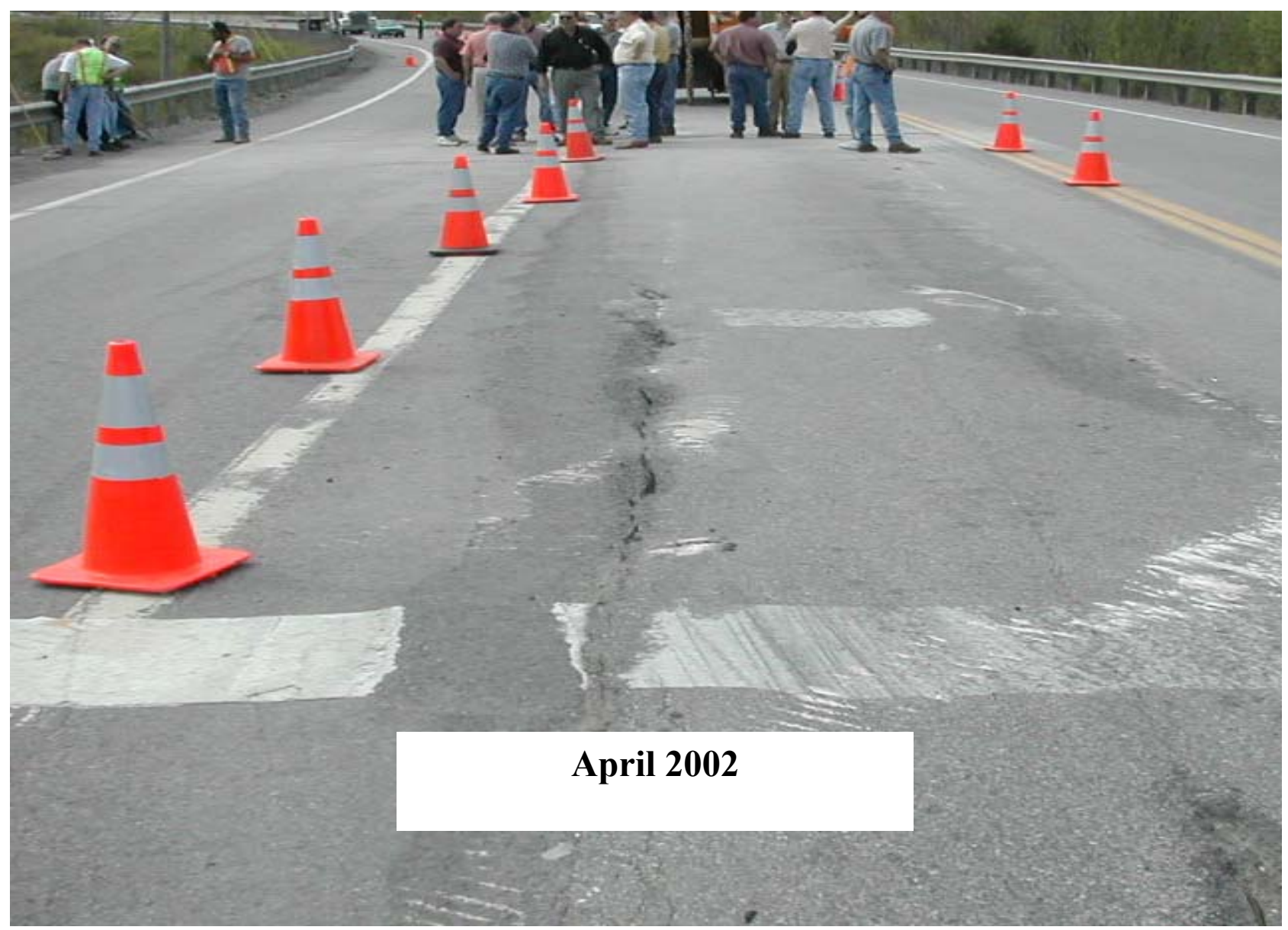

Figure 1.2 Condition of north bound approach on intersection 


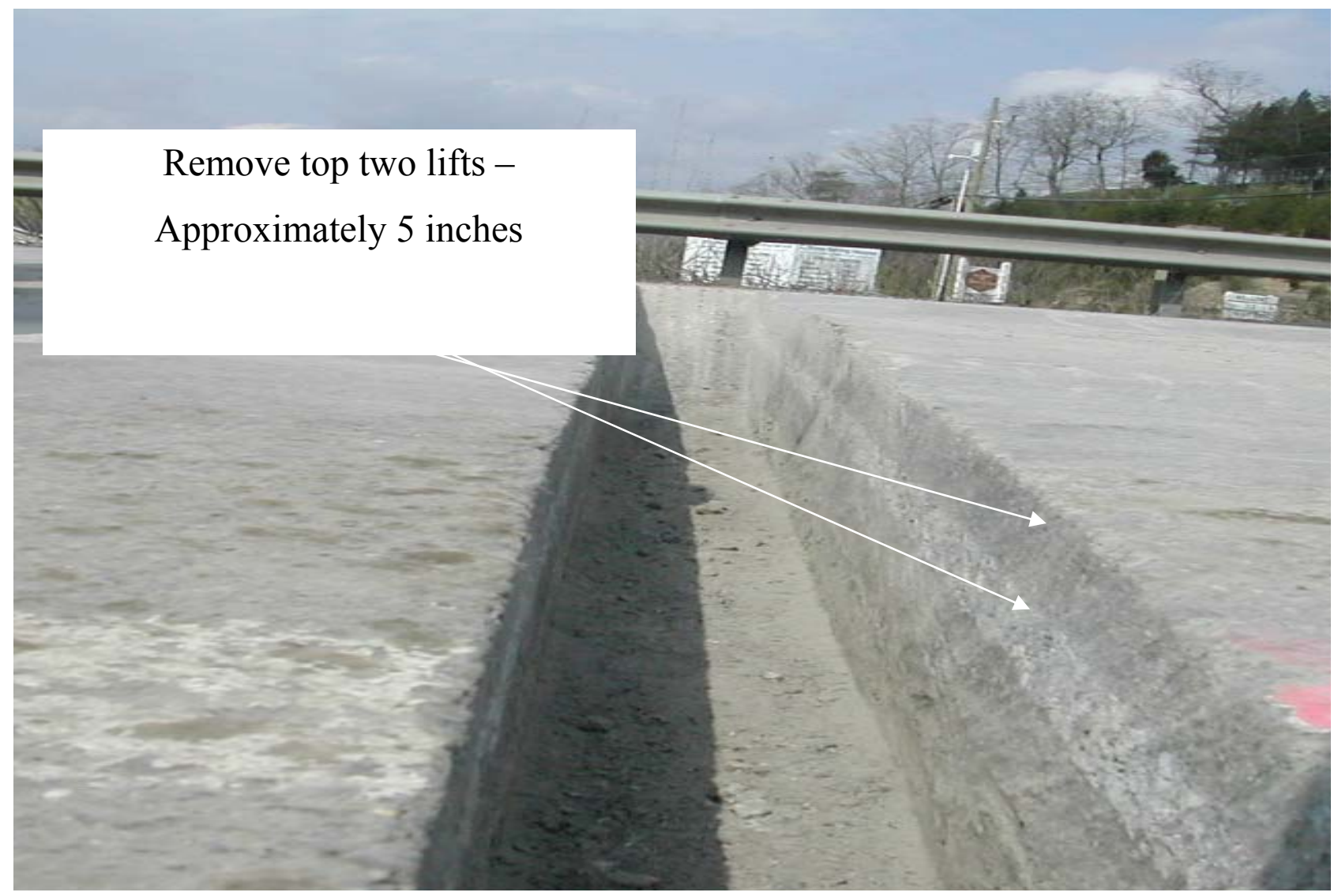

Figure 1.3 Trench of Fort Gay intersection pavement

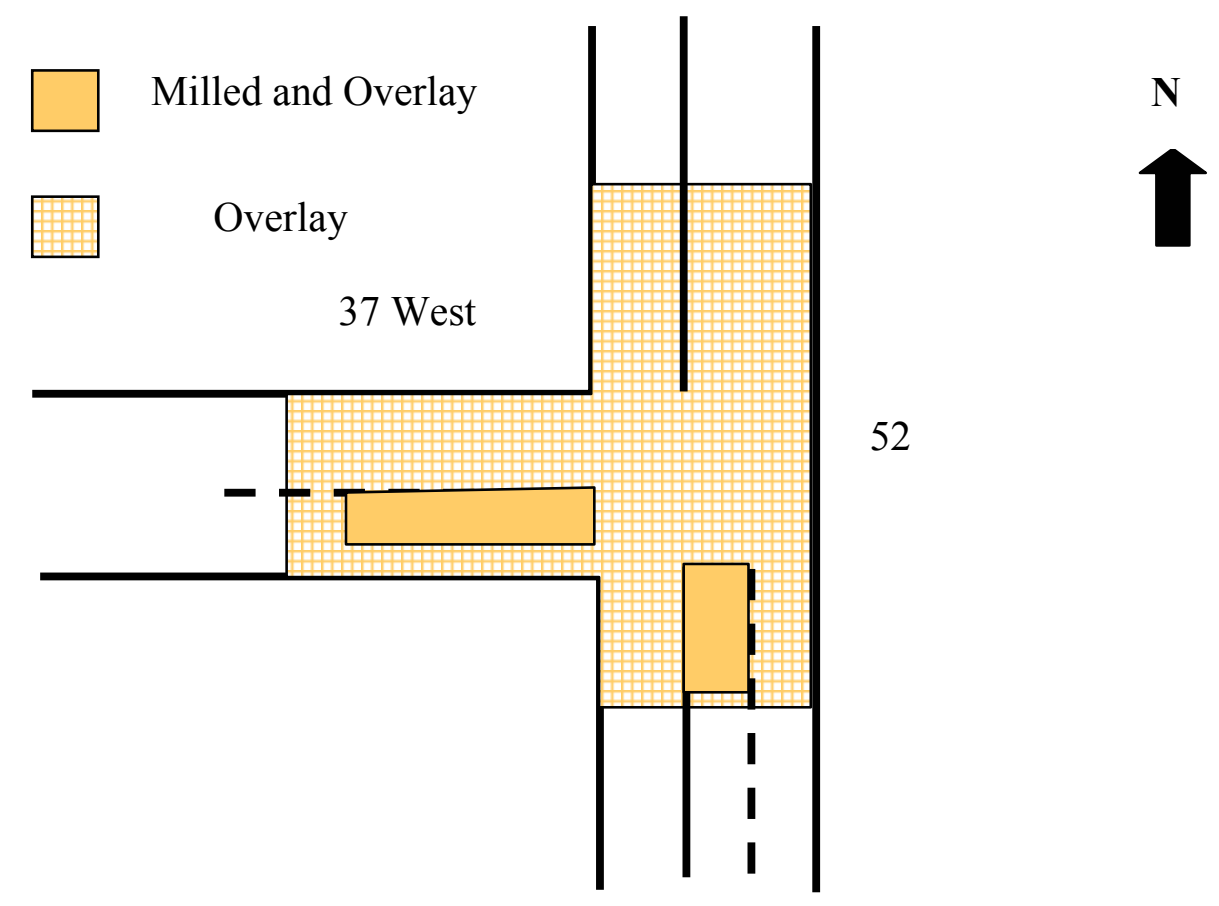

Figure 1.4 Construction plan for Fort Gay intersection 
Then the entire intersection was overlaid with 2 inches of the wearing course, as shown in Figure 1.4.

The design of the Fort Gay intersection was innovative for West Virginia as it was the first project to use a polymer-modified asphalt, PG 76-22, and it was the first project to use a $12.5 \mathrm{~mm}$ wearing course. Since this was the first application of these materials in West Virginia, it was decided to evaluate their rutting potential using the Asphalt Pavement Analyzer available at the WVU Asphalt Technology Laboratory. This study compared rutting potential of the asphalt concrete using three different asphalt binder grades for base and wearing courses. The mix designs were prepared using the Superpave criteria and evaluated with the Asphalt Pavement Analyzer. It should be noted that although these materials had not been used before in West Virginia, the contractor had successfully used these mix designs on several projects in Kentucky.

\subsection{OBJECTIVES}

The objective of this research was to evaluate the rutting potential of the asphalt concrete mixes prepared with three binder grades. The research included mix designs for the base course and the wearing course of the pavement. The base course was a $37.5 \mathrm{~mm}$ mix with limestone aggregates and the wearing course was a $12.5 \mathrm{~mm}$ mix with predominantly blast furnace slag aggregates.

\subsection{SCOPE OF WORK AND LIMITATIONS}

In this study, $37.5 \mathrm{~mm}$ and $12.5 \mathrm{~mm}$ Superpave mixes were evaluated for rutting. The Superpave mix design procedures of the WVDOH were followed. Superpave Gyratory Compactor, SGC, was used to make the Asphalt Pavement Analyzer, APA, samples to evaluate rutting potential. Results from the tests with different aggregate gradations and binder types show that the APA is sensitive to these factors and, therefore, has a potential to predict relative rutting of hot mix asphalt mixtures.

The experimental design used for this study provides comparison between the binders, the aggregates and their interactions. The research was conducted using $37.5 \mathrm{~mm}$, and $12.5 \mathrm{~mm}$ nominal maximum size aggregates and three different binder grades. Mountain Enterprises Inc. provided the aggregate used for this research. The 
asphalt binders used were PG 64-22, PG 70-22, and PG 76-22. The PG 76-22 binder was a polymer-modified binder using Styrene Butadiene Styrene copolymer. Asphalt binder was supplied by Marathon Ashland Petroleum LLC. The Superpave mix design was provided by the Mountain Enterprises Inc.

\subsection{THESIS OVERVIEW}

This thesis is organized into five chapters and four appendices. After the first chapter of introduction, Chapter 2 discusses the summary of literature review, tests on asphalts, large stone mixes, rutting, and modified asphalt binder. The method of rut testing with the Asphalt Pavement Analyzer is explained in detail. The Chapter 3 presents research methodology and procedures for preparing, testing and analyzing samples. The results with the experimental design and analysis are shown in the Chapter 4. Chapter 5 concludes the thesis with recommendations for further study.

The aggregate test data are provided in Appendix A. Mix specific gravity data are provided in Appendix B. Appendix C presents detailed rut depth data from the Asphalt Pavement Analyzer. Appendix D presents photographs showing the ruts of the specimens made using the three binders and the two mix designs. 


\section{CHAPTER 2 LITERATURE REVIEW}

\subsection{INTRODUCTION}

Asphalt pavements typically provide excellent performance and value. They are smooth, quiet and durable. They do not require long construction times and they are easy to maintain resulting in minimal traffic delays (Walker and Buncher, 1999). Asphalt surfaced roads subjected to heavy traffic in hot climates may experience early failures in the form of rutting. The rutting failures are the result of heavy truckloads with high tire pressures and high pavement temperatures.

Careful selection of asphalt binder and aggregate combination will help in providing optimum performing Hot Mix Asphalt, HMA, pavements. The use of the Performance Graded binder system has the advantage of the binder being selected based on the climate in which it will serve. The aggregate structure used must be capable of carrying the load and developing a high degree of stone-to-stone interlock that will resist shear. In addition to materials selection, the mix design procedure is crucial in achieving desired performance.

The Superpave binder tests that were performed on the asphalt binders, large stone mixes, and modified asphalt binders are discussed in this chapter along with the Gyratory Compactor and the Asphalt Pavement Analyzer, APA.

\subsection{PERFORMANCE GRADE BINDER TESTS}

The asphalt binder affects various performance aspects of the asphalt mixtures such as permanent deformation, fatigue cracking, and low temperature cracking. The Performance Grade, PG, binder specification (AASHTO M 320-02) is intended to select the binder to optimize its effect on the performance of the pavement. The PG binder specification is based on the rheological properties of the asphalt binder measured over wide range of temperatures and aging conditions. The $\mathrm{PG}$ of a binder is rated based on the maximum and minimum pavement temperatures. For example a PG 64-22 is rated to

perform on pavements where the maximum pavement temperature is $64^{\circ} \mathrm{C}$ or less and the minimum pavement temperature is $-22^{\circ} \mathrm{C}$ or higher. 
Various pieces of equipment are used to measure stress strain relationships in the binder at the specified testing temperatures. The equipment includes the Rotational Viscometer, RV, Dynamic Shear Rheometer, DSR, the Bending Beam Rheometer, BBR, and the Direct Tension Tester, DTT (D’Angelo and Fee, 2000).

While performing in the pavement, the asphalt binder changes with time. This is primarily through oxidative aging. As the binder ages, the rheological properties change. The binder will become stiffer with the age and its performance characteristics change. To accurately characterize the asphalt binder, the pavement aging process has to be simulated in the laboratory. The PG binder specification uses a two-step process to simulate aging of the binder, the Rolling Thin Film Oven, RTFO, and the Pressure Aging Vessel, PAV. Table 2.1 (Roberts, et al, 1996) presents list of testing equipment to conduct various Performance Grade physical tests, the related purpose for testing, and the related performance parameters of pavements which are partly influenced by the binder.

\subsubsection{ROTATIONAL VISCOMETER}

The rotational viscosity test (AASHTO T 316-02) was adopted in Superpave to replace the kinematic viscosity test (AASHTO T 201-95) for determining the viscosity of the asphalt binder at high temperatures, above $135^{\circ} \mathrm{C}$, to ensure that the binder is sufficiently fluid for pumping and mixing. A maximum viscosity is specified at $135^{\circ} \mathrm{C}$ to ensure pumpability during storage, transport, and at the mixing plant. Most asphalt binders behave as Newtonian fluids (stress response not dependent on shear rate) and have a totally viscous response at such high temperatures. Therefore, a viscosity measurement is sufficient to represent workability of the binder. The Rotational Viscometer, RV, Figure 2.1, is more suited for testing modified asphalt binders, such as those containing crumb rubber modified, compared to the Capillary Viscometer because the later can get clogged up, partially inhibiting flow. The Performance Grade binder specification limits the viscosity to $3 \mathrm{~Pa} . \mathrm{s}$ at $135^{\circ} \mathrm{C}$ (Roberts, et al, 1996).

Rotational viscosity is determined by measuring the torque required to maintain a constant rotational speed, 20 RPM, of a cylindrical spindle while submerged in an asphalt binder at a constant temperature (Roberts, et al, 1996). The measured torque is directly 
Table 2.1 Performance grade asphalt binder testing equipment and purpose

\begin{tabular}{|l|l|l|}
\hline \multicolumn{1}{|c|}{ Equipment } & \multicolumn{1}{c|}{ Purpose } & Performance parameter \\
\hline $\begin{array}{l}\text { Rolling Thin Film Oven } \\
\text { (RTFO) }\end{array}$ & $\begin{array}{l}\text { Simulate binder aging } \\
\text { during HMA production } \\
\text { and construction }\end{array}$ & $\begin{array}{l}\text { Resistance to aging during } \\
\text { construction }\end{array}$ \\
\hline $\begin{array}{l}\text { Pressure Aging Vessel } \\
\text { (PAV) }\end{array}$ & $\begin{array}{l}\text { Simulate binder aging } \\
\text { during HMA service life }\end{array}$ & $\begin{array}{l}\text { Resistance to aging during } \\
\text { service life }\end{array}$ \\
\hline $\begin{array}{l}\text { Rotational Viscometer } \\
\text { (RV) }\end{array}$ & $\begin{array}{l}\text { Measure binder properties } \\
\text { at high construction } \\
\text { temperatures }\end{array}$ & Handling and pumping \\
\hline $\begin{array}{l}\text { Dynamic Shear } \\
\text { Rheometer (DSR) }\end{array}$ & $\begin{array}{l}\text { Measure binder properties } \\
\text { at high and intermediate } \\
\text { temperatures }\end{array}$ & $\begin{array}{l}\text { Resistance to permanent } \\
\text { deformation and fatigue } \\
\text { cracking }\end{array}$ \\
\hline $\begin{array}{l}\text { Bending Beam } \\
\text { Rheometer (BBR) }\end{array}$ & $\begin{array}{l}\text { Measure binder properties } \\
\text { at low service temperatures }\end{array}$ & $\begin{array}{l}\text { Resistance to thermal } \\
\text { cracking }\end{array}$ \\
\hline $\begin{array}{l}\text { Direct Tension Tester } \\
\text { (DTT) }\end{array}$ & $\begin{array}{l}\text { Measure binder properties } \\
\text { at low service temperatures }\end{array}$ & $\begin{array}{l}\text { Resistance to thermal } \\
\text { cracking. }\end{array}$ \\
\hline
\end{tabular}

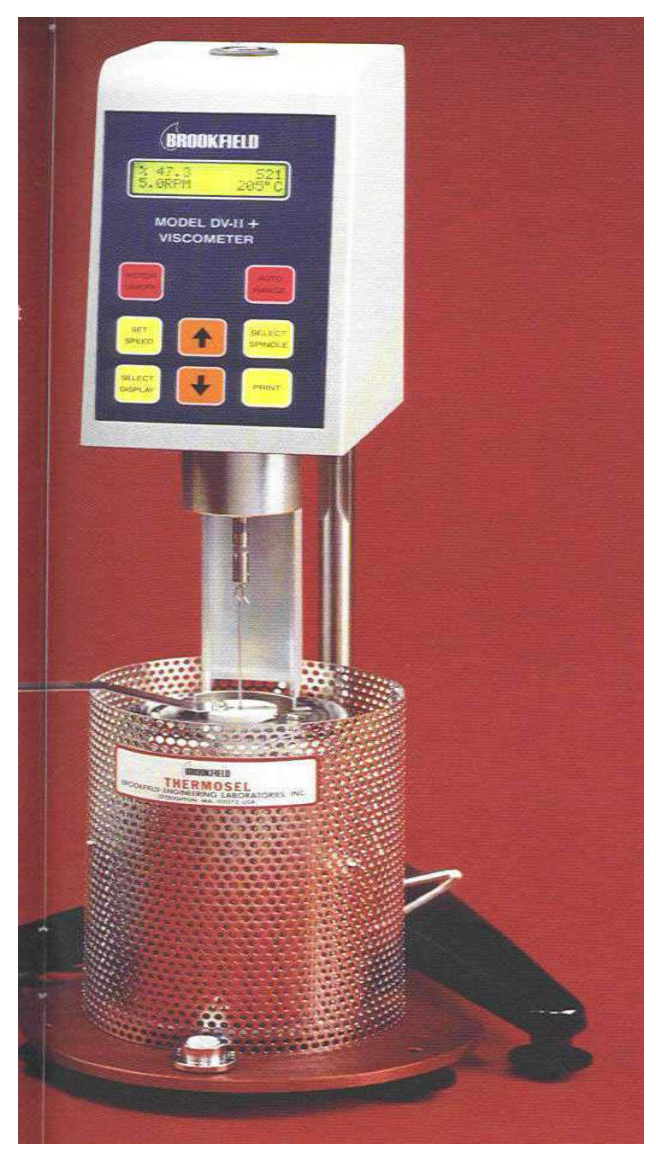

Figure 2.1 Rotational Viscometer 
related to the viscosity of the binder sample, the later is automatically determined and displayed by computerized software.

\subsubsection{ROLLING THIN FILM OVEN}

The Rolling Thin Film Oven, RTFO, test is used to simulate the aging process that takes place during production and up to the first year of life of the pavement. The binder is poured into cylindrical bottles, placed horizontally in a convection oven and rotated at $163^{\circ} \mathrm{C}$ for 85 minutes. This process creates a thin film of asphalt on the inner surface of bottles. The asphalt ages due to heat and injection of air into the bottles. The RTFO is used as a standard process for the aging of the binder and not for duplicating the actual aging that will take place in the field. The intent of the RTFO is only to establish a standardized process that can be used in a purchase specification that will simulate early aging of the binder during production. AASHTO T 240 specifies the procedures for RTFO. Figure 2.2 presents test equipment for RTFO.

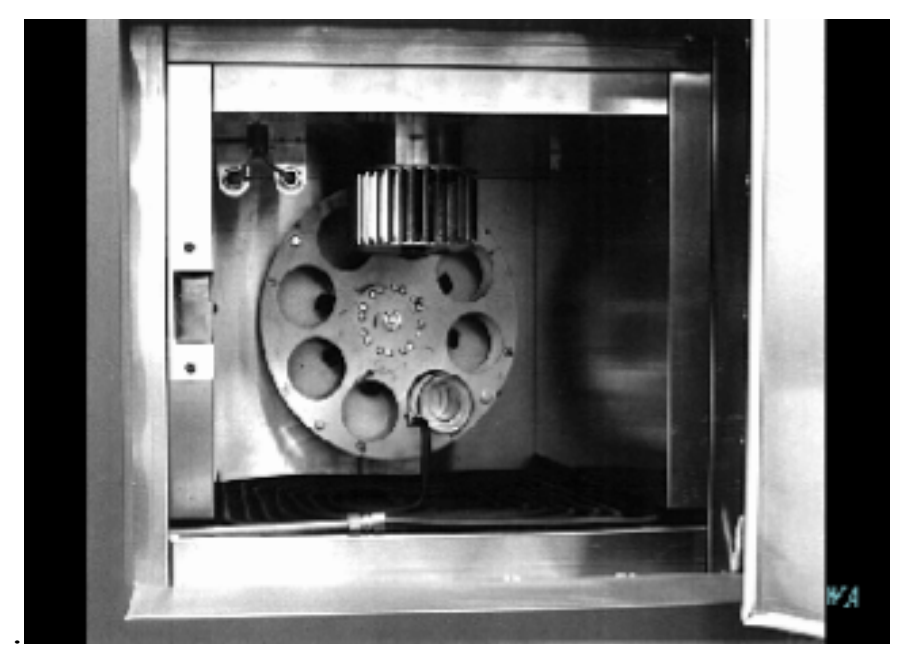

Figure 2.2 Rolling Thin Film Oven

\subsubsection{DYNAMIC SHEAR RHEOMETER}

The Dynamic Shear Rheometer, DSR, is used in the Superpave specification to measure the properties of the asphalt binder at high and intermediate temperatures. The DSR measures the complex shear modulus, $\mathrm{G}^{*}$, and the phase angle, $\delta$, of asphalt binders at the desired temperature and frequency of loading. Complex modulus can be considered 
as the resistance of the binder to deformation when repeatedly sheared. The DSR gives a complete picture of the behavior of asphalt binders by measuring both $\mathrm{G}^{*}$ and $\delta$. For rutting resistance a high complex modulus, $\mathrm{G}^{*}$, value and low phase angle, $\delta$, are both desirable. The asphalt binder will be stiffer and would offer greater resistance to rutting as the $\mathrm{G}^{*}$ value increase. The asphalt binder is more elastic if the $\delta$ value is high (Roberts, et al, 1996).

AASHTO TP 315 specifies the procedures for DSR. An asphalt binder sample is placed between metal plates and a sinusoidal torsional load is applied to the binder at a specified temperature. The binder's response to loading is measured and lag time to that response is determined (D'Angelo and Fee, 2000). From the data, the complex modulus, $\mathrm{G}^{*}$, and phase angle, $\delta$, are determined and used to calculate the viscous and elastic properties of the binder by a computer software. The software directly provides results whether a certain asphalt binder meets or fails the PG criteria. Figure 2.3 presents test equipment for DSR.

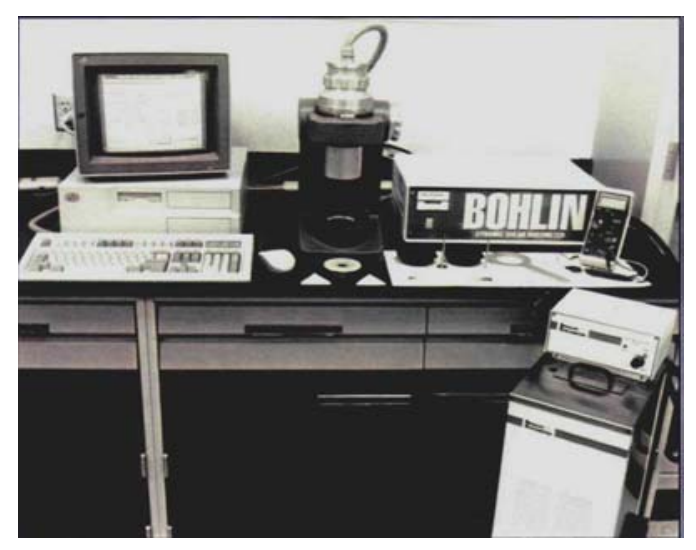

Figure 2.3 Dynamic Shear Rheometer

The specifications for bituminous binders established by the Strategic Highway Research Program, SHRP, require maximum temperature rating of the binder, the value of $\mathrm{G}^{*} / \sin \delta$ should remain above $1 \mathrm{kPa}$ at frequency of $10 \mathrm{radians} / \mathrm{sec}$ (AASHTO M 32002). To minimize rutting, the value of $\mathrm{G}^{*} / \sin \delta$ should be a minimum of $2.20 \mathrm{kPa}$, at the maximum rated binder temperature, after aging using the Rolling Thin Film Oven. At the intermediate temperature, the $\mathrm{G}^{*} \sin \delta$ is required to be less than $5000 \mathrm{kPa}$. The 
intermediate temperature is defined as the average of the maximum and minimum rated temperatures for the binder plus $4^{\circ} \mathrm{C}$.

\subsection{RUTTING}

Rutting in asphalt concrete layers develops gradually as the number of load applications increases, usually appearing as longitudinal depressions in the wheel paths accompanied by small upheavals to the sides. It is caused by a combination of densification and shear deformation (Sousa and Weissman, 1994).

Densification is the further compaction of HMA pavements by traffic after construction. When compaction is poor, the channelized traffic provides a repeated kneading action in the wheel track areas and completes the consolidation. A substantial amount of rutting can occur if thick layers of asphalt are consolidated by the traffic.

The lateral plastic flow of the HMA from the wheel tracks also results in rutting. Use of excessive asphalt cement in the mix causes the loss of internal friction between aggregate particles, which results in the loads being carried by the asphalt cement rather than the aggregate structure. Plastic flow can also occur when the aggregates lack angularity and surface texture needed for adequate interparticle friction. Plastic flow can be minimized by using large size aggregate, angular and rough-textured coarse and fine aggregate, stiffer binder and by providing adequate compaction at the time of construction (Roberts, et al, 1996).

Mechanical deformation might be one of the mechanisms involved in rut development. Mechanical deformation can occur when an element under the pavement surface loses its integrity for one reason or another and is displaced under the load. A rut resulting from this type of action will generally be accompanied by substantial pattern cracking, provided the distress is allowed to progress sufficiently (Kandhal, Mallick and Brown, 1998).

Several states have experienced an increase in the amount and severity of permanent deformation in their hot mix asphalt pavements. This increase in permanent deformation or rutting has been attributed to the increase in truck tire pressures, axle loads and volume of traffic (Brown and Cross, 1992). A rutting study was initiated in 
1987 by National Center for Asphalt Technology, NCAT, to evaluate pavements across the United States. The study encompassed various climatic regions, containing aggregates of different origins and angularity, including different specifying agencies, construction practices and containing large sample size to make the results national in scope (Brown and Cross, 1992). Based on this study, some observations were made and the following conclusions were drawn:

- Most of the rutting observed from the trench cuts of rutted pavements occurred in the top 3 to 4 inches of the HMA. Hence, high quality mixtures should be required in the top two layers,

- The properties of the asphalt cements extracted from the mixtures are not closely related to rutting. The amount of asphalt cement is of primary importance but the properties of the asphalt cement are of secondary importance, and

- Rutting on high volume roadways can be prevented if angular coarse and fine aggregates are used and if the air voids in the mixture do not fall below approximately 3.0 percent.

The Brown and Cross (1992) study was done before the introduction of the Superpave mix design. Hence, there is less importance on the properties of the asphalt cement. Superpave gives importance to the properties of the binders because they play a vital role in the pavement performance.

Permanent deformation of asphalt-aggregate mixes is a complex phenomenon where aggregate, asphalt and aggregate-asphalt interface properties control the overall performance (Sousa and Weissman, 1994). Furthermore, over time, these properties change until the mix reaches the end of its useful life. The properties of the binders that influence rutting are:

- Temperature susceptibility and rate of loading,

- Aging effects, and

- Moisture effects. 
Temperature susceptibility and rate of loading affect the mixes, this can be generally presented in terms of master curves for complex modulus and phase angles. The key element of the PG specification is the use of the parameters $\mathrm{G}^{*} / \sin \delta$ which, rank binders in terms of asphalt rutting resistance (Oliver and Tredrea, 1998). Aging of asphalt is an important aspect controlling the mix behavior over the life of the pavement structure. Moisture effects cannot be directly associated with the binder or with the aggregate as they usually affect the interface between the asphalt and the aggregate. However, because it influences the inter-aggregate bond it could be thought of as degradation of the asphalt.

Aggregates influence rutting, the factors that affect rutting related to aggregates are given by Sousa and Weissman (1994) as follows:

- Air void content,

- Stress hardening due to confining pressure,

- Dilation, and

- Plasticity

Air void content affects permanent deformation characteristics of asphalt aggregate mixes. With increase in confining pressure, the permanent deformation is reduced. Dilation is a phenomenon that accounts for the tendency of the development of confining stresses when the mix is subjected to shear strains. These confining stresses will in turn provide an increase in shear stiffness that reduces permanent deformation. Dilatency is mainly due to the aggregate particles trying to slide past each other. According to Sousa and Weissman (1994), dilatency can also be due to modified asphalt that exhibits rate dependent dilatency. Some properties which are most difficult to isolate are directly related to plastic behavior of the mix and are mainly controlled by the aggregate skeleton.

Research performed over several decades has shown that the susceptibility to rutting can be linked to several materials attributes (Archilla and Madanat, 2000), including:

- Excessive asphalt content, 
- Excessive fine grained aggregate,

- High percentage of natural sand,

- Rounded aggregate particles,

- Excessive permissible moisture in the mix or in granular materials and soils, and

- Temperature susceptible asphalt cement.

In addition, construction factors, such as cold weather paving leading to low density, environmental conditions, including temperature and precipitation and load magnitude, duration, and number of repetitions affect the rutting of asphalt pavements.

Some asphalt mixes that have a good history of resisting rutting in posted speed applications may not perform well in intersections, climbing lanes, truck weigh stations, and other slow speed areas. The slow moving or standing loads occurring at these sites subject the pavement to higher stress conditions which can be enough to induce rutting and shoving. Braking, accelerating and turning movements generate shear stresses at the pavement surface. Engine fluid droppings and heat exhaust increases with slower traffic and has a softening effect on asphalt. In addition, load repetitions at intersections are sometimes double than that of mainline pavement due to the cross flow of traffic (Walker and Buncher, 1999).

To achieve desired performance for asphalt intersections these pavements have to be treated differently than regular open-road pavements by designing them for more severe conditions. The intersection can be built for more severe conditions by following these steps (Walker and Buncher, 1999):

- Insuring structural adequacy,

- Selecting and controlling materials,

- Following good construction practices, and

- Implementing the plan.

To perform well, an intersection pavement must first have adequate thickness to provide the structural capacity to meet traffic needs. The voids in mineral aggregate, 
VMA, property of the mix is an important factor. Mixes with marginally low VMA can be sensitive to relatively small changes in the binder content. Small increase in binder can cause these mixes to be susceptible to rutting and shoving. On the other hand mixes with high VMA have thick asphalt coatings on the aggregate particles. This can act like lubricant, allowing the particles to reorient themselves under traffic, which leads to rutting, shoving or bleeding. Careful selection of the asphalt binder and the aggregate is required to provide optimum pavement performance. More rut resistant binders are needed at intersections. AASHTO's MP-2, standard specification for Superpave volumetric mix design, requires that the high temperature grade be increased by two grades for standing traffic (less than $20 \mathrm{~km} / \mathrm{hr}$ ) and by one grade for slow traffic (20 to 70 $\mathrm{km} / \mathrm{hr}$ ). Experience at numerous sites across the nation has shown that PG 76-XXs ${ }^{1}$ have performed well in intersections (Walker and Buncher, 1999).

A field investigation of rutting near a signalized intersection in Pittsburgh, Pennsylvania by Kandhal, Cross and Brown, (1993) indicated the following causes relating to poor performance of the pavement:

- Low voids in the mineral aggregate,

- Low air voids, and

- Use of sub rounded to sub angular sand.

Although the mixes were designed in the laboratory with high VMA and air void content, the asphalt pavements densified significantly in the field to yield very low VMA and air voids. It was recommended that the HMA at the intersections should have the following attributes:

- Should maintain adequate VMA to ensure durability,

- Should not densify below 4 percent air voids under slow and standing traffic during hot summer days, and

- Should contain stiff asphalt binder to resist creep behavior.

\footnotetext{
${ }^{1}$ The XX term is used to indicate different low temperature ratings of the asphalt.
} 
Recommendations were made based on documented experience in the United States by Kandhal, Mallick and Brown, (1998):

- Use of $50 \mathrm{~mm}$ thick stone matrix asphalt, SMA, wearing course with a maximum nominal aggregate size of $12.5 \mathrm{~mm}$,

- Use of $50 \mathrm{~mm}$ thick SMA binder course with a maximum nominal aggregate size of $19.0 \mathrm{~mm}$, and

- Use of $150 \mathrm{~mm}$ thick dense graded large stone mix with a maximum nominal aggregate size of $25 \mathrm{~mm}$. This mix should be designed either by Superpave mix design method or by Marshall method modified for 6-inch diameter specimens.

Walker (2000) documents Maryland and Kentucky experience with constructing intersections to meet the demands of high traffic volume. The highlights of these projects are mentioned below.

MARYLAND PROJECT: The project is located at the intersection of US 40 and Maryland 213 in Cecil County, Maryland. This location had a history of severe rutting that needed milling and repaving on an almost yearly basis. For this project, the Superpave mix designs were conducted for the base and surface courses. The resulting aggregate blends were 90\% limestone and 10\% natural sand. PG 76-22 was used in both the base and surface mixes. The base course was a $25 \mathrm{~mm}$ mix and was covered by a $19 \mathrm{~mm}$ wearing surface mix.

KENTUCKY PROJECT: The location of this intersection is on US 27 and KY 80. The designers selected to use the Superpave process for materials characterization and mix design. The gradation of the base and wearing courses were both essentially Superpave gradations, but were slightly coarser than the bottom control points. One hundred percent crushed aggregate was selected with PG 76-22 binder.

The records show that these asphalt pavements are performing well after reconstruction following the new procedures (Walker, 2000). 


\subsection{LARGE STONE ASPHALT MIXES}

Large stone asphalt mixes also known as LSAM's are gaining popularity among the highway agencies. LSAM's high resistance to deformation makes them attractive for construction in heavy truck traffic routes. LSAM's develop strength by the stress bridging effect and stone to stone contact.

Large stone asphalt mixture is defined as HMA paving mixtures containing maximum aggregate sizes between $25 \mathrm{~mm}$ and $63 \mathrm{~mm}$. The use of large stone mixes is not new. Warren Brothers Company had a patent issued in 1903, which specified a top size aggregate of three inches (Kandhal, 1990). With rapid increase of traffic loads and volume, premature rutting and fatigue cracking have been more and more frequently encountered in recent years. The concept of stone-to-stone contact in large stone asphalt mixtures seems to provide a solution for rut resistance in heavy duty mixtures. According to the survey conducted during NCHRP 4-18, thirty out of fifty two highway agencies in US had constructed pavements using LSAM (Mohammad et al, 2000).

Mohammad, et al (2000) studied the performance of large stone (37.5 mm) Superpave and open graded large stone mixtures for use as structural and drainage layers. They used Styrene Butadiene (SB) polymer-modified asphalt cement meeting Louisiana Department of Transportation and Development specification. The aggregate used in the study was siliceous limestone. A comparative laboratory evaluation was conducted on large stone Superpave and open grade mixtures along with the conventional Louisiana Type 5A base course mixture and Type 508 drainable mixture. Volumetric properties as well as engineering performance parameters were evaluated through laboratory tests. The following observation was made based on the laboratory study. The open graded large stone asphalt mixture showed significantly better performance in axial creep, Indirect Tensile Strength, ITS, and Asphalt Pavement Analyzer, APA, rut tests when compared to the Louisiana conventional Type 508 drainable base mixture.

Kentucky has used LSAM to address the problem of rutting (Mahboub and Allen, 1990). This study found large stone asphalt mixes offers a number of desirable properties for heavy duty asphalt pavements. The LSAM's were found to have desirable compressive strength, resilient modulus, and resistance, all of which contribute to rut 
resistant mix. Large stone mixes offer higher structural capacity at lower optimum asphalt content when compared with conventional mixes, which makes them cost competitive.

The large stone mixes are more sensitive to construction errors than their conventional counterparts according to Mahboub and Williams (1990). Several factors contribute to successful LSAM mix design. Adequate asphalt film thickness is necessary to ensure workability and durability. Film thickness is controlled by asphalt content and percent mineral filler in the aggregate. Percent voids in the mineral aggregate, VMA, must be enough to accommodate the desired film thickness at maximum field density without excessive reduction in air voids. Plant mixing time may need to be slightly adjusted for LSAM. A longer mixing time, as compared with conventional HMA may become necessary to ensure coating of larger aggregate particles. In addition, careful attention to aggregate feeding and mixture handling to avoid segregation is essential. A quality control routine should follow the construction of LSAM closely in order to ensure adherence to design parameters such as aggregate gradation, asphalt content, density, and air void content.

\subsection{MODIFIED BINDERS}

Asphalt binders have a limited capacity to perform when under wide range of loads and weather conditions which occur over the life of a pavement (Chen, Liao and Shiah, 2002). Therefore, binders are modified to improve their performance. The use of bitumen modified with thermoplastic copolymers, elastomers or plastomers in special hot mixes for industrial road surfacing dates back to the 1970's (Brule and Maze, 1995). Improvement in resistance to rutting, thermal cracking, fatigue damage, stripping, and temperature susceptibility have led polymer-modified binders, PMA, to be substituted for asphalt in many paving and maintenance applications. Based on their functions and behaviors, polymers can be divided into three types (Khattak and Baladi, 1998):

- Dispersed thermoplastics such as Polyethylene,

- Network thermoplastics such as Styrene-Butadiene-Styrene, SBS, and

- Reacting polymers such as Elvaloy AM. 
The SBS triblock copolymer is one of the most promising polymers for asphalt modification (Khattak and Baladi, 1998). SBS is an inhomogeneous material, the engineering properties are strongly influenced by the morphology of the composite. The microstructure of PMA is related to the characteristics of each constituent that forms the material.

According to Khattak and Baladi (1998) who did a study under laboratory conditions on the structural and engineering properties of PMA, modified with SBS polymer system, indicated a considerable increase in indirect tensile strength and fracture toughness of asphalt mixtures at $25^{\circ} \mathrm{C}$ and $60^{\circ} \mathrm{C}$. This implies increased resistance to fatigue cracking and rutting. The higher number of load cycles to develop plastic deformations and the almost constant resilient modulus indicate that the SBS polymer system cause a decrease in the energy stored in the sample due to plastic deformation. The fatigue life of PMA mixtures is considerably higher than for straight and processed asphalt mixtures. The increase in fatigue life is due to increases in tensile strength and plastic properties of the mixes.

Chen, Liao and Shiah (2002) studied the properties of SBS polymer-modified asphalt. The engineering properties of the asphalt modified by SBS showed an increase in complex modulus as a function of SBS copolymer. Because of the colloidal nature of asphalt cements, their mechanical properties were highly enhanced after SBS modification due to the presence of the dispersed phase, and swelling of the polymer. The minimum percentage of polymer to ensure the formation of its continuous phase depends to a greater extent on the base asphalt and the polymer itself.

Wegan and Brule (1999) studied the structure of polymer-modified asphalts in twenty five asphalt mixtures produced using 12 different polymer-modified binders. A comparison of the polymer-modified binder was carried out between the binder and the corresponding asphalt mixtures. In most cases, it was seen that the structure of the modified binder was completely different from the structure of the polymer-modified binder in the asphalt concrete mixture. Where a continuous phase could be observed in the binder, no continuous network of the polymer phase can be detected in the asphalt mixture. The polymer in the binder can be seen as globules with more or less irregular 
shapes in a continuous asphalt phase. The polymer globules were often smaller in the mixture produced from these binders. In all asphalt mixtures produced with SBS modified binders, the SBS were present as irregular globules in a continuous asphalt phase. This study showed there exists a specific interaction between properties of a modified binder and the performance of an asphalt mixture. This indicates that it would be very difficult to establish general relationships between properties of a modified binder and the performance of an asphalt concrete mixture. Performance of the asphalt concrete mixture could not be predicted based on the type or nature of the polymer. Hence, it is necessary to evaluate the performance on the asphalt concrete mixture rather than relying on estimates of the properties of the modified asphalt binders to indicate performance.

Asphalt mixtures with PG 76-22 binder modified with polymer were compared with PG 64-22 binder by Hawkins (2001) in a research project for the South Carolina Department of Transportation. An Asphalt Pavement Analyzer was used to evaluate the performance of the mixtures. The addition of the polymer-modified binder greatly improved the performance of the mixes. The measured rutting of the $12.5 \mathrm{~mm}$ Superpave designs was reduced on an average by approximately 56 percent by using PG 76-22 in lieu of PG 64-22. This indicates that the addition of polymer-modified binders will help increase the life expectancy of asphalt pavements by increasing the resistance to rutting.

Polymer-modified asphalt has been claimed to resist rutting and has been used in a side-by-side experimental study on I-55 highway near Grenada in northern Mississippi. Uddin and Nanagiri (2002) compared a neat AC 30 asphalt binder and eight modified binders. Each section was $0.8 \mathrm{~km}$ long and consisted of $38 \mathrm{~mm}$ binder course and $38 \mathrm{~mm}$ surface course. The binder course and surface course were HTBC type 6 and HTSC type 8 mixes, respectively, designed using the Marshall method. The HTBC and HTSC specifications have a nominal maximum aggregate size of 25 and $19 \mathrm{~mm}$ respectively. The modified binders performed better than the control binder in both theoretical and field evaluations in resisting rutting.

Stuart and Mogawer (2002) studied the ability of eleven different asphalt binders to contribute to the ability of a mix to resist rutting. Eight of the binders were polymer- 
modified, one was modified air blown asphalt and two were unmodified asphalt cements. The primary objective of the research was to evaluate if the Performance Grade specifications are valid for modified binders. The research approach was to perform the specification tests, prepare mixes and evaluate the rutting potential with the cumulative permanent shear strains from the repeated shear - constant height test and the French pavement rutting tester. In addition to concluding that the Performance Grade specifications are valid, the authors demonstrated that the modified binders provide superior rutting resistance when compared to the unmodified binders.

\subsection{SUPERPAVE MIX DESIGN}

In 1988, the Strategic Highway Research Program, SHRP, was initiated with a primary goal of developing an improved mix design procedure. At the conclusion of the SHRP program in 1993, the resulting system contained the following elements: consensus properties of aggregate, new mix design procedure and mixture analysis procedures. The PG specifications were implemented concurrently and are used for Superpave mixes.

\subsubsection{AGGREGATE SPECIFICATIONS}

Under the Superpave mix design method, two classes of aggregate properties are identified: source and consensus requirements. Source requirements are implemented at the discretion of each agency to reflect local conditions. These typically include durability, soundness, and deleterious material specifications. The consensus specifications prescribed within the Superpave methodology with the intention that all agencies would use a common set of test methods and criteria. The consensus properties are:

- Coarse aggregate angularity (ASTM D 5821) - materials retained on $4.75 \mathrm{~mm}$ sieve,

- Fine aggregate angularity (AASHTO T 340) - materials passing the $2.36 \mathrm{~mm}$ sieve,

- Flat and elongated particles (ASTM D 4791) - materials retained on $9.5 \mathrm{~mm}$ sieve, and 
- Sand equivalent (AASHTO T 176) - materials passing the $4.75 \mathrm{~mm}$ sieve.

In addition, the Superpave specifications prescribe control points for allowable aggregate gradations. Mix types are designated by the nominal maximum aggregate size of the aggregate blend. Five mix designations are defined in the Superpave methodology as shown in the Table 2.2 (WVDOT MP 401.02.29). Under the Superpave methodology, the nominal maximum aggregate size is defined as one sieve larger than the first sieve to retain more than 10 percent of aggregate blend. The maximum aggregate size is defined as one sieve size larger than the nominal maximum aggregate size.

Table 2.2 Design aggregate gradation requirements

\begin{tabular}{|c|c|c|c|c|c|c|}
\hline $\begin{array}{c}\text { Nominal } \\
\text { Maximum } \\
\text { Size }\end{array}$ & $\begin{array}{c}37.5 \mathrm{~mm} \\
\text { (11/2 inch) }\end{array}$ & $\begin{array}{l}25 \mathrm{~mm} \\
(1 \mathrm{inch})\end{array}$ & $\begin{array}{c}19 \mathrm{~mm} \\
(3 / 4 \mathrm{inch})\end{array}$ & $\begin{array}{c}12.5 \mathrm{~mm} \\
(1 / 2 \mathrm{inch})\end{array}$ & $\begin{array}{c}9.5 \mathrm{~mm} \\
\text { (3/8 inch) }\end{array}$ & \multirow{2}{*}{$\begin{array}{c}\text { Gradation } \\
\text { tolerances } \\
\text { shall be the } \\
\text { design } \\
\text { control } \\
\text { points with } \\
\text { exception as } \\
\text { noted below }\end{array}$} \\
\hline $\begin{array}{c}\text { Standard } \\
\text { Sieve Size }\end{array}$ & Base-I & & $\begin{array}{c}\text { Base-II } \\
\text { (P\&L) } \\
\text { Wearing-IV }\end{array}$ & & $\begin{array}{l}\text { Wearing-1 } \\
\text { (Scratch) }\end{array}$ & \\
\hline $50 \mathrm{~mm}$ & 100.0 & & & & & - \\
\hline $37.5 \mathrm{~mm}$ & $90.0-100.0$ & 100.0 & & & & - \\
\hline $25 \mathrm{~mm}$ & $90.0 \max$ & $90.0-100.0$ & 100.0 & & & - \\
\hline $19 \mathrm{~mm}$ & & $90.0 \max$ & $90.0-100.0$ & 100.0 & & - \\
\hline $12.5 \mathrm{~mm}$ & & & $90.0 \max$ & $90.0-100.0$ & 100.0 & - \\
\hline $9.5 \mathrm{~mm}$ & & & & $90.0 \max$ & $90.0-100.0$ & - \\
\hline $4.75 \mathrm{~mm}$ & & & & & $90.0 \max$ & - \\
\hline $2.36 \mathrm{~mm}$ & $15.0-41.0$ & $19.0-45.0$ & $23.0-49.0$ & $28.0-58.0$ & $32.0-67.0$ & $\mathrm{JMF} \pm 6$ \\
\hline \multicolumn{7}{|l|}{$1.18 \mathrm{~mm}$} \\
\hline \multicolumn{7}{|l|}{$600 \mu \mathrm{m}$} \\
\hline \multicolumn{7}{|l|}{$300 \mu \mathrm{m}$} \\
\hline $75 \mu \mathrm{m}$ & $0.0-6.0$ & $1.0-7.0$ & $2.0-8.0$ & & $2.0-10.0$ & \\
\hline
\end{tabular}

\subsubsection{SUPERPAVE GYRATORY COMPACTION}

The Superpave mix design procedure uses the Superpave Gyratory Compactor (Figure 2.4), SGC, to prepare samples for volumetric evaluation (AASHTO TP 4). Three factors contribute to the compaction effort of the SGC: vertical pressure, angle of gyration, and number of gyrations. The SGC imparts a constant vertical pressure of $600 \pm$ $5 \mathrm{kPa}$ to the sample, the sample is tilted $1.25 \pm 0.02^{\circ}$ from the vertical axis and the angle of the mold is gyrated at a speed of $30 \pm 0.5 \mathrm{rpm}$. The compaction effort is controlled by the number of gyrations. This method of compaction results in a material that more 
closely resembles that on the road in terms of particle alignment and density (Coree and VanDerHorst, 1998). Mixtures are compacted at the temperature where the viscosity of the binder is 0.28 Pa.s.

The required number of gyrations is based on traffic level. Mixtures that are exposed to higher traffic levels in the field are compacted in the laboratory to a higher density. This higher density is obtained in the laboratory by increasing the number of gyrations (Kandhal et al, 1998). The number of gyrations for specified traffic levels are shown in Table 2.3 (Roberts, et al, 1996).

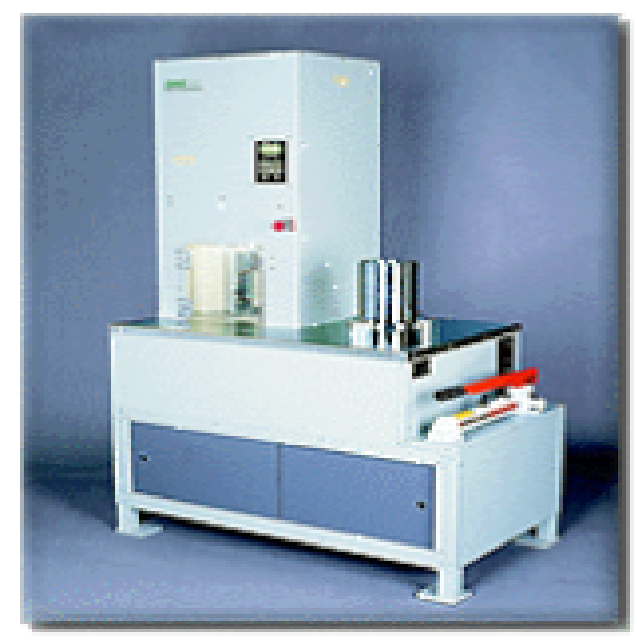

Figure 2.4 Superpave Gyratory Compactor

The term $\mathrm{N}_{\mathrm{i}}$ is $\mathrm{N}$-initial and is a measure of mixture compactibility. $\mathrm{N}_{\mathrm{d}}$, or $\mathrm{N}$-design, and is number of gyrations required to produce a density in the mix that is equivalent to the expected density in the field after the indicated amount of traffic. In the mix design process, an asphalt content is selected that will provide 4 percent air voids when the mix is compacted to $\mathrm{N}_{\mathrm{d}}$ gyrations. $\mathrm{N}_{\mathrm{m}}$ provides an estimate of the ultimate field density. $\mathrm{N}_{\mathrm{m}}$ is the $\mathrm{N}$-maximum and is the number of gyrations required to produce a density in the laboratory that should absolutely never be exceeded in the field. 
Table 2.3 Selection of number of gyrations for Superpave Gyratory Compactor

\begin{tabular}{|c|c|c|c|}
\hline $\begin{array}{c}\text { Design ESALs } \\
\text { (millions) }\end{array}$ & $\mathrm{N}_{\mathrm{i}}$ & $\begin{array}{c}\text { Compaction Parameters } \\
\text { Number of Gyrations } \\
\mathrm{N}_{\mathrm{d}}\end{array}$ & $\mathrm{N}_{\mathrm{m}}$ \\
\hline $\begin{array}{c}<0.3 \\
\text { Light traffic }\end{array}$ & 6 & 50 & 75 \\
\hline $\begin{array}{c}0.3 \text { to }<3 \\
\text { Medium traffic }\end{array}$ & 7 & 75 & 115 \\
\hline $\begin{array}{c}3 \text { to }<30 \\
\text { Heavy traffic }\end{array}$ & 8 & 100 & 160 \\
\hline $\begin{array}{c}\geq 30 \\
\text { Extra heavy traffic }\end{array}$ & 9 & 125 & 205 \\
\hline
\end{tabular}

\subsection{ASPHALT PAVEMENT ANALYZER}

Permanent deformation or rutting can be evaluated by using Asphalt pavement Analyzer, APA, Figure 2.5. The standard method followed to determine rutting susceptibility using APA was developed by APAC Materials services and is given as a proposed procedure as AASHTO TP XXX. The APA allows for an accelerated evaluation of rutting potential after volumetric design of mixes. A typical testing time for a complete evaluation is 135 minutes ( 8000 cycles). The APA features, controllable wheel load and contact pressure that are representative of actual field conditions (Pavement Technology, Inc.)

Rutting susceptibility of the mixes is evaluated by placing beam or cylindrical samples under repetitive loads. Triplicate beam samples or cylindrical samples can be tested in APA under controllable high temperatures and in dry or submerged conditions. The rut depth is measured after the desired number of cycles of load application. Table 2.4 gives the test parameters specified in the APAC procedure.

Kandhal and Mallick (1999) conducted a study to evaluate the APA as a tool of evaluating rut potential of HMA with different aggregate gradations and asphalt binders. Kandhal found the APA is sensitive to aggregate gradation based on statistical significance of differences in rut depths. The APA was found to be sensitive to the asphalt binder PG grade based on statistical significance of differences in rut depths. The 
rut depths of mixes with PG 58-22 asphalt binder were higher than those of mixes with PG 64-22 asphalt binder.

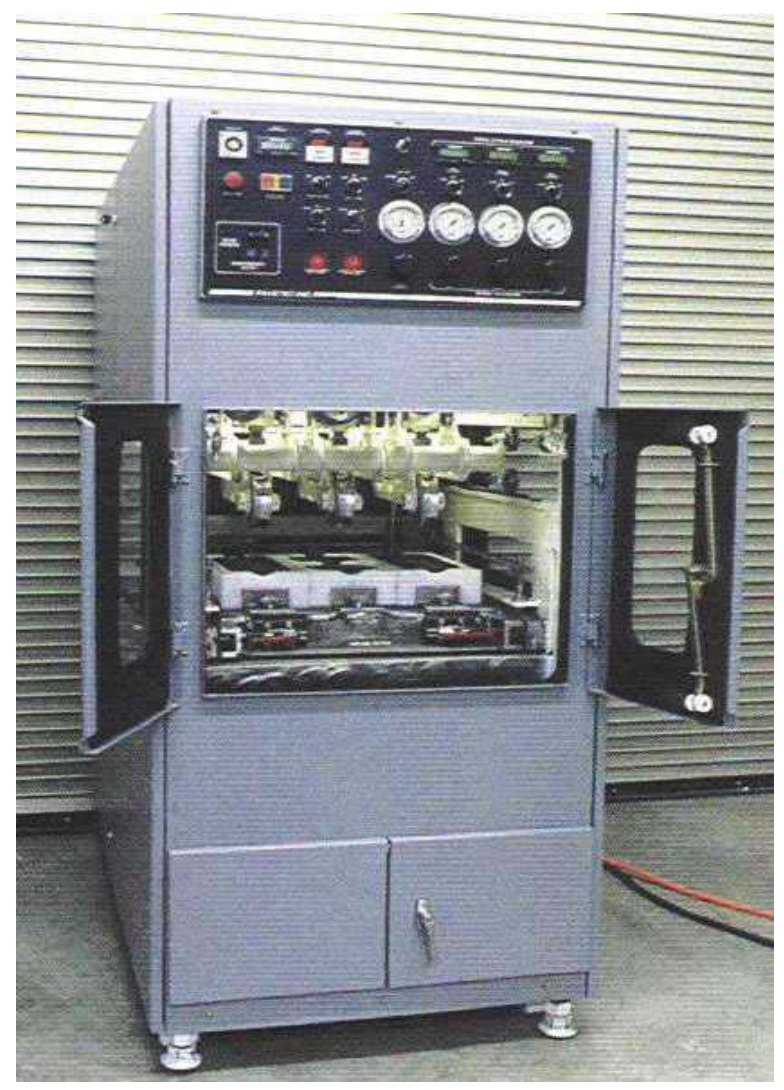

Figure 2.5 Asphalt Pavement Analyzer

Table 2.4 APA testing parameters

\begin{tabular}{|l|l|}
\hline Factors & Range specified in APAC procedure \\
\hline Air void content & $7 \pm 0.5 \%$ \\
\hline Test temperatures & Based on average high pavement temperatures \\
\hline Wheel load & $100 \pm 5 \mathrm{lb}$ \\
\hline Hose pressure & $100 \pm 5 \mathrm{psi}$ \\
\hline Specimen type & Beams, Cylinders \\
\hline Compaction & Rolling, Vibratory, and Gyratory \\
\hline
\end{tabular}

A study was conducted by Choubane, Page and Musselman (2000) to evaluate the suitability of APA for assessing the rutting potential of asphalt mixes. The evaluation process consisted of correlating the APA's predicted rutting with known field 
measurements. Based on the results obtained from the study the following conclusions were drawn by the authors:

- APA testing variability may differ from test to test and within each test sample location for both gyratory and beam samples,

- APA ranked the mixes considered in the study according to their field performance. This ranking is the same using either beam or the gyratory specimens,

- Average values within the ranges of 7 to $8 \mathrm{~mm}$ and 8 to $9 \mathrm{~mm}$ may be used as performance limiting criteria at 8000 cycles for beam and gyratory samples, respectively, and

- A good correlation was obtained between the respective average measurements on gyratory and beam samples.

Thirty four mixes from various locations within the state of Tennessee were tested in the APA by Jackson and Baldwin (2000) to determine if the APA was a suitable procedure to evaluate mixes during the mix design process. Based on the test results, the APA appeared to be sensitive to the critical material properties that contribute to rutting of HMA. Parameters that were evaluated and the resulting conclusions include:

- Conventional mixes prepared with the 75 blow Marshall procedure had a higher occurrence of rutting in excess of the criteria, $5 \mathrm{~mm}$, than mixes prepared with the Superpave method,

- Mixes prepared with PG 64-22 were more rut susceptible than mixes with PG 76-22 modified binder,

- There was a weak correlation between binder content and rutting potential, however, confounding factors in the experiment prevented developing a strong conclusion,

- Rutting potential was not correlated with dust content, however, low dust to asphalt ratios appears to contribute to rutting potential, and 
- Every mix that had more than $5 \mathrm{~mm}$ of rutting had a gradation that passed through the Superpave restricted zone. However, about one half of the mixes that did not demonstrate rutting potential also passed through the restricted zone. None of the mixes with gradations outside of the restricted zone exhibited high rutting potential.

According to Hawkins (2001), the APA, if used properly during the mix design phase, can help identify and reduce the mix design factors that contribute to pavement rutting. Based on his findings, he recommends in utilizing the APA to eliminate high volume asphalt mixtures that could potentially rut with the following specifications:

- Intermediate courses with PG 64-22, maximum rut depth of $7 \mathrm{~mm}$ at 8000 cycles,

- Surface courses with PG 64-22, maximum rut depth of $5 \mathrm{~mm}$ at 8000 cycles, and

- Intermediate and surface courses with PG 76-22, maximum rut depth of $3 \mathrm{~mm}$ at 8000 cycles.

The advantages of APA over other rut testing devices such as Hamburg wheel tracking device, French rutting tester and PUR wheel, are: APA can test cylindrical or beam samples, it simulates field traffic and temperatures. It is simple to perform testing and three to six samples can be tested together. The guidelines and criteria are available and cylindrical specimens are made using SGC (Skok, Turk and Johnson, 2002).

\subsection{CONCLUSIONS}

The tests for binder properties, which deal with the rutting, were described briefly in this chapter. The literature review demonstrates the seriousness of the rutting problem. Furthermore, rutting in the asphalt pavements is a complex phenomenon, dependent on several factors. Several authors have demonstrated that modified asphalt binders may significantly assist in controlling rutting. The literature review also demonstrates that several researchers are having good success using the APA to evaluate the rutting potential of mixes. 


\section{CHAPTER 3 RESEARCH METHODOLOGY}

\subsection{INTRODUCTION}

This research evaluates the effect of binders with respect to rutting performance. Starting with mix designs from Mountain Enterprise Inc. different grade binders were substituted and tested to evaluate the effect of binder type on rutting potential. The mix design was prepared with a SBS modified PG 76-22 binder. The other binders evaluated were PG 64-22 and PG 70-22. These are the binders normally used for pavements in West Virginia. The designs were based on Superpave method. Gyratory samples were made using Superpave Gyratory Compactor and were later tested in the Asphalt Pavement Analyzer. Both $37.5 \mathrm{~mm}$ and $12.5 \mathrm{~mm}$ mixes were analyzed. The following sections of this chapter explain the laboratory testing program.

\subsection{MATERIALS}

The aggregate used in this research work was provided by Mountain Enterprise Inc from their plants in Carter city and Greenup in Kentucky. Two types of aggregate, a crushed limestone and, a blast furnace slag were used during the project. The $37.5 \mathrm{~mm}$ mix consisted of 100 percent crushed limestone. The $12.5 \mathrm{~mm}$ mix consisted of 95 percent slag and 5 percent crushed limestone. In this mix, the crushed limestone was finer than $4.75 \mathrm{~mm}$. During construction, four stockpiles of materials were used to create the mix. However, the aggregates for this mix were delivered in three sacks, one each for the coarse and intermediate aggregates and one which was a blend of limestone and slag fine aggregates.

The asphalt binders used were supplied by Marathon Ashland Petroleum LLC. The binders were PG 64-22, PG 70-22 and PG 76-22. The PG 64-22 and PG 70-22 are produced by directly refining petroleum oil. To achieve the extended temperature range of PG 76-22 copolymers are used to alter the properties of the asphalt cement. The PG 76-22 binder used in this study was modified with Styrene Butadiene Styrene copolymer. The mixing and compacting temperatures, as supplied by the vender are given in Table 3.1 with viscosities at $135^{\circ} \mathrm{C}$. 
Table 3.1 Viscosity of binders at $135^{\circ} \mathrm{C}$ and the mixing and compaction temperatures

\begin{tabular}{|c|c|c|c|c|c|}
\hline $\begin{array}{c}\text { Binder } \\
\text { Grade }\end{array}$ & $\begin{array}{c}\text { Viscosity } \\
(\text { Pa.s })\end{array}$ & $\begin{array}{c}\text { Mixing } \\
\text { Temperature } \\
\text { Minimum } \\
\left({ }^{\circ} \mathrm{C}\right)\end{array}$ & $\begin{array}{c}\text { Mixing } \\
\text { Temperature } \\
\text { Maximum } \\
\left({ }^{\circ} \mathrm{C}\right)\end{array}$ & $\begin{array}{c}\text { Compaction } \\
\text { Temperature } \\
\text { Minimum } \\
\left({ }^{\circ} \mathrm{C}\right)\end{array}$ & $\begin{array}{c}\text { Compaction } \\
\text { Temperature } \\
\text { Maximum } \\
\left({ }^{\circ} \mathrm{C}\right)\end{array}$ \\
\hline PG 64-22 & 0.411 & 151 & 157 & 141 & 145 \\
\hline PG 70-22 & 0.592 & 159 & 165 & 148 & 153 \\
\hline PG 76-22 & 1.295 & 156 & 167 & 147 & 158 \\
\hline
\end{tabular}

\subsection{BINDER PREPARATION}

The binders supplied to the lab were first sampled following the specifications given in AASHTO T 40. Samples were heated in the oven until suitable for pouring. They were then quartered into different containers and stored for further testing.

\subsection{TESTS ON BINDERS}

The complex moduli of the binders were evaluated using the Dynamic Shear Rheometer. Unconditioned samples and samples conditioned in the Rolling Thin Film Oven were tested. Aging of the samples for the long term using the Pressure Aging Vessel was not carried out since this research was concerned with rutting, not fatigue.

\subsubsection{ROLLING THIN FILM OVEN}

Three different binders were tested in the RTFO to age the binders to achieve the aging that can be obtained during the mixing and construction of HMA. The aging in RTFO is obtained by following the specifications in AASHTO T 240.

\subsubsection{DYNAMIC SHEAR RHEOMETER}

The unaged and the aged binders were tested using the Dynamic Shear Rheometer to determine the complex modulus and phase angle. The averages of two results of the samples are shown in Table 3.2. The software for the DSR provides output indicating whether a particular sample failed or passed the test. The criteria which specifies the samples is the value of $\mathrm{G}^{*} / \mathrm{sin} \delta$, which should be a minimum of $1.00 \mathrm{kPa}$ for original asphalt binder and $2.20 \mathrm{kPa}$ after aging using the rolling thin film oven procedure 
Table 3.2 Dynamic Shear Rheometer results

\begin{tabular}{|c|c|c|c|c|}
\hline Binder Grade & $\begin{array}{c}\text { Unaged or } \\
\text { Aged }\end{array}$ & $\begin{array}{c}\text { Complex } \\
\text { Modulus, Pa.s }\end{array}$ & $\begin{array}{c}\text { Phase angle, } \\
\text { degree }\end{array}$ & $\begin{array}{c}\text { G*/Sin } \delta, ~ \\
\text { Pa.s }\end{array}$ \\
\hline $64-22$ & U & 1891 & 85.60 & 1897 \\
\hline $64-22$ & A & 3561 & 84.50 & 3577 \\
\hline $70-22$ & U & 2178 & 84.20 & 2189 \\
\hline $70-22$ & A & 3255 & 82.80 & 3281 \\
\hline $76-22$ & U & 1020 & 84.45 & 1076 \\
\hline $76-22$ & A & 3028 & 67.30 & 3285 \\
\hline
\end{tabular}

(AASHTO T 315). The samples tested for dynamic modulus passed the test. In the table "U" represents for unaged binder and " $A$ " represents the aged binder.

\subsection{AGGREGATE PREPARATION}

The aggregates were processed by sieving, washing and oven drying. Dried aggregates were sieved with a nest of sieves, consisting of $50 \mathrm{~mm}, 37.5 \mathrm{~mm}, 25 \mathrm{~mm}$, $19 \mathrm{~mm}, 12.5 \mathrm{~mm}, 4.75 \mathrm{~mm}, 2.36 \mathrm{~mm}, 1.18 \mathrm{~mm}, 600 \mu \mathrm{m}, 300 \mu \mathrm{m}$ and $75 \mu \mathrm{m}$. The material retained in each sieve was washed and placed in storage bins. The pan material from the dry sieving was placed in the storage bins. Dust material removed when washing was discarded. Sieving was done only to get material to prepare asphalt concrete samples, and not for gradation analysis.

\subsubsection{SPECIFIC GRAVITY OF AGGREGATES}

Two samples of each aggregate were tested to determine the specific gravity and absorption, AASHTO T 85 for coarse aggregate, and AASHTO T 84 for fine aggregate specifies the procedures for determining specific gravities. Sample was split following the specifications in AASHTO T 248. Two samples were taken from each bag and the tests were done to determine the specific gravity and the absorption percentage. The average specific gravity and absorption values determined in the laboratory are given in Table 3.3 for $37.5 \mathrm{~mm}$ mix aggregates and Table 3.4 for $12.5 \mathrm{~mm}$ mix aggregates. The data is provided in Appendix A. 
Table 3.3 Specific gravities of limestone aggregates for $37.5 \mathrm{~mm}$ mix

\begin{tabular}{|c|c|c|c|c|}
\hline Stone Size & $\begin{array}{c}\text { Bulk Specific } \\
\text { Gravity } \\
\text { (Oven Dried) }\end{array}$ & $\begin{array}{c}\text { Apparent } \\
\text { Specific Gravity }\end{array}$ & $\begin{array}{c}\text { Absorption } \\
\text { Percent }\end{array}$ & $\begin{array}{c}\text { Blend } \\
\text { Percent }\end{array}$ \\
\hline$\# 4$ & 2.668 & 2.716 & 0.675 & 30 \\
\hline$\# 57$ & 2.690 & 2.728 & 0.524 & 20 \\
\hline$\# 8$ & 2.694 & 2.745 & 0.697 & 25 \\
\hline Sand & 2.515 & 2.724 & 3.046 & 25 \\
\hline $\begin{array}{c}\text { Blend } \\
\text { Values }\end{array}$ & 2.639 & 2.728 & \multicolumn{2}{|c}{} \\
\cline { 1 - 3 } & & &
\end{tabular}

Table 3.4 Specific gravities of blast furnace slag aggregates for $12.5 \mathrm{~mm}$ mix

\begin{tabular}{|c|c|c|c|c|}
\hline Stone Size & $\begin{array}{c}\text { Bulk Specific } \\
\text { Gravity } \\
\text { (Oven Dried) }\end{array}$ & $\begin{array}{c}\text { Apparent } \\
\text { Specific Gravity }\end{array}$ & $\begin{array}{c}\text { Absorption } \\
\text { Percent }\end{array}$ & $\begin{array}{c}\text { Blend } \\
\text { Percent }\end{array}$ \\
\hline$\# 78$ & 2.426 & 2.580 & 2.464 & 35 \\
\hline$\# 8$ & 2.764 & 3.014 & 3.002 & 40 \\
\hline Sand & 2.513 & 2.882 & 5.098 & 25 \\
\hline $\begin{array}{c}\text { Blend } \\
\text { Values }\end{array}$ & 2.574 & 2.816 & \multicolumn{2}{|c}{} \\
\cline { 1 - 2 } & \multicolumn{3}{|l}{}
\end{tabular}

\subsubsection{AGGREGATE BLEND}

The aggregate blend was designed by Mountain Enterprises Inc. for the Fort Gay Intersection for $37.5 \mathrm{~mm}$ and $12.5 \mathrm{~mm}$ courses. The same blend was used for this study to make specimens for APA using the three different binders. The design aggregate blends are summarized in Tables 3.5 and 3.6.

Samples of production material were obtained for fabricating APA samples.

During the research, it was noted that the compaction characteristics of the production material were different than the characteristics of the samples prepared in the laboratory to the mix design gradations. This raised concern that the production, or field, mix had different gradations than the mix designs. The gradations of the mixes were checked by obtaining the quality control results from the contractor, WVDOH District $2 \mathrm{Lab}$, and the WVDOH Central Lab. In addition, the NCAT oven in the WVU Asphalt Technology Lab was used to burn off the asphalt from the production samples and the gradation of the 
remaining aggregate was determined. These results are also presented in Tables 3.5 and 3.6 and the gradation charts are presented in Figures 3.1 and 3.2.

For the $37.5 \mathrm{~mm}$ mix, the amount of material retained on the $25 \mathrm{~mm}$ sieve was different between the contractor's lab and the other labs. The contractor's results indicate 89 percent of the aggregate passes the $25 \mathrm{~mm}$ sieve where as the other labs indicate about 94 percent of the material aggregates pass the $25 \mathrm{~mm}$ sieve. The contractor's results fall within the quality control requirements for a mix where as the results from the other labs indicate a violation of the requirement of a maximum of 90 percent of the material passing the $25 \mathrm{~mm}$ sieve for a $37.5 \mathrm{~mm}$ mix. The reason for the discrepancy between the contractor's results and the other results are unknown. It may be speculated that a sampling error could be the source of the differences. With a $37.5 \mathrm{~mm}$ mix, only a few large stones are required to meet the criteria. It is entirely feasible that the sampling missed some of the larger aggregates in the mix, which resulted in the differences in between the field mix gradations and the mix design gradations. Due to the limited size of the project, only a few quality control samples were available, so the discrepancies between the results cannot be resolved.

The issues with the gradations were discovered after the APA samples were prepared for the $37.5 \mathrm{~mm}$ mix. Due to the lag in time between the construction of the project and the research work, it was not possible to obtain more material from the stockpiles used during the construction. As a result, the APA testing was performed on material prepared in accordance with the mix design.

The $12.5 \mathrm{~mm}$ mix also shows discrepancies between the field mix gradations and the mix design gradations. However, all results fall with in the quality control requirements of the WVDOH. Since the differences between the field and mix design gradations were discovered before the APA samples were prepared, it was decided to use the field gradations, as measured by the contractor, for these samples. 
Table 3.5 Gradations of the $37.5 \mathrm{~mm}$ mix

\begin{tabular}{|c|c|c|c|c|c|}
\cline { 3 - 6 } \multicolumn{2}{c|}{} & \multicolumn{4}{c|}{ Field Mixes } \\
\hline $\begin{array}{c}\text { Nominal } \\
\text { Maximum } \\
\text { Size }\end{array}$ & $\begin{array}{c}\mathbf{3 7 . 5} \mathbf{~ m m *} \\
\text { (Design) }\end{array}$ & $\begin{array}{c}\mathbf{3 7 . 5} \mathbf{~ m m} \\
\text { (Central } \\
\text { Lab) }\end{array}$ & $\begin{array}{c}\mathbf{3 7 . 5} \mathbf{~ m m} \\
\text { (D-2) }\end{array}$ & $\begin{array}{c}\mathbf{3 7 . 5} \mathbf{~ m m} \\
\text { (Contractor) }\end{array}$ & $\begin{array}{c}\mathbf{3 7 . 5} \mathbf{~ m m} \\
\text { (WVU Lab) }\end{array}$ \\
\hline $\begin{array}{c}\text { Standard } \\
\text { Sieve Size }\end{array}$ & & & & & \\
\hline $50 \mathrm{~mm}$ & 100 & 100 & 100 & 100 & 100 \\
\hline $37.5 \mathrm{~mm}$ & 96 & 100 & 100 & 100 & 100 \\
\hline $25 \mathrm{~mm}$ & 80 & 94 & 94 & 89 & 95 \\
\hline $19 \mathrm{~mm}$ & 73 & 75 & 76 & 80 & 73 \\
\hline $12.5 \mathrm{~mm}$ & 60 & 58 & 60 & 60 & 56 \\
\hline $9.5 \mathrm{~mm}$ & 52 & 51 & 50 & 51 & 49 \\
\hline $4.75 \mathrm{~mm}$ & 32 & 30 & 30 & 30 & 31 \\
\hline $2.36 \mathrm{~mm}$ & 24 & 22 & 22 & 21 & 23 \\
\hline $1.18 \mathrm{~mm}$ & 18 & 17 & 17 & 17 & 18 \\
\hline $600 \mu \mathrm{m}$ & 13 & 14 & 14 & 14 & 16 \\
\hline $300 \mu \mathrm{m}$ & 10 & 11 & 11 & 11 & 11 \\
\hline $75 \mu \mathrm{m}$ & 4.0 & 5.6 & 5.6 & 5.5 & 4.8 \\
\hline
\end{tabular}

*Gradation used to make APA samples

Table 3.6 Gradations of $12.5 \mathrm{~mm}$ mix

\begin{tabular}{|c|c|c|c|c|c|}
\cline { 3 - 6 } \multicolumn{1}{c|}{} & \multicolumn{5}{c|}{ Field Mixes } \\
\hline $\begin{array}{c}\text { Nominal } \\
\text { Maximum } \\
\text { Size }\end{array}$ & $\begin{array}{c}\mathbf{1 2 . 5} \mathbf{~ m m} \\
\text { (Design) }\end{array}$ & $\begin{array}{c}\mathbf{1 2 . 5} \mathbf{~ m m} \\
\text { (Central } \\
\text { Lab) }\end{array}$ & $\begin{array}{c}\mathbf{1 2 . 5} \mathbf{~ m m} \\
\text { (D-2) }\end{array}$ & $\begin{array}{c}\mathbf{1 2 . 5} \mathbf{~ m m}^{*} \\
(\text { Contractor) }\end{array}$ & $\begin{array}{c}\mathbf{1 2 . 5} \mathbf{~ m m} \\
\text { (WVU Lab) }\end{array}$ \\
\hline $\begin{array}{c}\text { Standard } \\
\text { Sieve Size }\end{array}$ & & & & & \\
\hline $50 \mathrm{~mm}$ & - & - & - & - & - \\
\hline $37.5 \mathrm{~mm}$ & - & - & - & - & - \\
\hline $25 \mathrm{~mm}$ & - & - & - & - & - \\
\hline $19 \mathrm{~mm}$ & 100 & 100 & 100 & 100 & 100 \\
\hline $12.5 \mathrm{~mm}$ & 90 & 97 & 95 & 94 & 95 \\
\hline $9.5 \mathrm{~mm}$ & 68 & 85 & 83 & 82 & 82 \\
\hline $4.75 \mathrm{~mm}$ & 39 & 44 & 42 & 42 & 44 \\
\hline $2.36 \mathrm{~mm}$ & 34 & 31 & 30 & 30 & 33 \\
\hline $1.18 \mathrm{~mm}$ & 19 & 23 & 23 & 23 & 25 \\
\hline $600 \mu \mathrm{m}$ & 14 & 18 & 18 & 18 & 22 \\
\hline $300 \mu \mathrm{m}$ & 10 & 14 & 14 & 14 & 15 \\
\hline $75 \mu \mathrm{m}$ & 4.0 & 7.4 & 7.6 & 7.4 & 6.0 \\
\hline
\end{tabular}

*Gradations used for APA samples 


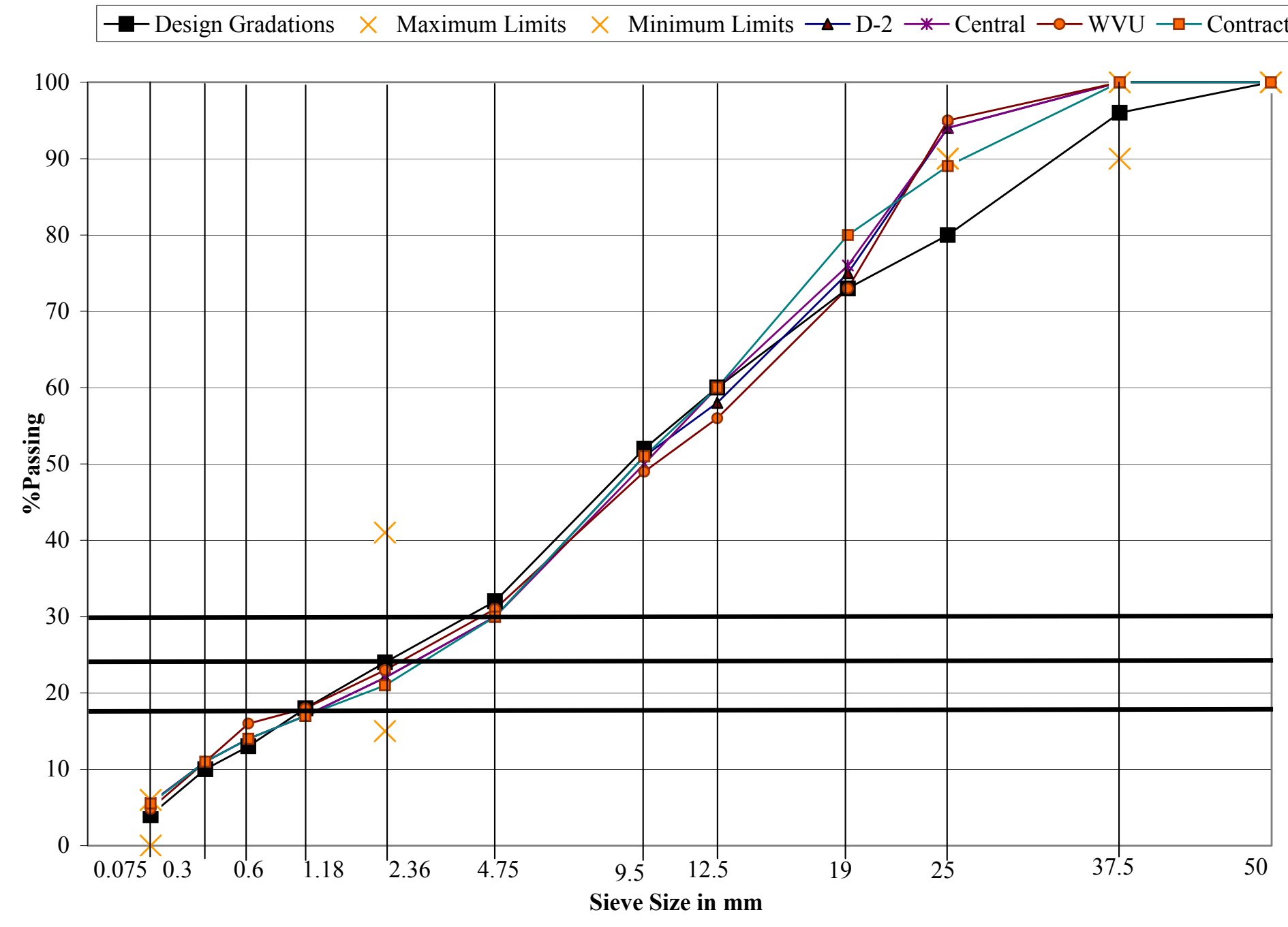

Figure 3.1 Gradation chart for $\mathbf{3 7 . 5} \mathrm{mm}$ mix 


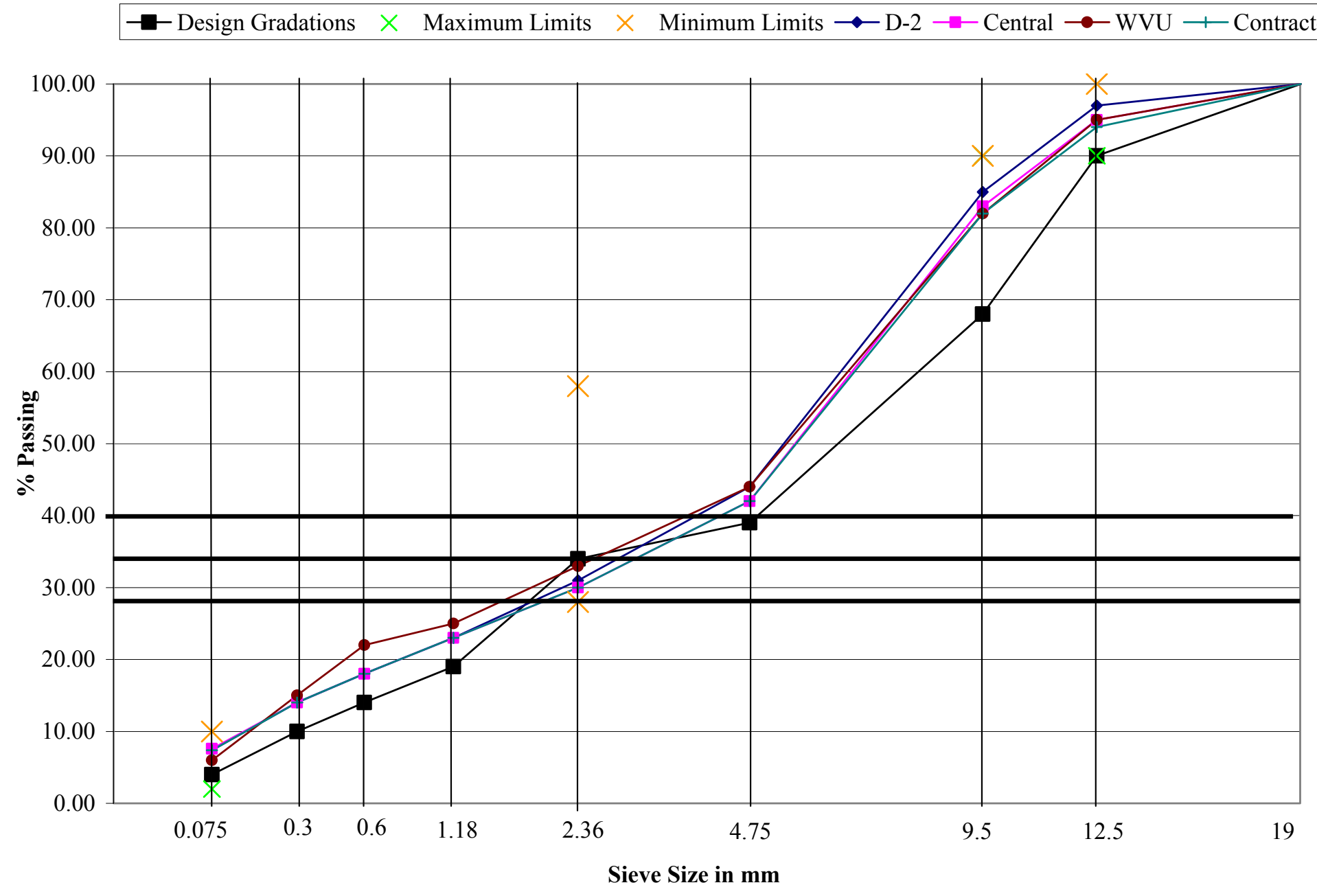

Figure 3.2 Gradation chart for $12.5 \mathrm{~mm}$ mix 


\subsection{THEORETICAL MAXIMUM SPECIFIC GRAVITY}

The materials were proportioned according to the mix design formula to make theoretical maximum specific gravity, $G_{\mathrm{mm}}$, (AASHTO T 209) samples. $\mathrm{G}_{\mathrm{mm}}$ was determined for two samples for each mix and binder to check variability. The values of $\mathrm{G}_{\mathrm{mm}}$ for these samples were within the precision limits as specified in AASHTO T 209. Table 3.7 presents the average $\mathrm{G}_{\mathrm{mm}}$ for the two mixes using three binders. Field samples of HMA were obtained for the mixes made using PG 76-22 binder. The average $\mathrm{G}_{\mathrm{mm}}$ of these samples is also presented in Table 3.7. The samples made in the lab for $37.5 \mathrm{~mm}$ mix used design gradations, for the $12.5 \mathrm{~mm}$ mix field gradations were used. Detailed $\mathrm{G}_{\mathrm{mm}}$ data for the samples are presented in Appendix B.

Table 3.7 Average $G_{\mathrm{mm}}$ of HMA for the two mixes using three asphalt binders

\begin{tabular}{|c|c|c|c|c|}
\hline Asphalt Grade & $\begin{array}{c}\text { 37.5 mm Mix } \\
\text { (Laboratory) }\end{array}$ & $\begin{array}{c}\text { 37.5 mm Mix } \\
\text { (Field) }\end{array}$ & $\begin{array}{c}\text { 12.5 mm Mix } \\
\text { (Laboratory) }\end{array}$ & $\begin{array}{c}\mathbf{1 2 . 5} \text { mm Mix } \\
\text { (Field) }\end{array}$ \\
\hline PG 64-22 & 2.544 & - & 2.541 & - \\
\hline PG 70-22 & 2.550 & - & 2.539 & - \\
\hline PG 76-22 & 2.553 & 2.550 & 2.540 & 2.544 \\
\hline
\end{tabular}

\subsection{BULK SPECIFIC GRAVITY}

Materials were proportioned according to mix design and contractor's gradations to make samples for checking bulk specific gravity, $\mathrm{G}_{\mathrm{mb}}$. AASHTO T 166 standard method was followed. $G_{m b}$ was checked for the samples prepared in the laboratory. The samples were compacted in the SGC to N-design, 125 gyrations. Two samples were fabricated for each field and mix design for the two mixes. Table 3.8 presents average $\mathrm{G}_{\mathrm{mb}}$ based on the laboratory results presented in Appendix B.

Table 3.8 Average $G_{m b}$ for the HMA mixes

\begin{tabular}{|c|c|c|c|}
\hline \multicolumn{2}{|c|}{ 37.5 mm mix } & \multicolumn{2}{c|}{$\mathbf{1 2 . 5}$ mm mix } \\
\hline $\begin{array}{c}\text { Design } \\
\text { Gradations }\end{array}$ & $\begin{array}{c}\text { Contractor's } \\
\text { Gradation }\end{array}$ & $\begin{array}{c}\text { Design } \\
\text { Gradations }\end{array}$ & $\begin{array}{c}\text { Contractor's } \\
\text { Gradation }\end{array}$ \\
\hline 2.521 & 2.506 & 2.291 & 2.325 \\
\hline
\end{tabular}




\subsection{PREPARING APA SPECIMEN}

The materials for making the specimens were proportioned according to the mix design. These proportions depend on the weight of the sample, which depends on the mix type, which in turn depends on the value of the $\mathrm{G}_{\mathrm{mm}}$. Table 3.7 demonstrates that the $\mathrm{G}_{\mathrm{mm}}$ changes for each mix and also for different binder. The APA sample weight was estimated taking into consideration the volume of the specimen to be compacted. While making specimens for APA, $7 \pm 0.5$ percent air voids is required. The following equations were used to estimate the weight of the samples.

$$
\begin{aligned}
& \mathrm{V}_{\mathrm{mm}} \approx 0.93 * \mathrm{~V}_{\mathrm{C}} \\
& \mathrm{V}_{\mathrm{C}}=\Pi * \mathrm{R}^{2 *} \mathrm{H} \\
& \mathrm{W}_{\mathrm{m}}=\mathrm{V}_{\mathrm{mm}} / \mathrm{G}_{\mathrm{mm}}
\end{aligned}
$$

Where,

$\mathrm{V}_{\mathrm{mm}}=$ Volume of the mix

$\mathrm{V}_{\mathrm{C}}=$ Gross volume of the sample

$\mathrm{R}=$ Radius of the mold

$\mathrm{H}=$ Height of the sample

$\mathrm{W}_{\mathrm{m}}=$ Weight of the mix

$\mathrm{G}_{\mathrm{mm}}=$ Theoretical maximum specific gravity of the mix

The samples were weighed according to the mix design proportions for the $37.5 \mathrm{mix}$ and the contractor's field gradations for the $12.5 \mathrm{~mm}$ mix. The blended aggregate samples were then heated to the mixing temperatures corresponding to each binder shown in Table 3.1. The asphalt binder was heated to the desired temperature and weighed into the heated aggregate. The aggregate and the binder were mixed in a heated mixer until a homogeneous mixture is achieved. The sample was then placed in a pan and cured in an oven at compaction temperature for a period of two hours. For every half hour the sample was taken out of the ovens and mixed to achieve proper curing. After 
curing, the sample was transferred into molds and placed in the SGC for compaction. All samples were compacted to a height of $75 \mathrm{~mm}$.

HMA samples that were obtained from the field were initially sampled following the specification given in AASHTO T 168, and placed in the oven for half hour at the compaction temperatures to achieve temperatures for compacting in the SGC.

With experience gained from preparation the following observations were made:

- For the $37.5 \mathrm{~mm}$ mix, the aggregate had to be mixed for longer periods of time compared to a $12.5 \mathrm{~mm}$ mix to get the aggregate coated properly with asphalt.

- The slag aggregate had to be heated to a higher temperature than the limestone aggregate, since the slag looses heat rapidly and becomes difficult to compact it in SGC. This observation is based on the fact that it takes more gyrations to compact the slag mixes than the limestone mixes.

- The PG 76-22 binder had to be heated to higher temperature because of presence of polymers. If allowed to cool it becomes very difficult to mix and compact the mix. So the mixing and compaction process has to be accomplished more rapidly when working with modified binders compared to unmodified binders.

- Flat and elongated particles in the 37.5 mix caused difficulty in compacting the specimens for the APA. It was necessary to remove these particles to get consistent compaction results.

\subsection{SPECIMENS FOR APA TESTING}

The APA specimens were made to $75 \mathrm{~mm}$ height with $7.0 \pm 0.5$ percent air voids. The specimens out of this air voids range were discarded and replacement specimens were fabricated. Samples mixed in the laboratory and HMA samples collected from the field were tested in the APA. Specimens were made using the $37.5 \mathrm{~mm}$ mix and the 12.5 mm mix. Twelve specimens were made for each mix designs from the field HMA and six each for the samples mixed in the laboratory. 
For the specimens made in the laboratory, the final weight of the samples was determined after making several trial samples. For the $37.5 \mathrm{~mm}$ mix, the design mix as given by the contractor was used. About 50 percent of the samples prepared in the laboratory for the $37.5 \mathrm{~mm}$ mix had to be discarded due to unacceptable void content. This problem of achieving percent air with in the range was not observed when the specimens were made using the field HMA. The difficulty in fabricating samples with the 37.5 mix design gradations was attributed to the very coarse nature of the mix. Since the production material had a finer gradation, there was considerably less variation in preparing the samples.

Both the laboratory prepared and field samples of the $12.5 \mathrm{~mm}$ mix could be compacted to the desired void content. Only about 5 percent of the samples had to be discarded due to air void variation.

\subsection{ASPHALT PAVEMENT ANALYZER RUNS}

The layout of the APA test bed is shown in Figure 3.3. Six cylindrical specimens (150 mm (diameter) x $75 \mathrm{~mm}$ (tall)) were tested in each run of the APA. All the specimens were tested at $140^{\circ} \mathrm{F}$ with a hose pressure of $100 \pm 5 \mathrm{psi}$ and wheel load of $100 \pm 5 \mathrm{lb}$. Rut depth measurements were taken after 8000 cycles. The rut depths were measured with the help of a rut depth measurement template and a Digimatic depth gauge. The rut depth was measured to the nearest $0.1 \mathrm{~mm}$. The depth was measured at two locations, front and back of the specimen, for each specimen and an average rut value was reported. The front and rear specimens were the same mix for each APA run. The average rut depth of the front and rear specimen was used as the sample rut depth. 


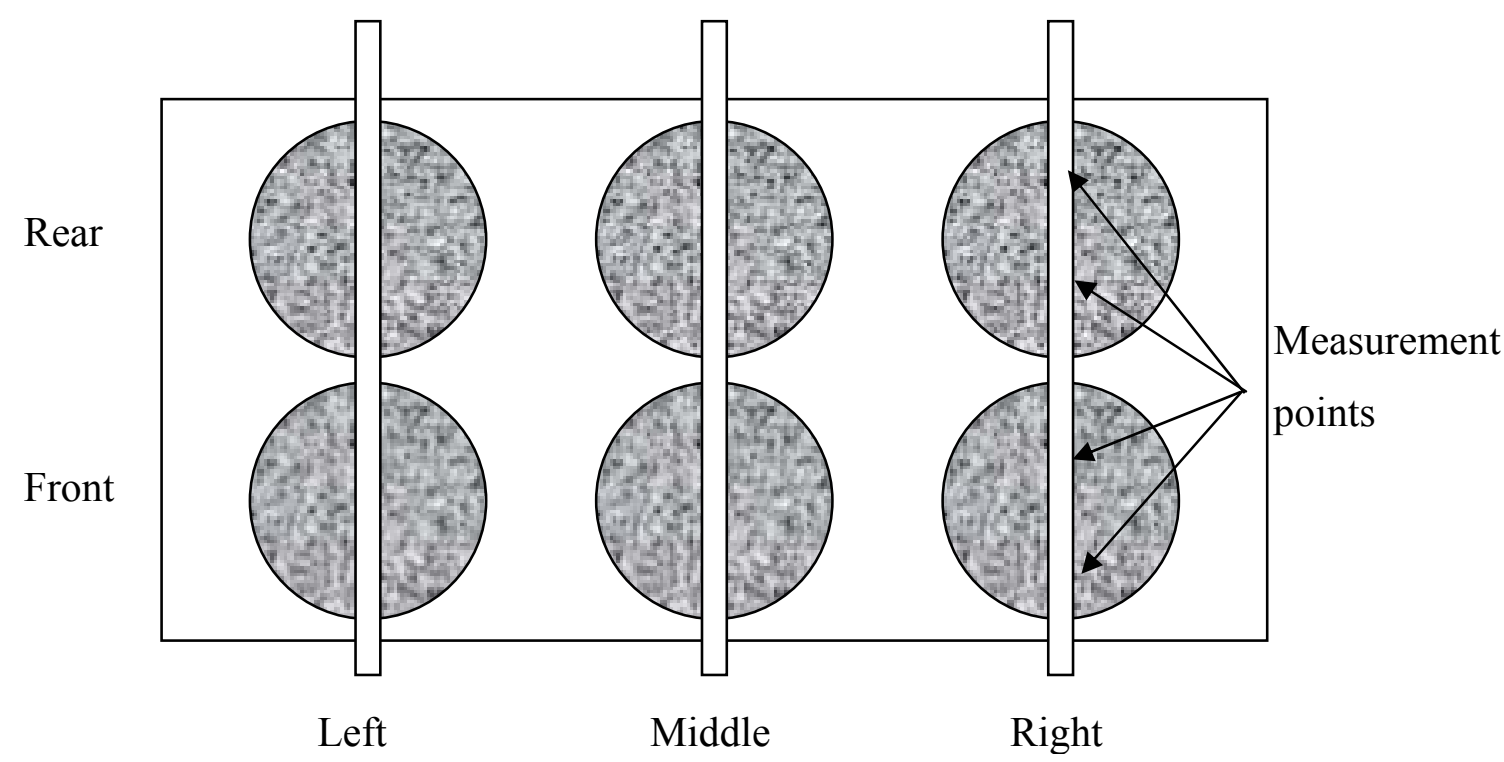

Figure 3.3 APA specimen layout

Twelve specimens were made using the HMA from the field for each mix design. Six specimens were mixed in the laboratory and compacted for each mix design using the three different binders. The sequence in which these specimens were tested in the APA is presented in Table 3.9.

Table 3.9 Laboratory testing pattern for APA samples

\begin{tabular}{|c|c|c|c|c|}
\hline $\begin{array}{l}\text { APA Testing } \\
\text { Sequence }\end{array}$ & $\begin{array}{l}\text { Number of } \\
\text { Samples }\end{array}$ & $\mathbf{3 7 . 5} \mathbf{~ m m ~ M i x}$ & $\mathbf{1 2 . 5} \mathbf{~ m m ~ M i x}$ & Binder Type \\
\hline 1 & 12 & 12 & & PG 76-22 \\
\hline 2 & 12 & & 12 & PG 76-22 \\
\hline & & & & $\begin{array}{c}\text { PG 76-22 } \\
\text { PG 70-22 } \\
\text { PG 64-22 }\end{array}$ \\
\hline 3 & 18 & 18 & & $\begin{array}{c}\text { PG 76-22 } \\
\text { PG 70-22 } \\
\end{array}$ \\
& 18 & & 18 & PG 64-22 \\
\hline
\end{tabular}

To minimize the effects of position in the APA machine a sample was prepared and tested in each location. The testing sequence for laboratory mixes are presented in Tables 3.10 and 3.11 . 
In Table 3.11, the treatment number assigned depends on the mix type and binder grade. For example, the number 3 is for $37.5 \mathrm{~mm}$ mix and PG 64-22 binder. In Table 3.11, the APA sequence No. 3 is the third run in APA for field gradation specimens, in which the $37.5 \mathrm{~mm}$ mix was tested in position left, middle and right for PG 64-22, PG 7622 and PG 70-22 binders, respectively. Rut depths data for all specimens tested are presented in Appendix C.

Table 3.10 Treatments used

\begin{tabular}{|c|c|c|}
\hline Treatment No. & Mix Design & Asphalt Grade \\
\hline 1 & $37.5 \mathrm{~mm}$ & $76-22$ \\
\hline 2 & $37.5 \mathrm{~mm}$ & $70-22$ \\
\hline 3 & $37.5 \mathrm{~mm}$ & $64-22$ \\
\hline 4 & $12.5 \mathrm{~mm}$ & $76-22$ \\
\hline 5 & $12.5 \mathrm{~mm}$ & $70-22$ \\
\hline 6 & $12.5 \mathrm{~mm}$ & $64-22$ \\
\hline
\end{tabular}

Table 3.11 Testing sequence for laboratory mixes

\begin{tabular}{|c|c|c|c|}
\hline $\begin{array}{c}\text { APA Test } \\
\text { Sequence }\end{array}$ & Left & $\begin{array}{c}\text { Position } \\
\text { Middle }\end{array}$ & Right \\
\hline 1 & $1^{*}$ & 2 & 3 \\
\hline 2 & 2 & 3 & 1 \\
\hline 3 & 3 & 1 & 2 \\
\hline 4 & 4 & 5 & 6 \\
\hline 5 & 5 & 6 & 4 \\
\hline 6 & 6 & 4 & 5 \\
\hline
\end{tabular}

Number indicates treatment as defined in Table 3.10. Rut depth is an average of rut depth at front and back for a sample. 


\section{CHAPTER 4 RESULTS AND DATA ANALYSIS}

Using the data as reported in Chapter 3, the results of the experiment were analyzed. First, due to the observed differences between the mix design and the field mix, the volumetric properties of the mixes were evaluated. Then statistical analysis of the APA results were performed.

This chapter also documents some observations of field performance on the intersection. This information was collected by WVDOH personnel.

\subsection{VOLUMETRIC PROPERTIES}

Samples with the mix design and contractor's field gradations were prepared to check the volumetric properties of the $37.5 \mathrm{~mm}$ and $12.5 \mathrm{~mm}$ mixes. The results are summarized in Table 4.1. The volumetric properties for the specimens compacted to $\mathrm{N}$-design, 125 gyrations, do not meet the criteria. For the $37.5 \mathrm{~mm}$ mix, VTM is 1.3 percent for design gradations, which is below the criteria of 4 percent for specimens compacted to $\mathrm{N}$-design. When the samples were made using the field gradations the VTM is 1.7 percent which does not meet the criteria. The VMA percent is lower than criteria for both the gradations. VFA are higher than the criteria by 10 and 4 percent for the mix design and field gradations, respectively. For the $12.5 \mathrm{~mm}$ mix, VTM is 9.8 percent for the design gradations, which is 100 percent more than the criteria of 4 percent. The VTM of the field gradation mix was 8.6 percent. The $12.5 \mathrm{~mm}$ mix VMA is within the criteria for both gradations. However, due to the high air voids of the $12.5 \mathrm{~mm}$ mix, the VFA is half design criteria for both gradations.

The discrepancy in these results is disconcerting. It calls into question the validity of either the mix design or the results produced in the WVU Asphalt Technology Laboratory. However, these volumetric properties do not have a direct influence on the objectives of this research. The rutting potential of the mixes used on the Fort Gay project, and the influence of binder selection on rutting potential can still be evaluated. 
Table 4.1 Volumetric properties of mixes

\begin{tabular}{|c|c|c|c|c|}
\hline Properties & Criteria & $\begin{array}{c}\text { Job Mix } \\
\text { Values }\end{array}$ & $\begin{array}{c}\text { Design } \\
\text { gradations, } \\
\text { Lab } \\
\end{array}$ & $\begin{array}{c}\text { Contractor's } \\
\text { gradations, } \\
\text { Lab } \\
\end{array}$ \\
\hline \multicolumn{5}{|l|}{$37.5 \mathrm{~mm}$ mix } \\
\hline$\%$ Binder & - & 4.0 & 4.0 & 3.6 \\
\hline VTM \% & 4 & 4.0 & 1.3 & 1.7 \\
\hline VMA \% & $\min 11.0$ & 13.0 & 9.7 & 8.5 \\
\hline VFA $\%$ & $65-75$ & 68.0 & 87.1 & 79.6 \\
\hline $\mathrm{G}_{\mathrm{sb}}$ & - & 2.680 & 2.680 & 2.639 \\
\hline $\mathrm{G}_{\mathrm{mm}}$ & - & - & 2.553 & 2.550 \\
\hline $\mathrm{G}_{\mathrm{mb}}$ & - & - & 2.521 & 2.506 \\
\hline \multicolumn{5}{|l|}{$12.5 \mathrm{~mm}$ mix } \\
\hline$\%$ Binder & - & 5.1 & 5.1 & 5.2 \\
\hline VTM \% & 4 & 4.0 & 9.8 & 8.6 \\
\hline VMA \% & $\min 14.0$ & 14.5 & 18.3 & 14.4 \\
\hline VFA $\%$ & $65-75$ & 70.0 & 46.3 & 40.1 \\
\hline $\mathrm{G}_{\mathrm{sb}}$ & - & 2.660 & 2.660 & 2.574 \\
\hline $\mathrm{G}_{\mathrm{mm}}$ & - & - & 2.540 & 2.544 \\
\hline $\mathrm{G}_{\mathrm{mb}}$ & - & - & 2.291 & 2.325 \\
\hline
\end{tabular}

\subsection{APA RESULTS}

Twelve specimens made using field HMA were tested in the APA to check for rutting potential. Six specimens for each mix design and corresponding binders were made in the laboratory. The rut depth and the percent air are presented in Tables 4.2 and 4.3. The complete rut depth and air void data sets are provided in Appendix C. The results in Tables 4.2 and 4.3 are an average of rut depth and percent air of two specimens at a single position, left, middle or right. The rut depth for each specimen is measured at front and back of the specimen. Analysis was done between the three binders and three positions for the specimens made in the lab for each mix. For the samples made from field HMA, analysis was done between the positions and between the two mix designs.

Figure 4.1 is an example of the sample after it has been tested in the APA. Other examples are presented in Appendix D. 
Table 4.2 Average rut values with percent air for the field specimens with position

\begin{tabular}{|c|c|c|c|c|}
\hline $\begin{array}{c}\text { APA } \\
\text { Sequence }\end{array}$ & Mix Type & $\begin{array}{c}\text { Left } \\
\text { Rd (air)* }\end{array}$ & $\begin{array}{c}\text { Middle } \\
\text { Rd (air)* }\end{array}$ & $\begin{array}{c}\text { Right } \\
\text { Rd (air)* }\end{array}$ \\
\hline 1 & $37.5 \mathrm{~mm}$ & $1.91(6.3)$ & $1.96(6.3)$ & $2.65(6.5)$ \\
\hline 2 & $37.5 \mathrm{~mm}$ & $2.32(6.7)$ & $2.04(6.3)$ & $2.76(6.7)$ \\
\hline Average & $37.5 \mathrm{~mm}$ & $2.12(6.5)$ & $2.00(6.3)$ & $2.70(6.6)$ \\
\hline 3 & $12.5 \mathrm{~mm}$ & $1.55(6.2)$ & $1.42(6.4)$ & $1.95(6.6)$ \\
\hline 4 & $12.5 \mathrm{~mm}$ & $1.62(6.6)$ & $1.71(6.6)$ & $1.52(6.4)$ \\
\hline Average & $12.5 \mathrm{~mm}$ & $1.58(6.4)$ & $1.56(6.5)$ & $1.73(6.5)$ \\
\hline
\end{tabular}

$* \mathrm{Rd}$ is rut depth; (air) is percent air for the specimens

Table 4.3 Average rut values with percent air for the lab specimens with position

\begin{tabular}{|c|c|c|c|c|}
\hline & & \multicolumn{3}{|c|}{ Position } \\
\hline Mix & Binder Type & $\begin{array}{c}\text { Left } \\
\text { Rd (air)* }\end{array}$ & $\begin{array}{c}\text { Middle } \\
\text { Rd (air)* }\end{array}$ & $\begin{array}{c}\text { Right } \\
\text { Rd (air)* }\end{array}$ \\
\hline $37.5 \mathrm{~mm}$ & $64-22$ & $9.91(6.7)$ & $6.96(6.5)$ & $8.33(6.9)$ \\
\hline $37.5 \mathrm{~mm}$ & $70-22$ & $9.61(7.2)$ & $7.47(7.2)$ & $7.06(7.0)$ \\
\hline $37.5 \mathrm{~mm}$ & $76-22$ & $4.62(6.8)$ & $2.90(7.1)$ & $3.48(7.0)$ \\
\hline $12.5 \mathrm{~mm}$ & $64-22$ & $3.49(6.8)$ & $4.06(6.6)$ & $3.80(6.7)$ \\
\hline $12.5 \mathrm{~mm}$ & $70-22$ & $2.15(6.7)$ & $2.22(7.1)$ & $2.77(7.1)$ \\
\hline $12.5 \mathrm{~mm}$ & $76-22$ & $1.59(7.5)$ & $0.92(7.4)$ & $1.62(7.1)$ \\
\hline
\end{tabular}

* $\mathrm{Rd}$ is rut depth; (air) is percent air for the specimens

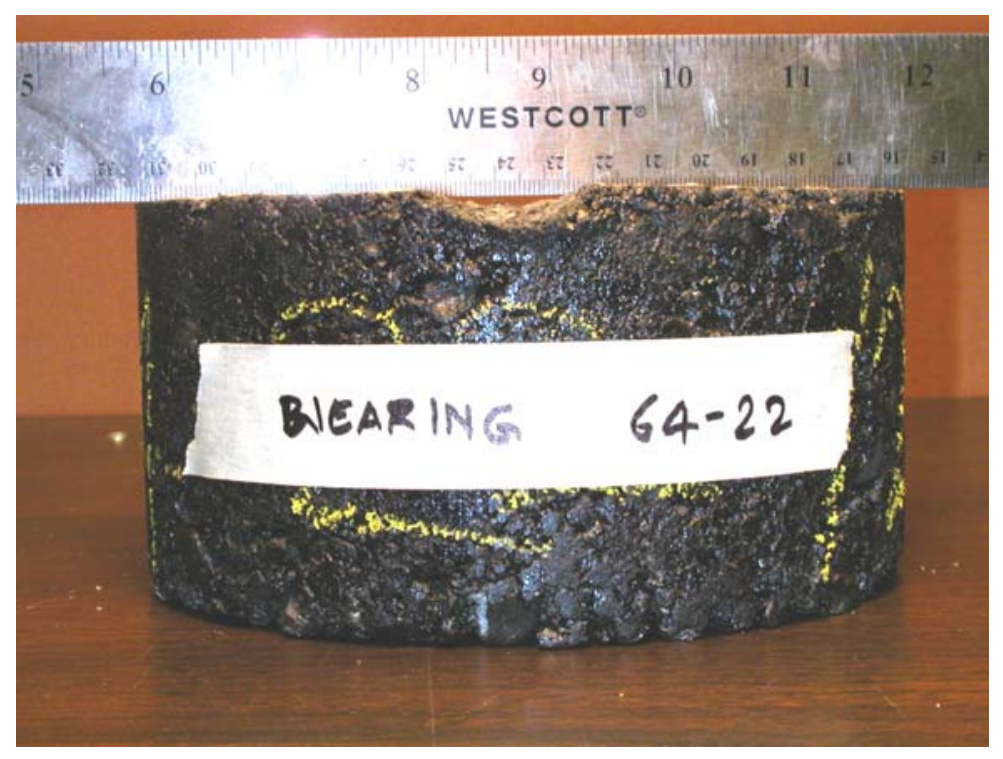

Figure 4.1 Sample after APA testing, $12.5 \mathrm{~mm}$ specimen, field gradation and PG 64-22 binder 


\subsection{DATA ANALYSIS}

In order to examine the effect of binder and position in APA on the depth of rut, two sample equal variance Student-t tests were conducted. Since the objective of the experiment was to compare the effect of binders and position in APA on mean rut depth, the null hypothesis for the test has been assumed as $\mu_{1}-\mu_{2}=0$. The details of the $\mathrm{t}$-test are given below:

Null Hypothesis:

$\mathrm{H}_{\mathrm{o}}: \mu_{1}-\mu_{2}=0$

Alternative Hypothesis;

$\mathrm{H}_{\mathrm{a}}: \mu_{1}-\mu_{2} \neq 0$

Test Statistic:

$\mathrm{t}=\frac{\bar{X}_{1}-\bar{X}_{2}-\left(\mu_{1}-\mu_{2}\right)}{\sqrt{\left(\left(n_{1}-1\right) * s_{1}^{2}\right)+\left(\left(n_{2}-1\right) * s_{2}^{2}\right)}} * \sqrt{\frac{n_{1} * n_{2} *\left(n_{1}+n_{2}-2\right)}{n_{1}+n_{2}}}$

Where,

$\bar{X}_{1}$ and $\bar{X}_{2}$ are sample means

$s_{1}^{2}$ and $s_{2}^{2}$ are sample variances

$\mathrm{n}_{1}$ and $\mathrm{n}_{2}$ are the number of observations

The ttest function in Microsoft's Excel spread sheet was used to perform the Student $t$ analysis. According to the help function in Excel, "This t-test form assumes that the means of both data sets are equal; it is referred to as a homoscedastic t-test." The value returned by the function, P-value, is the probability that the two means of the samples are equal. By comparing the computed probability to the desired significance level, the null hypothesis can be either accepted or rejected. In keeping with traditional 
practices, a significance level of 5 percent was selected for this analysis. Table 4.4 and 4.5 presents the P-values for the field and laboratory samples respectively.

Table 4.4 shows that for the field mixes, the null hypothesis cannot be rejected for the tests on testing position. This indicates there was no effect of testing position within the APA on the results produced. However, the P-value for the comparison of the $12.5 \mathrm{~mm}$ and $37.5 \mathrm{~mm}$ mixes is less than 5 percent, indicating the null hypotheses should be rejected, which supports a conclusion that the rutting potential of these mixes is different. The $12.5 \mathrm{~mm}$ mix rutted less than $37.5 \mathrm{~mm}$ mix. This result is counter initiative as normally rutting is reduced as aggregate size increases. However, the $12.5 \mathrm{~mm}$ mix used in this research was composed of 95 percent slag and 5 percent limestone, where as the $37.5 \mathrm{~mm}$ mix is all limestone. It is hypothesized that the very high texture of the slag was the predominant factor affecting rutting of these mixes.

Table 4.5 presents the results of the Student $t$ analysis for the laboratory prepared samples. As with the field mix, the laboratory prepared mixes did not show a difference between the test position in the APA. Also, there was a significant difference between the 12.5 and $37.5 \mathrm{~mm}$ mixes, with the $12.5 \mathrm{~mm}$ mix showing less rutting. The comparison of binder PG 76-22 Vs PG 70-22 and PG 76-22 Vs PG 64-22 showed the null hypothesis was not accepted and hence there was a significant difference between the rut depths. Since the PG 76-22 mixes rutted less than the mixes with the other binders leading to a conclusion that the rutting potential is reduced with the use of the PG 76-22 binder. There was no significant difference between the PG 70-22 and PG 64-22 binders for the $37.5 \mathrm{~mm}$ mix. However, for the $12.5 \mathrm{~mm}$ mix, the null hypothesis was not accepted indicating a difference in the performance of the mixes for the PG 70-22 and PG 64-22 binders. The average rutting potential for the PG 70-22 was less than for the PG 64-22. 
Table 4.4 P-Values for the field samples

\begin{tabular}{|c|c|c|}
\hline Designation & Comparison & P-Value \\
\hline P1 & Left Vs Middle Position & 0.773 \\
\hline P2 & Left Vs Right Position & 0.321 \\
\hline P3 & Middle Vs Right Position & 0.228 \\
\hline P4 & $37.5 \mathrm{~mm}$ Vs $12.5 \mathrm{~mm}$ & $\mathbf{0 . 0 4 3}$ \\
\hline
\end{tabular}

Table 4.5 P-values for lab mixed samples

\begin{tabular}{|c|c|c|c|}
\hline Designation & Comparison & P-Value & Mix Type \\
\hline P 5 & Left Vs Middle & 0.369 & $37.5 \mathrm{~mm}$ \\
\hline P 6 & Left Vs Right & 0.478 & $37.5 \mathrm{~mm}$ \\
\hline P 7 & Middle Vs Right & 0.815 & $37.5 \mathrm{~mm}$ \\
\hline P 8 & $76-22$ Vs 70-22 & $\mathbf{0 . 0 1 0}$ & $37.5 \mathrm{~mm}$ \\
\hline P 9 & $76-22$ Vs 64-22 & $\mathbf{0 . 0 0 9}$ & $37.5 \mathrm{~mm}$ \\
\hline P 10 & 70-22 Vs 64-22 & 0.776 & $37.5 \mathrm{~mm}$ \\
\hline P 11 & Left Vs Middle & 0.993 & $12.5 \mathrm{~mm}$ \\
\hline P 12 & Left Vs Right & 0.724 & $12.5 \mathrm{~mm}$ \\
\hline P 13 & Middle Vs Right & 0.781 & $12.5 \mathrm{~mm}$ \\
\hline P 14 & 76-22 Vs 70-22 & $\mathbf{0 . 0 2 9}$ & $12.5 \mathrm{~mm}$ \\
\hline P 15 & $76-22$ Vs 64-22 & $\mathbf{0 . 0 0 5}$ & $12.5 \mathrm{~mm}$ \\
\hline P 16 & $70-22$ Vs 64-22 & $\mathbf{0 . 0 0 1}$ & $12.5 \mathrm{~mm}$ \\
\hline P 17 & $37.5 \mathrm{~mm}$ Vs 12.5mm & $\mathbf{0 . 0 0 4}$ & \multicolumn{1}{|c}{} \\
\cline { 1 - 3 } & \multicolumn{2}{|l}{}
\end{tabular}

Finally, the rutting potential of field and laboratory mixes was compared, with the results shown in Table 4.6. There is not sufficient evidence from the data to reject the null hypothesis, indicating the rutting potential of the field and laboratory prepared mixes is the same.

Table 4.6 Comparison of field and laboratory mixes

\begin{tabular}{|c|c|}
\hline Comparison & P-value \\
\hline 37.5 field Vs lab & 0.064 \\
\hline 12.5 field Vs lab & 0.353 \\
\hline
\end{tabular}

\subsection{COMPARISON TO PREVIOUS WV SUPERPAVE MIXES}

The WVU Asphalt Technology Laboratory has evaluated the rutting potential of Superpave mixes placed throughout the state for several years. Figure 4.2 shows a 
summary of the results from this research as compared to the average data from previous projects. All the PG 76-22 mixes demonstrate less rutting potential than has been observed on previous projects. The $37.5 \mathrm{~mm}$ mix has higher rutting potential with PG 70-22 and PG 64-22 binder that has been observed on other projects. The WVDOH has not constructed other $12.5 \mathrm{~mm}$ mixes. Figure 4.2 indicates the rutting potential of the $12.5 \mathrm{~mm}$ mix used on the Fort Gay project is lower than the average rutting potential of both 37.5 and $9.5 \mathrm{~mm}$ mixes used on previous projects.

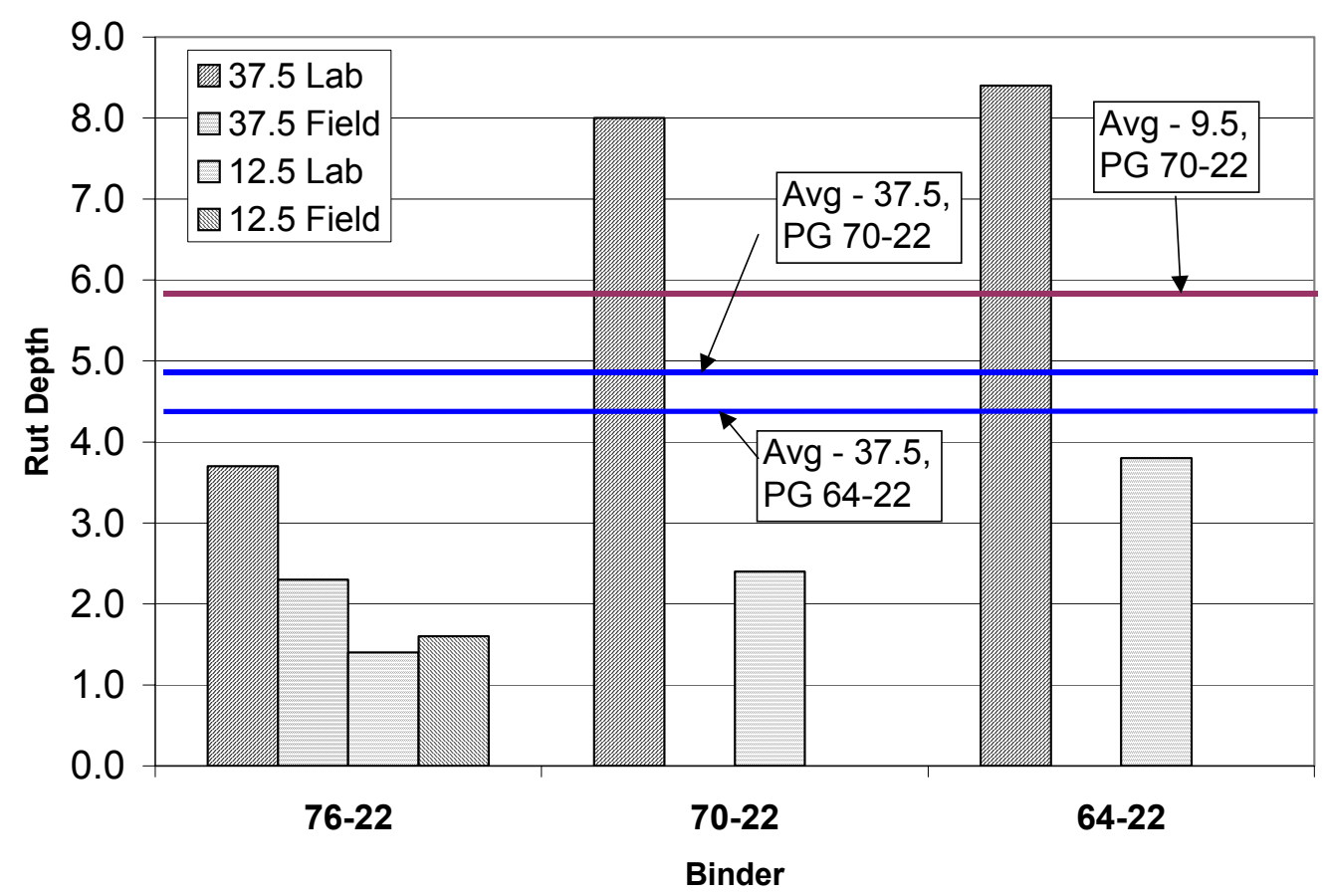

Figure 4.2 Comparison of Fort Gay mixes to other WVDOH Superpave mixes

\subsection{FIELD OBSERVATIONS}

Since construction in June 2002, WVDOH personnel have periodically surveyed the pavement. The most recent survey was done on January 15, 2003. At that time no, distress was observed on the pavement. As shown on Figure 4.3 the pavement is in excellent condition. There was no measurable rutting over a three foot straight edge. There is some mild consolidation of the pavement, less than 1/4 inch. However, this consolidation is not limited to the wheel path. 


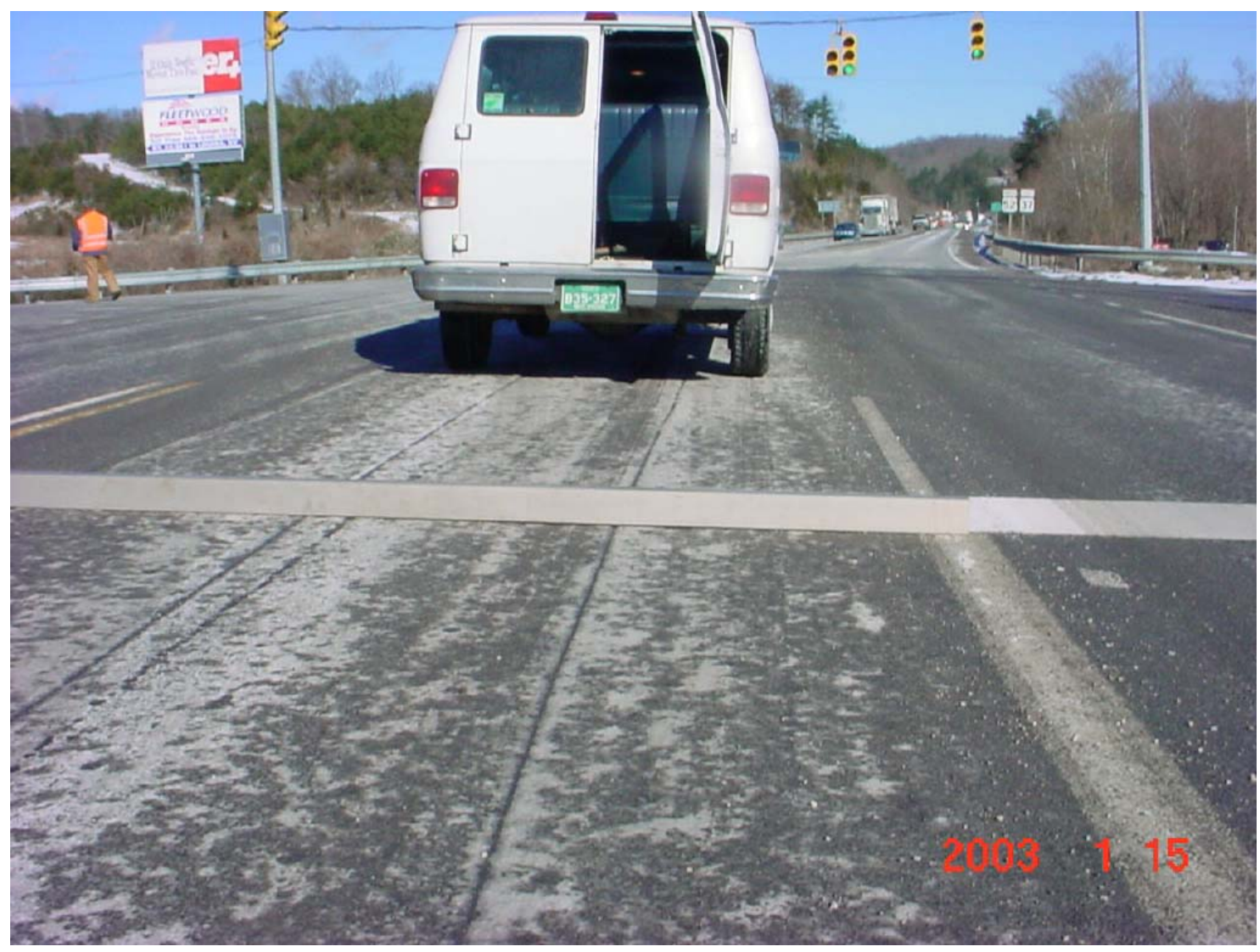

Figure 4.3 Fort Gay Intersection in Mid-January 


\section{CHAPTER 5 CONCLUSIONS AND RECOMMENDATIONS}

\subsection{CONCLUSIONS}

The reconstruction of the Fort Gay intersection used materials that had not been field evaluated in West Virginia. In particular, the state had not used polymer-modified binders and $12.5 \mathrm{~mm}$ wearing course. Initial field assessments of the performance of the intersection indicate that, to date rutting is not a problem. However, the pavement was constructed in July 2002 so it has not endured a full summer of traffic loading. Even with this caveat, based on the initial assessment, it is anticipated that the intersection will perform well. As shown in Figure 1.2 conventional treatments on the intersection were failing in six months.

Due to the innovative materials used on the project, it was decided to perform a laboratory evaluation of the rutting potential of these materials. In particular, the laboratory evaluation using the Asphalt Pavement Analyzer allowed an economical means for comparing the relative performance of these materials compared to conventional materials. As demonstrated through the testing and statistical analysis, the mixes containing the polymer-modified PG 76-22 asphalt performed better than the mixes with unmodified binders.

Comparison of the mixes with the unmodified binders produced mixed results. The expectation is that PG 70-22 mixes should perform better than PG 64-22 mixes and this was the case for the $12.5 \mathrm{~mm}$ mix. However, the $37.5 \mathrm{~mm}$ mix did not show a statistically different performance with the two unmodified binders. There could be an interaction effect between the aggregate type and the binder's contribution to rutting resistance. The $12.5 \mathrm{~mm}$ mix predominantly contained slag aggregates, which have very high surface texture. All the 12.5 mixes showed lower rutting potential than the $37.5 \mathrm{~mm}$ mixes, which had 100 percent limestone aggregates. This difference in performance was attributed to the texture of the aggregates.

Figure 4.2 demonstrates that the mixes used for the Fort Gay intersection have a lower rutting potential than other Superpave mixes that have been placed in West 
Virginia. The $37.5 \mathrm{~mm}$ mix with the PG 76-22 binder had an average rut depth of less than $3 \mathrm{~mm}$. The average rut depth for $37.5 \mathrm{~mm}$ mixes placed on other projects in the state have rut depth of approximately $4.5 \mathrm{~mm}$. However, these projects used unmodified binders. Comparing the results of the $37.5 \mathrm{~mm}$ mixes with the Fort Gay aggregates and unmodified binders to other $37.5 \mathrm{~mm}$ mixes constructed in the state indicates that the mixes used for the Fort Gay intersection would not perform as well as, the average $37.5 \mathrm{~mm}$ mix, if an unmodified binder had been used.

Figure 4.2 also demonstrates that the $12.5 \mathrm{~mm}$ mix with the PG 76-22 binder had an average rut depth of less than $2 \mathrm{~mm}$, which is much better than the results obtained for other mixes in the state, regardless on the nominal maximum aggregate size. Since the $12.5 \mathrm{~mm}$ mix was being used for the first time there are no direct comparisons available for quantifying this relative performance. Since the superior performance was also obtained with unmodified binders, it is speculated that the excellent performance is due to the nature of the slag aggregates used in the mix rather than the nominal maximum aggregate size of the aggregate.

One of the concerns about APA testing is that the position of the sample in the machine can affect the results. Statistical evaluation of the data indicated that position did not affect the results in a statistically significant manner. Kanneganti (2002) using the same APA test machine also arrived at this conclusion.

During the preparation of the samples, it was noted that the mixes with the polymer-modified binder were more difficult to mix and compact. Any cooling of the mix greatly increases the viscosity of the asphalt and the stiffness of the mix. Minimizing the mixing and compaction times with good laboratory practices is more critical with the modified binder mixes.

\subsection{ISSUES FOR FUTURE STUDY}

The APA samples are limited to $75 \mathrm{~mm}$ tall. Generally, in asphalt testing, the sample dimensions should be four times the nominal-maximum aggregate size diameter. Thus, the APA sample size in reality is only appropriate for mixes with a nominal-maximum aggregate size of $19 \mathrm{~mm}$ or less. Testing $37.5 \mathrm{~mm}$ mixes would require a sample size of $150 \mathrm{~mm}$. It may be feasible to prepare samples in the Superpave 
Gyratory Compactor to this height, but this has not been evaluated. Testing samples of this height would require a redesign of the Asphalt Pavement Analyzer. The machine's design limits the sample height to $75 \mathrm{~mm}$.

Similarly, the flat and elongated particles can cause issues with the compaction of mixes in the SGC. The Superpave specification limits flat and elongated particles to less than 10 percent of the volume of the mix, however it was noted while preparing the samples that flat and elongated particles caused issues with the consistency of compaction. The APA testing procedure should address the issue of flat and elongated particles.

As shown in Table 4.1, the volumetric properties of the mix design could not be verified for either the 12.5 or the $37.5 \mathrm{~mm}$ mixes and for the mix design and contractor's field gradations. In addition, as shown in Tables 3.5 and 3.6, there are considerable differences in the mix design and field gradations. The contractor has successfully used these mixes on projects in Kentucky. The reasons for these discrepancies are unknown and are of concern. Further research should be carried out to determine if these problems have influenced the conclusions of this research.

The $12.5 \mathrm{~mm}$ mix studied in this research demonstrated excellent characteristics with respect to rutting potential. However, this does not infer that all $12.5 \mathrm{~mm}$ mixes would have this level of performance. Since the majority of mixes for heavy traffic roads in West Virginia are constructed with crushed limestone aggregate, the performance of $12.5 \mathrm{~mm}$ limestone mixes should be evaluated. The results obtained with the $37.5 \mathrm{~mm}$ mix indicate that the PG 76-22 binder significantly reduces the rutting potential of crushed limestone mixes.

This research was limited to a single source of SBS polymer-modified binder. As demonstrated in the literature review, there are a wide variety of modifiers available in the market. The results produced during this research should not be used to infer that other products would perform equally well. Further research should be performed with alternative suppliers of modified binders.

One of the limitations of this study was that the decision was made to use the mix design asphalt contents for the evaluation of the other binder types. This provided 
consistency in the treatment of the mixes. An alternative to this decision would be to determine the optimum asphalt content for each binder and use the revised mix design for the evaluation.

Although the PG 76-22 binder used in this study appears to provide superior performance, it is more expensive than unmodified materials. The decision to use the more expensive material should be based on a life cycle cost analysis. In the case of the Fort Gay intersection, due to the rapid failure of previous treatments, a life cycle analysis would certainly favor the use of the materials evaluated in this study. However, as more projects are considered, where the difference in performance may not be as great, the life cycle analysis would provide a valuable information for the selection of the most economical materials.

\subsection{RECOMMENDATIONS}

Although it cannot be stated with certainty, the indications of this research are that the use of SBS polymer-modified asphalt appears to provide asphalt concrete mixes with superior performance. The initial field review of the performance of the Fort Gay intersection indicates it is performing much better than previous treatments. This conclusion is supported by the laboratory study performed during this research. In addition to intersections with high truck volume, the use of a polymer-modified material should be considered at other locations with heavy traffic and slow speeds, such as truck weigh stations and climbing lanes. 


\section{REFERENCES}

1. Archilla A. R., and S. Madanat, Development of a Pavement Rutting Model from Experimental Data, pp. 291, Journal of Transportation Engineering, Reston, VA, July 2000.

2. Brown E. R., and S. A. Cross, A National Study of Rutting in Hot Mix Asphalt (HMA) Pavements, NCAT Report No. 92-5, Auburn University, Auburn, AL, 1992.

3. Brown E. R., P. S. Kandhal, and J. Zhang. Performance Testing for Hot Mix Asphalt, NCAT Report No. 01-05A, Auburn University, Auburn, AL, 2001.

4. Brule B., and M. Maze, Application of SHRP Binder Tests to the Characterization of Polymer Modified Bitumens, pp. 367, Association of Asphalt Paving Technologist, Volume 64, MN, 1995.

5. Chen J., M. Liao, and M. Shiah, Asphalt Modified by Styrene - Butadiene Styrene Triblock Copolymer: Morphology and Model, pp. 224, Journal of Materials in Civil Engineering, Reston, VA, May 2002.

6. Choubane B., G. C. Page, and J. A. Musselman. Suitability of Asphalt Pavement Analyzer for Predicting Pavement Rutting, pp. 107, Transportation Research Record 1723, National Research Council, Washington, D.C., 2000.

7. Coree B. J., and K. VanDerHorst, Superpave Compaction, Transportation Conference Proceedings. Center for Transportation Research and Education, Ames, Iowa, 1998.

8. D'Angelo J. A., and F. Fee, Superpave Binder Tests and Specifications How Have They Performed in the Real World, pp. 697, Association of Asphalt Paving Technologist, Volume 69, MN, 2000.

9. Hawkins C. W., Investigation of SCDOT Asphalt Mixtures Using the Pavement Analyzer-Phase 1, South Carolina Department of Transportation, Columbia, SC, 2001.

10. Jackson N. M., and C. D. Baldwin, Assessing the Relative Rutting susceptibility of HMA in the Laboratory with the Asphalt Pavement Analyzer, International Journal of Pavement Engineering, Volume 1(3), University of Mississippi, University, MS, 2000.

11. Kandhal P. S., Intersection rutting Rectified, Roads and Bridges, Des Plaines, IL, May 1998.

12. Kandhal P. S., Large Stone Mixes: Design and Construction, NCAT Report No. 90-4, Auburn University, Auburn, AL, 1990.

13. Kandhal P. S., S. A. Cross, and E. R. Brown, Heavy Duty Asphalt Pavements in Pennsylvania: an Evaluation for Rutting, NCAT Report No. 93-2, Auburn University, Auburn, AL, 1993. 
14. Kandhal P. S., R. B. Mallick, and E. R. Brown, Hot Mix Asphalt for Intersections in Hot Climates, NCAT Report No. 98-6, Auburn University, Auburn, AL, 1998.

15. Kandhal P. S., and R. B. Mallick, Evaluation of Asphalt Pavement Analyzer for HMA Mix Design, NCAT Report No 99-4, Auburn University, Auburn, AL, 1999.

16. Kanneganti, V., Comparison of $19 \mathrm{~mm}$ Superpave and Marshall Base II Mixes in West Virginia, Master's Thesis, West Virginia University, Morgantown, West Virginia, 2002

17. Khattak M. J., and G. Y. Baladi, Engineering Properties of Polymer-Modified Asphalt Mixtures, Transportation Research Record 1638, National Research Council, Washington, D.C., 1998.

18. Mahboub K., and D. L. Allen, Characterization of Rutting Potential of Large Stone Asphalt Mixes in Kentucky, pp. 133, Transportation Research Record 1259, National Research Council, Washington, D.C., 1990.

19. Mahboub K., and E. G. Williams, Construction of Large - Stone Asphalt Mixes (LSAMs) in Kentucky, pp. 41, Transportation Research Record 1259, National Research Council, Washington, D.C., 1990.

20. Mallick R. B., S. Buchanan, E. R. Brown, and M. Huner, An Evaluation of Superpave Gyratory Compaction of Hot Mix Asphalt, NCAT Report No.98-5, Auburn University, Auburn, AL, 1998.

21. Mohammad L. N., B. Huang, C. Abadie, and A. Raghavendra, Laboratory Study of Large Stone Asphalt Mixtures, pp. 122, Association of Asphalt Paving Technologist, Volume 69, MN, 2000.

22. Oliver J. W. H., and P. F. Tredrea, Relationships between Asphalt Rut Resistance and Binder Rheological Properties, pp. 623, Association of Asphalt Paving Technologist, Volume 67, MN, 1998.

23. Pavement Technology, Inc., Asphalt Pavement Analyzer Automation User's Guide, Asphalt Pavement Analyzer, Conyers, Georgia, (Undated).

24. Roberts F. L., P. S. Kandhal, E. R. Brown, D. Lee, and T. W. Kennedy, Hot Mix Asphalt Materials, Mixture Design and Construction, NAPA Education Foundation, Lanham, MD, 1996.

25. Skok E. L., A. Turk, and E. Johnson, Asphalt Pavement Analyzer Evaluation, Minnesota Department of Transportation, St.Paul, MN, 2002.

26. Sousa J. B., and S. L. Weissman, Modeling Permanent Deformation of Asphalt Aggregate Mixes, pp. 224, Association of Asphalt Paving Technologist, Volume 63, MD, 1994.

27. Stuart K.D., and W.S. Mogawer, Understanding the Performance of Modified Asphalt Binders in Mixtures: High - Temperature Characterization, FHWA Report No.RD-02-042, Lanham, MD, 2002. 
28. Uddin W., and Y. Nanagiri, Performance of Polymer - Modified Asphalt Overlays in Mississippi based on Mechanistic Analysis and Field Evaluation, pp. 13, International Journal of Pavements, Volume 1 (1), University of Mississippi, University, MS, 2002.

29. Walker D., and M. Buncher. How you can Build Better Intersections, source [http://www.betterroads.com/articles/braug99a.htm], August 1999.

30. Walker D., How are Asphalt Intersections Doing? , Better Roads, Des Plaines, IL, September 2000.

31. Wegan V., and B. Brule, The Structure of Polymer Modified Binders and Corresponding Asphalt Mixtures, pp. 64, Association of Asphalt Paving Technologist, Volume 68, MN, 1999.

\section{SPECIFICATIONS AND TEST METHODS}

1. West Virginia Division of Highways Standard Specifications, Charleston, West Virginia, 2000.

2. Guide for Quality Control and Acceptance Requirements for Superpave HotMix Asphalt, WVDOT MP 401.02.29, Charleston, West Virginia, 2000.

3. Standard Specification for Superpave Volumetric Mix Design, AASHTO MP 2, 1999.

4. Determining of Specific Gravity and Absorption of Coarse Aggregate, AASHTO T 85, 1996.

5. Determining of Specific Gravity and Absorption of Fine Aggregate, AASHTO T 84, 2000.

6. Effect of Heat and Air on a Moving Film of Asphalt (Rolling Thin - Film Oven Test), AASHTO T 240, 1997.

7. Viscosity Determination of Asphalt Binder Using Rotational Viscometer, AASHTO T 316, 2002.

8. Kinematic Viscosity of Asphalts, AASHTO T 201, 1995.

9. Determining the Rheological Properties of Asphalt Binder Using a Dynamic Shear Rheometer, AASHTO T 315, 2002.

10. Reducing Samples of Aggregate to Testing Size, AASHTO T 248, 1996.

11. Sampling Bituminous Materials, AASHTO T 40, 1996.

12. Sampling Bituminous Paving Mixtures, AASHTO T 168, 1999.

13. Theoretical Maximum Specific Gravity and Density of Bituminous Paving Mixtures, AASHTO T 209, 1999. 
14. Bulk Specific Gravity of Compacted Bituminous Mixtures using Saturated Surface - Dry Specimens, AASHTO T 166, 2000.

15. Determining the Asphalt Binder Content of Hot Mix Asphalt (HMA) by Ignition Method, AASHTO T 308, 1999.

16. Method for Preparing and Determining the Density of HMA Specimens by Means of the SHRP Gyratory Compactor, AASHTO TP 4, 1997.

17. Determining Rutting Susceptibility of Asphalt Paving Mixtures using the Asphalt Pavement Analyzer, AASHTO TP XXX.

18. Specification for Performance Graded Asphalt Binder, AASHTO M 320-02, 2002.

19. Mississippi Department of Transportation specifications, source http://www.stonemont.com/stonemont/webhelp/AgencySpecs/ SPEC_MSDOT.htm, June 2003. 


\section{APPENDIX A. AGGREGATES SPECIFIC GRAVITIES}

Table A.1 Specific gravities of $37.5 \mathrm{~mm}$ mix aggregates

\begin{tabular}{|l|c|c|c|c|c|c|}
\hline & \multicolumn{2}{|c|}{$\# \mathbf{4}$} & \multicolumn{2}{c|}{$\# \mathbf{5 7}$} & \multicolumn{2}{c|}{ \#8 } \\
\hline Sample No. & $\mathbf{1}$ & $\mathbf{2}$ & $\mathbf{1}$ & $\mathbf{2}$ & $\mathbf{1}$ & $\mathbf{2}$ \\
\hline Dry Wt. (g) A & 5326.3 & 5326.2 & 2932.1 & 2930.4 & 1930.0 & 1959.9 \\
\hline SSD Wt. (g) B & 5363.2 & 5361.2 & 2945.9 & 2947.3 & 1943.7 & 1973.3 \\
\hline Wet Wt. (g) C & 3367.6 & 3363.4 & 1858.5 & 1855.1 & 1229.3 & 1243.7 \\
\hline $\begin{array}{l}\text { Bulk Sp.gr } \\
\text { (Oven Dried) } \\
\text { A/(B-C) }\end{array}$ & 2.669 & 2.666 & 2.696 & 2.683 & 2.702 & 2.686 \\
\hline $\begin{array}{l}\text { Apparent } \\
\text { Sp.gr A/(A-C) }\end{array}$ & 2.719 & 2.714 & 2.731 & 2.725 & 2.754 & 2.737 \\
\hline $\begin{array}{l}\text { Absorption \% } \\
\text { (B-A)/A*100 }\end{array}$ & 0.693 & 0.657 & 0.471 & 0.577 & 0.710 & 0.684 \\
\hline
\end{tabular}

Table A.2 Specific gravities of $\mathbf{1 2 . 5} \mathrm{mm}$ mix aggregates

\begin{tabular}{|l|c|c|c|c|}
\cline { 2 - 5 } \multicolumn{1}{c|}{} & \multicolumn{2}{c|}{$\mathbf{1 7 8}$} & \multicolumn{2}{c|}{$\mathbf{1}$} \\
\hline Sample No. & $\mathbf{1}$ & $\mathbf{2}$ & $\mathbf{1}$ \\
\hline Dry Wt. (g) A & 3190.2 & 3174.6 & 2108.8 & 2095.6 \\
\hline SSD Wt. (g) B & 3268.5 & 3253.1 & 2171.2 & 2159.4 \\
\hline Wet Wt. (g) C & 1956.9 & 1940.7 & 1410.9 & 1398.7 \\
\hline $\begin{array}{l}\text { Bulk Sp.gr } \\
\text { (Oven Dried) } \\
\text { A/(B-C) }\end{array}$ & 2.432 & 2.419 & 2.774 & 2.755 \\
\hline $\begin{array}{l}\text { Apparent Sp.gr } \\
\text { A/(A-C) }\end{array}$ & 2.587 & 2.573 & 3.022 & 3.007 \\
\hline $\begin{array}{l}\text { Absorption \% } \\
\text { (B-A)/A*100 }\end{array}$ & 2.454 & 2.473 & 2.959 & 3.044 \\
\hline
\end{tabular}


Table A.3 Specific gravities of sand material

\begin{tabular}{|l|c|c|c|c|}
\cline { 2 - 5 } \multicolumn{1}{c|}{} & \multicolumn{2}{c|}{$\mathbf{1} 7.5 \mathbf{~ m m}$} & \multicolumn{2}{c|}{$\mathbf{1 2 . 5} \mathbf{~ m m}$} \\
\hline Sample No. & 488.94 & 487.29 & 476.90 & $\mathbf{2}$ \\
\hline Dr Wt. (g) A & 712.47 & 711.00 & 645.20 & 644.20 \\
\hline Sample Wt. (g) a & 223.53 & 223.71 & 168.30 & 167.70 \\
\hline Pan Wt. (g) b & 658.30 & 658.30 & 658.50 & 679.80 \\
\hline $\begin{array}{l}\text { Pyconometer filled } \\
\text { with water Wt. (g) B }\end{array}$ & 967.70 & 966.70 & 969.80 & 991.10 \\
\hline $\begin{array}{l}\text { Pyconometer, sample, } \\
\text { water Wt. (g) C }\end{array}$ & 503.08 & 502.88 & 501.10 & 500.90 \\
\hline $\begin{array}{l}\text { SSD Wt. (g) D } \\
\text { Bulk Sp.gr } \\
\text { (Oven Dried) } \\
\text { A/(B+D-C) }\end{array}$ & 2.524 & 2.506 & 2.513 & 2.513 \\
\hline $\begin{array}{l}\text { Apparent Sp.gr } \\
\text { A/(B+A-C) }\end{array}$ & 2.723 & 2.724 & 2.880 & 2.884 \\
\hline $\begin{array}{l}\text { Absorption \% } \\
\text { (D-A/A*100 }\end{array}$ & 2.892 & 3.199 & 5.074 & 5.121 \\
\hline
\end{tabular}




\section{APPENDIX B. MIX SPECIFIC GRAVITIES}

Table B.1 Theoretical maximum specific gravities for $37.5 \mathrm{~mm}$ mix

\begin{tabular}{|c|c|c|c|c|c|c|c|}
\hline $\begin{array}{c}\text { Gradations } \\
\text { Used }\end{array}$ & $\begin{array}{c}\text { Binder } \\
\text { Type }\end{array}$ & $\begin{array}{c}\text { Sample } \\
\text { No. }\end{array}$ & $\begin{array}{l}\text { Dry Wt. } \\
\text { (g) }\end{array}$ & $\begin{array}{c}\text { Wet Wt. } \\
\text { (g) }\end{array}$ & $\begin{array}{c}\text { Bowl Wt. } \\
\text { (g) }\end{array}$ & $\mathbf{G}_{\mathbf{m m}}$ & $\begin{array}{c}\text { Average } \\
\mathbf{G}_{\mathrm{mm}}\end{array}$ \\
\hline Design & 64-22 & 1 & 4129.9 & 4016.4 & 1511.1 & 2.542 & \multirow{2}{*}{2.544} \\
\hline Design & $64-22$ & 2 & 4145.1 & 3847.2 & 1330.0 & 2.546 & \\
\hline Design & $70-22$ & 1 & 4135.1 & 3846.8 & 1330.0 & 2.555 & \multirow{2}{*}{2.550} \\
\hline Design & $70-22$ & 2 & 4129.6 & 4018.2 & 1511.1 & 2.545 & \\
\hline Design & $76-22$ & 1 & 4136.3 & 4025.7 & 1511.1 & 2.551 & \multirow{2}{*}{2.553} \\
\hline Design & $76-22$ & 2 & 4123.3 & 3838.8 & 1330.0 & 2.554 & \\
\hline Field & $76-22$ & 1 & 4005.5 & 3768.3 & 1330.0 & 2.556 & \multirow{2}{*}{2.550} \\
\hline Field & $76-23$ & 2 & 4002.6 & 3939.8 & 1511.1 & 2.543 & \\
\hline
\end{tabular}

Table B.2 Theoretical maximum specific gravities for $12.5 \mathrm{~mm}$ mix

\begin{tabular}{|c|c|c|c|c|c|c|c|c|}
\hline $\begin{array}{c}\text { Gradations } \\
\text { Used } \\
\end{array}$ & $\begin{array}{c}\begin{array}{c}\text { Binder } \\
\text { Type }\end{array} \\
\end{array}$ & \begin{tabular}{|c} 
Sample \\
No. \\
\end{tabular} & $\begin{array}{c}\text { Dry Wt. } \\
\text { (g) } \\
\end{array}$ & $\begin{array}{c}\text { Wet Wt. } \\
\text { (g) }\end{array}$ & \begin{tabular}{|c} 
Bowl Wt. \\
(g) \\
\end{tabular} & $\begin{array}{c}\text { SSD Wt. } \\
\text { (g) }\end{array}$ & $\mathbf{G}_{\mathbf{m m}}$ & $\begin{array}{c}\text { Average } \\
\mathbf{G}_{\mathbf{m m}} \\
\end{array}$ \\
\hline Field & $64-22$ & 1 & 1479.7 & 2226.2 & 1330.0 & 1479.9 & 2.535 & \multirow{2}{*}{2.541} \\
\hline Field & $64-22$ & 2 & 1488.9 & 2412.4 & 1508.9 & 1488.2 & 2.546 & \\
\hline Field & $70-22$ & 1 & 1483.2 & 2405.7 & 1508.9 & 1481.7 & 2.536 & \multirow{2}{*}{2.539} \\
\hline Field & $70-22$ & 2 & 1490.6 & 2232.9 & 1330.0 & 1489.5 & 2.541 & \\
\hline Field & $76-22$ & 1 & 1474.5 & 2403.7 & 1508.9 & 1473.6 & 2.548 & \multirow{2}{*}{2.540} \\
\hline Field & $76-22$ & 2 & 1476.4 & 2222.9 & 1330.0 & 1475.9 & 2.532 & \\
\hline Design & $76-22$ & 1 & 1478.2 & 2406.0 & 1508.9 & 1478.4 & 2.544 & \multirow{2}{*}{2.544} \\
\hline Design & 76-22 & 2 & 1473.7 & 2224.3 & 1330.0 & 1472.8 & 2.543 & \\
\hline
\end{tabular}


Table B.3 Bulk specific gravity for mixes compacted to $\mathbf{N}_{d}$

\begin{tabular}{|c|c|c|c|c|c|c|c|c|}
\hline $\begin{array}{c}\text { Mix } \\
\text { type }\end{array}$ & $\begin{array}{c}\text { Gradations } \\
\text { Used }\end{array}$ & $\begin{array}{c}\text { Binder } \\
\text { Type }\end{array}$ & $\begin{array}{c}\text { Sample } \\
\text { No. }\end{array}$ & $\begin{array}{c}\text { Dry } \\
\text { Wt. (g) }\end{array}$ & $\begin{array}{c}\text { Wet } \\
\text { Wt. (g) }\end{array}$ & $\begin{array}{c}\text { SSD } \\
\text { Wt. (g) }\end{array}$ & $\mathbf{G}_{\mathbf{m b}}$ & $\begin{array}{c}\text { Average } \\
\mathbf{G}_{\mathbf{m b}}\end{array}$ \\
\hline \multirow{3}{*}{37.5} & Field & $76-22$ & 1 & 4800.1 & 2902.2 & 4815.5 & 2.509 & \multirow{2}{*}{2.506} \\
\cline { 2 - 8 } & Field & $76-22$ & 2 & 4768.7 & 2883.1 & 4789.2 & 2.502 & \\
\cline { 2 - 8 } & Design & $76-22$ & 1 & 4773.1 & 2888.3 & 4781.9 & 2.521 & \multirow{2}{*}{2.521} \\
\cline { 2 - 8 } & Design & $76-22$ & 2 & 4758.4 & 2879.0 & 4766.7 & 2.521 & \\
\hline \multirow{2}{*}{12.5} & Field & $76-22$ & 1 & 4766.3 & 2774.2 & 4825.3 & 2.324 & \multirow{2}{*}{2.325} \\
\cline { 2 - 8 } & Field & $76-22$ & 2 & 4704.2 & 2740.5 & 4763.9 & 2.325 & \\
\cline { 2 - 8 } & Design & $76-22$ & 1 & 4646.0 & 2672.3 & 4701.4 & 2.29 & \multirow{2}{*}{2.291} \\
\cline { 2 - 7 } & Design & $76-22$ & 2 & 4668.9 & 2688.9 & 4725.8 & 2.292 & \\
\hline
\end{tabular}




\section{EQUATIONS FOR VOLUMETRIC PROPERTIES}

$\mathrm{VTM}=\left(1-\frac{G_{m b}}{G_{m m}}\right) 100$

$\mathrm{VMA}=100\left(1-\frac{G_{m b}\left(1-P_{b}\right)}{G_{s b}}\right)$

$\mathrm{VFA}=100\left(\frac{V M A-V T M}{V M A}\right)$

Where,

$\mathrm{VTM}=$ Total voids in the mix

VMA $=$ Voids in mineral aggregate

$\mathrm{VFA}=$ Voids filled with aggregate

$\mathrm{G}_{\mathrm{mb}}=$ Bulk specific gravity of compacted mixture

$\mathrm{G}_{\mathrm{mm}}=$ Maximum theoretical specific gravity

$\mathrm{P}_{\mathrm{b}}=$ Asphalt content

$\mathrm{G}_{\mathrm{sb}}=$ Bulk specific gravity of the aggregate 


\section{APPENDIX C. RUT DEPTHS}

Table C.1 Rut depth data for field $37.5 \mathrm{~mm}$ mix

\begin{tabular}{|c|c|c|c|c|c|}
\hline $\begin{array}{c}\text { Sample } \\
\text { No. }\end{array}$ & $\begin{array}{c}\text { Air voids } \\
\text { percent }\end{array}$ & $\begin{array}{c}\text { Rut } \\
\text { front }\end{array}$ & $\begin{array}{c}\text { Rut } \\
\text { rear }\end{array}$ & $\begin{array}{c}\text { Average } \\
\text { Rut }\end{array}$ & Position \\
\hline 1 & 6.1 & 2.57 & 1.59 & 2.08 & LR* \\
\hline 2 & 6.5 & 1.35 & 2.13 & 1.74 & LF \\
\hline 3 & 6.5 & 1.92 & 2.03 & 1.98 & MR \\
\hline 4 & 6.1 & 1.74 & 2.14 & 1.94 & MF \\
\hline 5 & 6.5 & 2.60 & 4.52 & 3.56 & RR \\
\hline 6 & 6.5 & 1.22 & 2.26 & 1.74 & RF \\
\hline 7 & 6.5 & 0.84 & 4.07 & 2.46 & LR \\
\hline 8 & 6.9 & 2.17 & 2.18 & 2.18 & LF \\
\hline 9 & 6.5 & 1.41 & 1.74 & 1.58 & MR \\
\hline 10 & 6.1 & 3.16 & 1.82 & 2.49 & MF \\
\hline 11 & 6.9 & 2.10 & 2.69 & 2.40 & RR \\
\hline 12 & 6.5 & 2.33 & 3.88 & 3.11 & RF \\
\hline
\end{tabular}

$* \mathrm{LR}=$ Left rear, $\mathrm{LF}=$ Left front, $\mathrm{MR}=$ Middle rear, $\mathrm{MF}=$ Middle front, $\mathrm{RR}=$ Right rear, $\mathrm{RF}=$ Right front

Table C.2 Rut depth data for field $12.5 \mathrm{~mm}$ mix

\begin{tabular}{|c|c|c|c|c|c|}
\hline $\begin{array}{c}\text { Sample } \\
\text { No. }\end{array}$ & $\begin{array}{c}\text { Air voids } \\
\text { percent }\end{array}$ & $\begin{array}{c}\text { Rut } \\
\text { front }\end{array}$ & $\begin{array}{c}\text { Rut } \\
\text { rear }\end{array}$ & $\begin{array}{c}\text { Average } \\
\text { Rut }\end{array}$ & Position \\
\hline 1 & 6.2 & 1.39 & 1.62 & 1.51 & LR $^{*}$ \\
\hline 2 & 6.2 & 1.79 & 1.38 & 1.59 & LF \\
\hline 3 & 6.2 & 1.04 & 1.09 & 1.07 & MR \\
\hline 4 & 6.6 & 1.54 & 1.97 & 1.76 & MF \\
\hline 5 & 6.6 & 1.59 & 2.62 & 2.11 & RR \\
\hline 6 & 6.6 & 1.28 & 2.27 & 1.78 & RF \\
\hline 7 & 6.6 & 1.30 & 1.40 & 1.35 & LR \\
\hline 8 & 6.6 & 1.37 & 2.39 & 1.88 & LF \\
\hline 9 & 6.6 & 1.45 & 1.61 & 1.53 & MR \\
\hline 10 & 6.6 & 1.53 & 2.25 & 1.89 & MF \\
\hline 11 & 6.6 & 1.21 & 1.65 & 1.43 & RR \\
\hline 12 & 6.2 & 1.78 & 1.41 & 1.60 & RF \\
\hline
\end{tabular}

$* \mathrm{LR}=$ Left rear, $\mathrm{LF}=$ Left front, $\mathrm{MR}=$ Middle rear, $\mathrm{MF}=$ Middle front, $\mathrm{RR}=$ Right rear, $\mathrm{RF}=$ Right front 
Table C.3 Rut depth data for $37.5 \mathrm{~mm}$ specimens made in laboratory

\begin{tabular}{|c|c|c|c|c|c|c|}
\hline $\begin{array}{c}\text { Sample } \\
\text { No. }\end{array}$ & $\begin{array}{c}\text { Binder } \\
\text { Grade }\end{array}$ & $\begin{array}{c}\text { Air voids } \\
\text { percent }\end{array}$ & $\begin{array}{c}\text { Rut } \\
\text { front }\end{array}$ & $\begin{array}{c}\text { Rut } \\
\text { rear }\end{array}$ & $\begin{array}{c}\text { Average } \\
\text { Rut }\end{array}$ & Position \\
\hline 1 & $76-22$ & 6.7 & 4.59 & 4.79 & 4.69 & LR* \\
\hline 2 & $76-22$ & 6.9 & 3.89 & 5.21 & 4.55 & LF \\
\hline 3 & $76-22$ & 6.7 & 2.79 & 4.01 & 3.40 & RR \\
\hline 4 & $76-22$ & 7.2 & 4.34 & 2.78 & 3.56 & RF \\
\hline 5 & $76-22$ & 7.2 & 3.43 & 3.46 & 3.45 & MR \\
\hline 6 & $76-22$ & 7.0 & 2.91 & 1.78 & 2.35 & MF \\
\hline 7 & $70-22$ & 7.2 & 8.28 & 7.73 & 8.01 & MR \\
\hline 8 & $70-22$ & 7.1 & 6.16 & 7.69 & 6.93 & MF \\
\hline 9 & $70-22$ & 7.2 & 9.13 & 11.50 & 10.32 & LR \\
\hline 10 & $70-22$ & 7.1 & 8.31 & 9.51 & 8.91 & LF \\
\hline 11 & $70-22$ & 7.3 & 6.69 & 7.43 & 7.06 & RR \\
\hline 12 & $70-22$ & 6.7 & 8.43 & 5.69 & 7.06 & RF \\
\hline 13 & $64-22$ & 6.7 & 8.92 & 8.50 & 8.71 & RR \\
\hline 14 & $64-22$ & 7.0 & 8.48 & 7.40 & 7.94 & RF \\
\hline 15 & $64-22$ & 6.5 & 7.18 & 6.83 & 7.01 & MR \\
\hline 16 & $64-22$ & 6.5 & 5.76 & 8.06 & 6.91 & MF \\
\hline 17 & $64-22$ & 6.7 & 10.39 & 9.91 & 10.15 & LR \\
\hline 18 & $64-22$ & 6.6 & 9.19 & 10.16 & 9.68 & LF \\
\hline
\end{tabular}

$* \mathrm{LR}=$ Left rear, $\mathrm{LF}=$ Left front, $\mathrm{MR}=$ Middle rear, $\mathrm{MF}=$ Middle front, $\mathrm{RR}=$ Right rear, $\mathrm{RF}=$ Right front 
Table C.4 Rut depth data for $\mathbf{1 2 . 5} \mathbf{~ m m}$ mix specimens made in laboratory

\begin{tabular}{|c|c|c|c|c|c|c|}
\hline $\begin{array}{c}\text { Sample } \\
\text { No. }\end{array}$ & $\begin{array}{c}\text { Binder } \\
\text { Grade }\end{array}$ & $\begin{array}{c}\text { Air voids } \\
\text { percent }\end{array}$ & $\begin{array}{c}\text { Rut } \\
\text { front }\end{array}$ & $\begin{array}{c}\text { Rut } \\
\text { rear }\end{array}$ & $\begin{array}{c}\text { Average } \\
\text { Rut }\end{array}$ & Position \\
\hline 1 & $76-22$ & 7.4 & 1.51 & 1.64 & 1.58 & LR* \\
\hline 2 & $76-22$ & 7.5 & 2.06 & 1.15 & 1.61 & LF \\
\hline 3 & $76-22$ & 7.0 & 1.98 & 1.15 & 1.57 & RR \\
\hline 4 & $76-22$ & 7.2 & 1.01 & 2.35 & 1.68 & RF \\
\hline 5 & $76-22$ & 7.4 & 1.04 & 0.86 & 0.95 & MR \\
\hline 6 & $76-22$ & 7.3 & 0.84 & 0.94 & 0.89 & MF \\
\hline 7 & $70-22$ & 7.0 & 2.59 & 2.66 & 2.63 & MR \\
\hline 8 & $70-22$ & 7.1 & 1.20 & 2.42 & 1.81 & MF \\
\hline 9 & $70-22$ & 6.7 & 1.28 & 3.69 & 2.49 & LR \\
\hline 10 & $70-22$ & 6.7 & 1.49 & 2.09 & 1.79 & LF \\
\hline 11 & $70-22$ & 7.2 & 3.53 & 3.28 & 3.41 & RR \\
\hline 12 & $70-22$ & 6.9 & 2.15 & 2.13 & 2.14 & RF \\
\hline 13 & $64-22$ & 6.5 & 4.03 & 4.71 & 4.37 & RR \\
\hline 14 & $64-22$ & 6.9 & 3.79 & 2.68 & 3.24 & RF \\
\hline 15 & $64-22$ & 6.5 & 4.23 & 4.30 & 4.27 & MR \\
\hline 16 & $64-22$ & 6.7 & 3.76 & 3.93 & 3.85 & MF \\
\hline 17 & $64-22$ & 6.8 & 3.78 & 3.69 & 3.74 & LR \\
\hline 18 & $64-22$ & 6.7 & 3.61 & 2.86 & 3.24 & LF \\
\hline
\end{tabular}

$* \mathrm{LR}=$ Left rear, LF $=$ Left front, MR $=$ Middle rear, MF = Middle front, $\mathrm{R}=$ Right rear, $\mathrm{RF}=\mathrm{Right}$ front 


\section{APPENDIX D. PHOTOGRAPHS OF RUT DEPTH SPECIMENS}

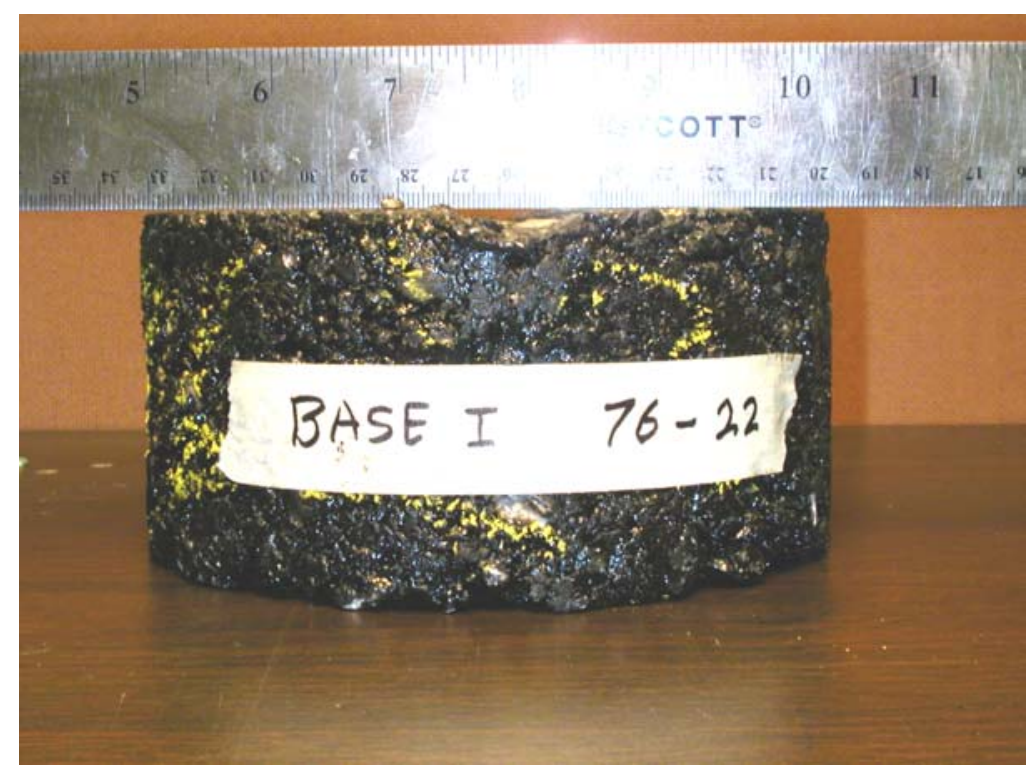

Figure D.1 37.5 mm specimen, design gradation and PG 76-22 binder

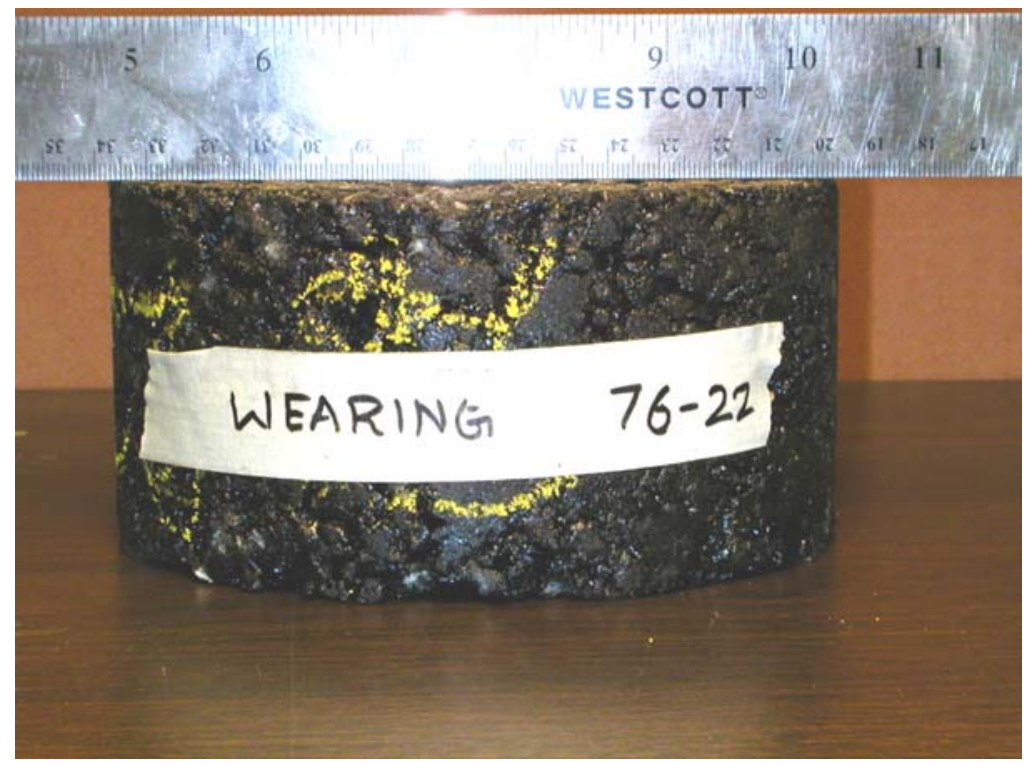

Figure D.2 12.5 mm specimen, field gradation and PG 76-22 binder 


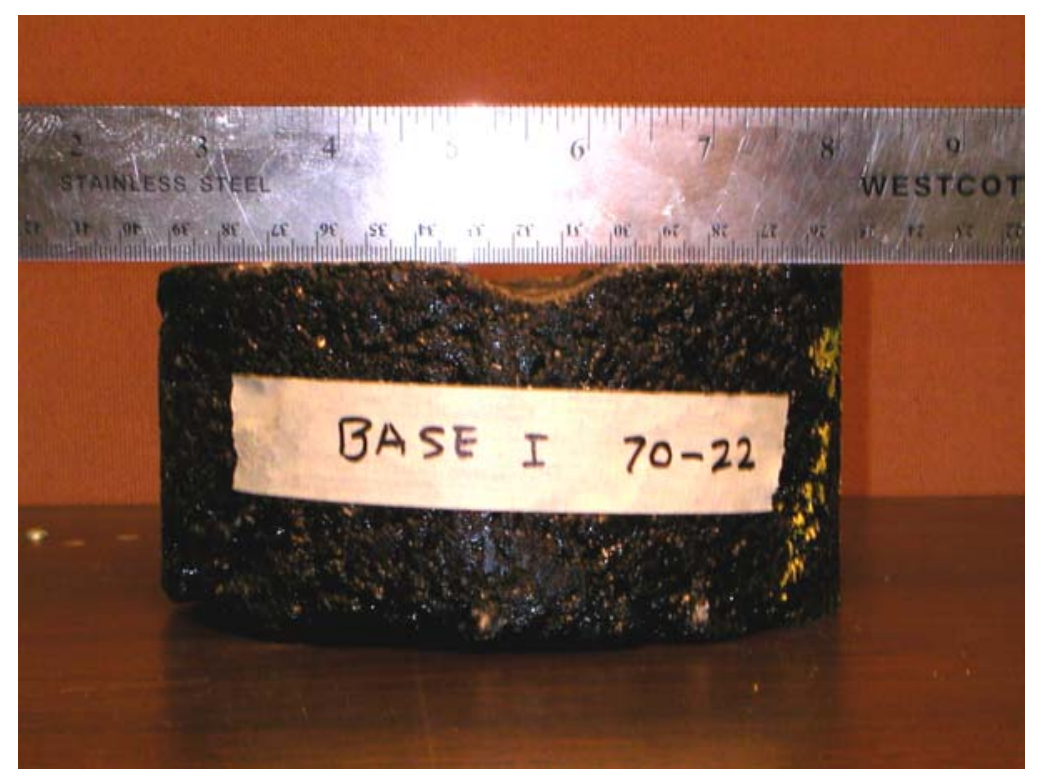

Figure D.3 $37.5 \mathrm{~mm}$ specimen, design gradation and PG 70-22 binder

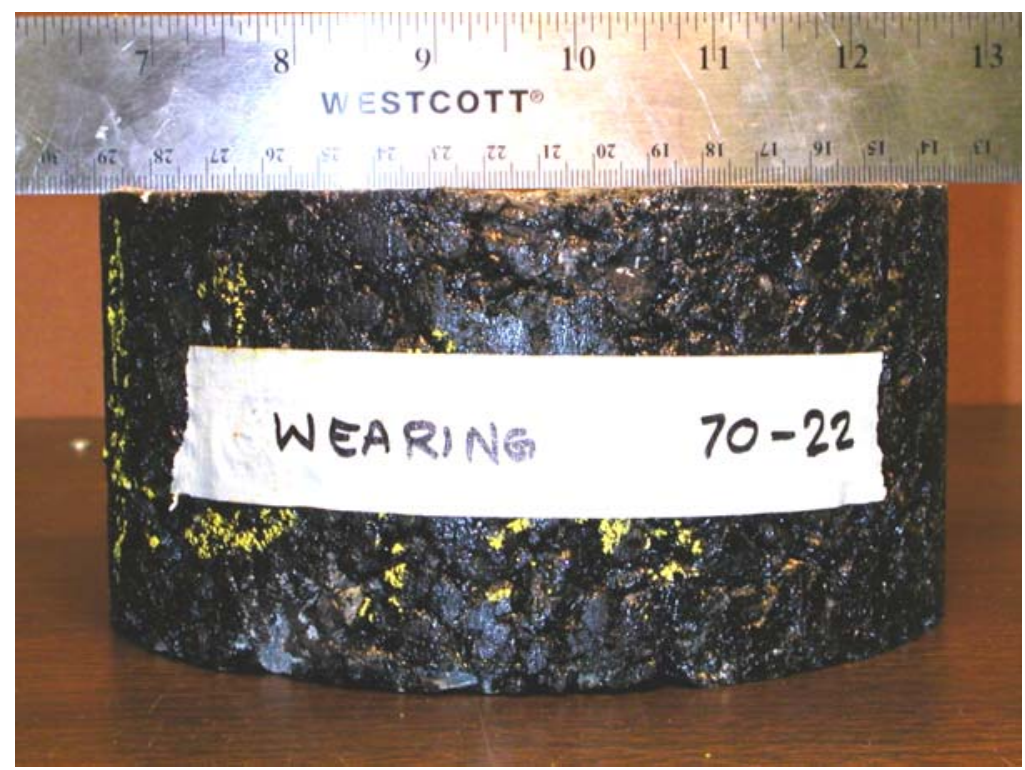

Figure D.4 12.5 mm specimen, field gradation and PG 70-22 binder 


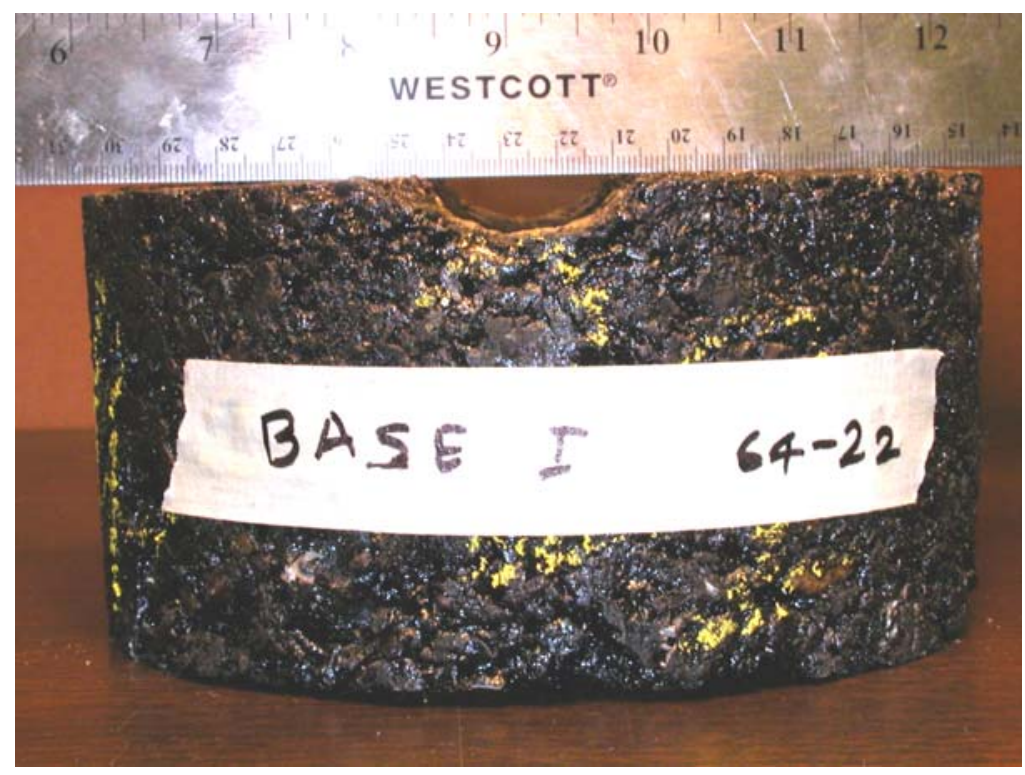

Figure D.5 37.5 mm specimen, design gradation and PG 64-22 binder 